Medidas em grafos para apoiar a avaliação da qualidade de projeções multidimensionais 



\title{
Medidas em grafos para apoiar a avaliação da qualidade de projeções multidimensionais
}

\author{
Robson Carlos da Motta
}

Orientadora: Profa. Dra. Maria Cristina Ferreira de Oliveira Coorientador: Prof. Dr. Alneu de Andrade Lopes

Tese apresentada ao Instituto de Ciências Matemáticas e de Computação - ICMC-USP, como parte dos requisitos para obtenção do título de Doutor em Ciências - Ciências de Computação e Matemática Computacional. VERSÃO REVISADA. 
Ficha Catalográfica elaborada pela Seção de Tratamento da Informação da Biblioteca Prof. Achille Bassi- Instituto de Ciências Matemáticas e de Computação - ICMC/USP.

Motta, Robson Carlos da

M921m Medidas em grafos para apoiar a avaliação da qualidade de projeções

multidimensionais / Robson Carlos da Motta; orientador Maria Cristina Ferreira

de Oliveira e co-orientador Alneu de Andrade Lopes. - - São Carlos, 2014.

$99 \mathrm{p.}$

Tese (Doutorado) - Programa de Pós-Graduação em Ciências de Computação e

Matemática Computacional . - - Instituto de Ciências Matemáticas e de Computação,

Universidade de São Paulo, 2014.

1. Projeção multidimensional. 2.Avaliação de projeções. 3. Grafos I. Oliveira,

Maria Cristina Ferreira de, orient. II. Lopes, Alneu de Andrade, co-orient. III. Título. 
Dedicatória

Aos meus pais, Alice e Francisco. 



\section{Agradecimentos}

Os últimos anos foram muito além do aprimoramento dos conhecimentos, foi um período de mudanças e aprendizados pessoais que fazem com que a conclusão deste ciclo vá muito além da leveza trazida por um grande esforço sendo finalizado. Este processo foi, acima de tudo, uma evolução pessoal, em autoconhecimento e autoconsciência, e me sinto muito satisfeito e honrado por ter participado de um programa no qual a ciência caminha junto com a valorização na formação humana.

Esta evolução acadêmica e pessoal se deve principalmente às pessoas que me acompanharam durante esse tempo. Tive e, certamente, continuarei tendo em meus orientadores acadêmicos exemplos de ética, comprometimento e responsabilidade. Além de todo apoio acadêmico, que foi imenso, foram também grandes educadores em minha formação de caráter.

Agradeço muito a todos que, de alguma forma, foram orientadores neste processo, em especial à Prof. ${ }^{a}$ Maria Cristina Ferreira de Oliveira, ao Prof. Alneu de Andrade Lopes, à Prof. ${ }^{a}$ Rosane Minghim, ao Prof. Alípio Jorge e ao Prof. Lars Linsen. Esta cooperação de diversos orientadores foi também uma transição entre culturas, facilitada pela FAPESP, à qual agradeço por todo financiamento do doutorado e por ter possibilitado a realização de parte do doutorado em Portugal e na Alemanha. Agradeço também ao ICMC/USP, à Universidade do Porto e à Jacobs University pelas estruturas acadêmicas que permitiram o desenvolvimento deste trabalho.

Além dos orientadores diretos, também agradeço aos colegas de laboratório e de pesquisa, pois, de alguma forma, todos colaboraram com o resultado alcançado. Um agradecimento também à empresa Chaordic, que mesmo durante um ano de trabalho, sempre me permitiu ter flexibilidade para caminhar com o doutorado.

Como apoio estrutural e emocional agradeço aos familiares e amigos. Meus pais, Francisco e Alice, e meus irmãos, Vitor e Vinícius, estiveram sempre próximos, até mesmo nas tardes de domingo, enquanto tinha comigo o computador em mãos e o foco distante dali. Em minha família posso sempre encontrar a confiança, a paz e o amor que fazem a vida parecer simples enquanto é também surpreendente. 
Também próximos estiveram os amigos, alguns dos quais crescemos juntos em Mogi Mirim, os amigos de universidade e da República Chico Lopes em São Carlos, até os mais atuais por Florianópolis. Todos proporcionando momentos de risadas e criatividade, e claro, algumas vezes também colaborando com a procrastinação.

E, por fim, quero agradecer à combinação de todos esses fatores. O doutorado abriu inúmeras portas e mudou o rumo de minha vida com essa expansão de oportunidades.

Sou muito grato a todos que passaram por minha vida durante esse período e espero que eu também tenha deixado algo em cada um. Obrigado. 


\section{Resumo}

Projeções Multidimensionais são úteis para gerar visualizações adequadas para apoiar a análise exploratória de uma grande variedade de dados complexos e de alta dimensionalidade. Tarefas de análise visual de dados têm se beneficiado de projeções para explorar dados textuais, de imagens, de sensores, entre outros. Porém, diferentes técnicas de projeção e diferentes parametrizações de uma mesma técnica produzem resultados distintos para um mesmo conjunto de dados, pois as técnicas adotam estratégias distintas para representar os dados originais em um espaço cuja dimensionalidade permite sua visualização. Atualmente, ainda há poucos recursos para avaliar a qualidade dessas projeções e, em geral, as soluções existentes avaliam propriedades específicas, demandando grande esforço do analista para uma avaliação mais abrangente. Neste trabalho, introduzimos um arcabouço para computar medidas de avaliação de projeções com enfoque em análise de vizinhanças e de agrupamentos. Para elaborar este arcabouço, foi realizado um estudo de percepção para entender melhor como os usuários observam as projeções e foi conduzida uma investigação de representações dos dados capazes de favorecer a identificação de vizinhanças e de agrupamentos. Os padrões identificados no estudo de percepção auxiliaram a validar a representação dos dados, em que foi proposto um modelo de grafo, chamado de Extended Minimum Spanning Tree (EMST), capaz de capturar características condizentes com as observações dos participantes no estudo. O grafo EMST também foi validado por meio de dois estudos comparativos de identificação de vizinhanças e de agrupamentos. Com base neste arcabouço foram propostas cinco medidas de qualidade de projeções multidimensionais, duas delas para avaliar características relacionadas à separação visual das classes, e outras três para avaliar a preservação de propriedades do espaço original, especificamente a separação das classes, as vizinhanças e os agrupamentos. As medidas são ilustradas por meio de sua aplicação a conjuntos de dados artificiais, favorecendo a sua interpretação, bem como a conjuntos de dados reais, evidenciando a sua potencial utilidade em cenários reais. Também é apresentada uma comparação das novas medidas de preservação de vizinhanças com medidas similares descritas na literatura, permitindo identificar diferenças e semelhanças entre elas. 



\section{Abstract}

Multidimensional projections are valuable tools to generate visualizations that support exploratory analysis of a wide variety of complex high-dimensional data. Many examples are found in the literature of visual data analysis tasks that employ projections to explore, for instance, text, image, network and sensor data. Nonetheless, different projection techniques applied to a particular data set, or even alternative parameterizations of a single technique, can produce very distinct outcomes, as techniques adopt different strategies to reduce data dimensionality. Few resources are available to support assessing projection quality and, in general, existing solutions focus on specific properties. Thus, a broader assessment typically requires considerable human effort. In this work we introduce a framework to compute projection evaluation measures that focus on neighborhoods and clusters. To elaborate this framework we conducted (i) an experimental study to better understand how users perceive projections and (ii) an investigation of possible data representations capable of favoring the identification of neighborhoods and clusters. The observations resulting from the experimental study have been considered to propose and validate a novel graph data model, called Extended Minimum Spanning Tree (EMST), which captures data properties shown to be consistent with the observations by the participants in the study. The EMST graph has been validated by means of two comparative studies conducted to identify neighborhoods and clusters in multidimensional data. Under this framework, five novel measures of projection quality are introduced, two of them to assess properties related to the visual separation of classes, and three to assess the preservation of data properties in the original space, in particular the preservation of class separation, the preservation of neighborhoods and the preservation of groups. The quality measures have been applied to projections of synthetic data sets, favoring their understanding and interpretation, and also to projections of real data sets, illustrating their potential applicability in real scenarios. The newly introduced neighborhood preservation measures are also compared with existing methods in order to illustrate their differences and similarities. 

Esta tese foi preparada com o formatador de texto ATEX. Nós utilizamos o estilo desenvolvido por Ronaldo Cristiano Prati. As citações bibliográficas seguem o padrão Apalike do sistema BibTEX. 



\section{Sumário}

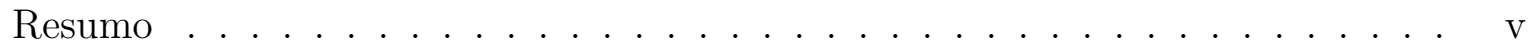

Abstract . . . . . . . . . . . . . . . . . vii

Sumário . . . . . . . . . . . . . . . . . . xii

Lista de Figuras . . . . . . . . . . . . . . . . . . . . . . . xvi

Lista de Tabelas . . . . . . . . . . . . . . . . . . . . xviii

1 Introdução 1

2 Avaliação de projeções multidimensionais 5

2.1 Técnicas de projeção multidimensional . . . . . . . . . . . . . . . . . . 8

2.2 Avaliação de projeções multidimensionais . . . . . . . . . . . . . . . . 10

2.2.1 Medidas qualitativas para interpretação de projeções . . . . . . . . 11

2.2.2 Funções de stress . . . . . . . . . . . . . . . . . . . . . . . . . . . . 12

2.2.3 Medidas de propriedades visuais das projeções . . . . . . . . . . . . 12

2.2.4 Medidas de preservação de vizinhanças . . . . . . . . . . . . . . . . 14

2.2.5 Medidas de preservação de agrupamentos . . . . . . . . . . . . . . 19

2.3 Medidas de avaliação de projeção e a percepção dos usuários . . . . . . . . 21

3 Percepção dos usuários na interpretação das projeções 25

3.1 Configuração do estudo com usuários . . . . . . . . . . . . . . 26

3.2 Análise da percepção de vizinhanças . . . . . . . . . . . . . . . . . . 30

3.3 Análise da percepção de agrupamentos . . . . . . . . . . . . . . . . . . 36

4 Representação dos dados e identificação de vizinhanças e agrupamentos 41

4.1 Representação relacional de dados . . . . . . . . . . . . . . . . . . . . . . 42

4.1.1 Modelos de grafos baseados em similaridade . . . . . . . . . . . . . 43

4.1 .2 Grafo EMST . . . . . . . . . . . . . . . . . 45

4.2 Identificação da vizinhança dos pontos . . . . . . . . . . . . . . . . 47

4.3 Identificação de agrupamentos nos dados . . . . . . . . . . . . . . . . 50 
4.3.1 Técnicas não relacionais . . . . . . . . . . . . . . . . 50

4.3 .2 Técnicas relacionais . . . . . . . . . . . . . . . . . 52

4.3.3 Estudo comparativo de técnicas relacionais e não relacionais . . . . 52

5 Avaliação de projeções baseada no grafo $E M S T$

5.1 Medidas de avaliação de projeção . . . . . . . . . . . . . . 58

5.1 .1 Medidas de caracterização de projeções . . . . . . . . . . . . . . 59

5.1.2 Medidas de preservação de propriedades dos dados . . . . . . . . . 61

5.2 Avaliação das medidas propostas . . . . . . . . . . . . . . 67

5.3 Comparação com outras medidas de preservação de vizinhança . . . . . . . 76

5.4 Comparação de diferentes parametrizações da técnica de projeção $t$-SNE $\quad$. 79

6 Conclusões $\quad 85$

6.1 Contribuições . . . . . . . . . . . . . . . . . 86

6.2 Limitações . . . . . . . . . . . . . . . . . . . . . . . . . . . . . . . . . . . 89

6.3 Trabalhos futuros . . . . . . . . . . . . . . . . . . 90

$\begin{array}{lr}\text { References } & 90\end{array}$ 


\section{Lista de Figuras}

2.1 Projeção de um conjunto textual de artigos científicos. Os marcadores gráficos indicam documentos e as cores mapeiam as áreas de conhecimento.

2.2 Visualização de um conjunto de autores e artigos científicos. Em (a) a visualização é gerada com uma estratégia de força baseada nas conexões que representam autores e co-autores, e em (b) com uma técnica de projeção multidimensional aplicada às distâncias entre os autores e artigos no grafo (Figura adaptada de Martins et al. (2012)). . . . . . . . . . . . . . . 7

2.3 Visualização de usuários da rede social Orkut, coloridos de acordo com seu (a) gênero e (b) estado civil (Figura adaptada de Martins et al. (2012)). . .

2.4 Quatro projeções do conjunto de artigos científicos $C B R$, utilizando as técnicas (a) Glimmer, (b) ISOMAP, (c) $L S P$ e (d) PCA. . . . . . . . . . . . . 10

2.5 Representações visuais para auxiliar usuários na compreensão dos dados, ilustrada para o conjunto de dados $C B R$. Em (a) é apresentado um histograma de distância, em (b) uma matriz de similaridade, e em (c) um diagrama de Shephard. Em (a) e (b) as distâncias foram computadas no espaço original, e o diagrama em (c) refere-se a projeção mostrada na Figura 2.1. . . . . . . . . . . . . . . . . . . 11

2.6 Gráfico da métrica Neighborhood Hit para as quatro projeções da Figura 2.4, relativas ao conjunto de dados $C B R$, com $k$ variando de 1 a $30 \ldots$. . . . . 13

2.7 Exemplo de gráfico Neighborhood Preservation para as quatro projeções da Figura 2.4, com $k$ variando de 1 a 30 . . . . . . . . . . . . . . . . . . . 15

2.8 Ilustração da matriz de co-ranking com o corte em $K$ (esquerda) e com a perda identificada como extrusions ou intrusions, nos quais os pontos saem da posição ideal na diagonal principal (Figura extraída de Mokbel et al. (2013)). 
2.9 Ilustração das células consideradas na matriz de co-ranking com um corte em $K$ (Lee e Verleysen, 2009) (área cinza na imagem (a)) e as variações propostas por Mokbel et al. (2013) ilustradas em dois cenários distintos (b) e (c). Em (b) e (c) observa-se o limite vertical dado por $K_{s}$ e o limite horizontal dado por $K_{t}$, mostrado nas duas paralelas diagonais (Figura extraída de Mokbel et al. (2013)). . . . . . . . . . . . . . . . . . . . . . 17

2.10 Projeções (a) PCA e (c) ISOMAP do Optdigits, e seus respectivos mapeamentos de cores proposto por Lespinats e Aupetit (2011) em (b) e (d). As cores indicam a presença de pontos ausentes (cor verde) e falsos positivos (cor roxa). O parâmetro $\sigma$ define o raio de vizinhança considerado (Figura extraída de Lespinats e Aupetit (2011)). . . . . . . . . . . . . . . . .

2.11 Exemplo de mapeamento visual proposto por Martins et al. (2014), no qual os pontos são coloridos segundo o respectivo erro (chamado de $e^{a g g r}$ ) e o mapeamento é configurado para exibir o erro em uma vizinhança usando uma função de densidade, permitindo a visualização por área e não por ponto específico. Em destaque são mostradas algumas regiões com alto erro $\left(A_{1}\right.$ a $\left.A_{4}\right)$ e com baixo erro $\left(A_{5}\right)$ (Figura extraída de Martins et al. (2014)).

2.12 Visualização iterativa proposta por Martins et al. (2014), que utiliza uma triangulação Delaunay para cálculo e exibição do erro. Em (a) as cores indicam as falsas vizinhanças de cada ponto e em (b) os pontos ausentes, com a vizinhança real destacada pela técnica de edge bundling (Figura extraída de Martins et al. (2014)). . . . . . . . . . . . . . . . . . . 23

3.1 Exemplo da tarefa apresentada aos participantes, na qual é solicidado que ordene os pontos segundo a proximidade ao ponto roxo. . . . . . . . . . . . 32

3.2 Probabilidade de seleção aleatória de um subconjunto de tamanho dado por \# escolhas, em um conjunto de 9 pontos . . . . . . . . . . . . . . . . . 34

3.3 Média de acerto dos participantes nas perspectivas com e sem ranqueamento do conjunto de vizinhos. Em tracejado é apresentado o valor médio da maior porcentagem de acerto na perspectiva sem ranqueamento para cada estímulo, considerando apenas as primeiras 5 escolhas. . . . . . . . . 35

3.4 Ilustração dos raios de distâncias do ponto de referência aos cinco primeiros vizinhos mais próximos em dois estímulos específicos. A circunferência em vermelho indica a resposta dos participantes com maior precisão na perspectiva sem ranqueamento. . . . . . . . . . . . . . . . 36

3.5 Exemplo de tarefa que solicitou ao participante indicar a quantidade de agrupamentos percebidos. . . . . . . . . . . . . . 37

3.6 Histograma das respostas referentes à quantidade de agrupamentos. . . . . 37 
3.7 Histograma das respostas referentes a quantidade de agrupamentos para cada projeção, nos quatro conjuntos de dados. . . . . . . . . . . . . . . . . 38

4.1 EMST para o Iris mapeado no espaço bidimensional com base nos valores dos atributos sepal length e sepal width. . . . . . . . . . . . . . . . . . 47

4.2 Conjunto de dados Iris representado por diferentes modelos de grafo de similaridade. Redes $k N N$ (a-d), PKNNG (e-h), $k D R$ (i-l) e $H S N$ (m-p) com respectivos valores de entrada iguais a 3, 5, 7 e 11, e grafos não paramétricos $M S T$ (q) e EMST (r). As cores de cada ponto indicam a classe da instância. 48

4.3 Diferença média entre o número de vizinhos dado por cada critério de identificação de vizinhança e o número mais frequente no estudo de percepção (tamanho "ideal" de vizinhança). . . . . . . . . . . . . . . . . .

4.4 Número de estímulos em que a quantidade de vizinhos dada por cada critério de identificação de vizinhança coincidiu com o tamanho "ideal" da vizinhança. . . . . . . . . . . . . . . .

4.5 Porcentagem média de acerto dos participantes para o número de vizinhos dado por cada critério de identificação de vizinhança. . . . . . . . . . . . . 50

5.1 Representação 2D do Swiss Roll: (a) quatro classes dos dados; (b) Class Separation; e (c) Class Aggregation mapeados com a escala de cores Heated Objects (cores escuras indicam valores maiores). . . . . . . . . . .

5.2 Representação 2D do Iris (a) três classes dos dados; (b) Class Separation e (c) Class Aggregation mapeados com a escala de cores Heated Objects (cores escuras indicam valores maiores). . . . . . . . . . . . . .

5.3 Swiss Roll: distribuições (a) 2D e (b) 3D com as cores mapeando as 4 classes. A medida Class Separation Validation é mapeada em cores para as distribuições (c) 2D e (d) 3D (na escala Heated Objects, com cores escuras indicam valores maiores). . . . . . . . . . . . . . . .

5.4 Swiss Roll: distribuições (a) 2D e (b) 3D com as cores mapeando a medida Neighborhood Validation. (c) mostra (esquerda) dois pontos destacados na distribuição 2D, um com máxima (preto) e outro com mínimo (branco) preservação, e (direita) ambos os pontos na distribuição 3D com seus correspondentes vizinhos (escala de cores Heated Objects, na qual cores escuras indicam valores maiores $). \ldots \ldots \ldots \ldots$

5.5 Swiss Roll: distribuição (a) 2D e (b) 3D com mapeamento em cores da medida Group Validation; em (c) dois grupos são destacados, com alta e baixa preservação; em (d) ambos os agrupamentos são mostrados em 3D (pontos pretos são do grupo superior e pontos marrons do grupo inferior). . 
5.6 Projeções LSP e PCA para o News2011, e os correspondentes valores de Class Separation e Class Aggregation mapeados em cores (cores escuras são melhores). Números se referem ao valor médio da medida para a projeção.

5.7 Projeções $L S P$ e $t$-SNE para o Optdigits: (a) $L S P$ com classes; (b) $L S P$ com cores mapeando a Class Separation Validation; (c) t-SNE com classes; (d) $t$-SNE com cores mapeando Class Separation Validation. Um valor global da medida é mostrado entre parênteses. . . . . . . . . . . . . . . . . 73

5.8 Projeções Sammon's, LSP, PCA e t-SNE do Optdigits, com a Neighborhood Validation mapeada em cores. . . . . . . . . . . . . . . . . . . . 74

5.9 Projeções LSP e $t$-SNE do conjunto de dados Optdigits, com as cores mapeando a medida Group Validation em (b) e (f), a medida Group Validation precisão em (c) e (g); e a medida Group Validation cobertura em (d) e (h).

5.10 Amostra de oito objetos do conjunto de dados Coil-20 visualizados em três rotações distintas. (a)-(d) ilustram classes com altos valores de Neighborhood Validation, (e)-(h) ilustram as classes com piores valores deNeighborhood Validation na Figura 5.11. . . . . . . . . . . . . . . . . . . 77

5.11 Projeções t-SNE do conjunto de dados Coil-20. (a) apresenta as classes, e (b)-(g) mostram diferentes medidas de preservação de vizinhança mapeadas em cores. . . . . . . . . . . . . . . . . . . . . . . 78

5.12 Projeções do conjunto de dados Optdigits, geradas com a técnica $t$-SNE e com valores de perplexity iguais a (a) 5, (b) 30 e (c) 100 . . . . . . . . . 80

5.13 Projeções t-SNE do Optdigits com as cores mapeando a medida de Class Separation. . . . . . . . . . . . . . . . . . 81

5.14 Projeções t-SNE do Optdigits com as cores mapeando a medida de Class Separation Validation. . . . . . . . . . . . . . . . . . . 81

5.15 Projeções t-SNE do Optdigits com as cores mapeando a medida de Class Aggregation. . . . . . . . . . . . . . . . . . 81

5.16 Projeções $t$-SNE do Optdigits com as cores mapeando a medida de Group Validation. . . . . . . . . . . . . . . . . . . . . . . 82

5.17 Projeções $t$-SNE do Optdigits com as cores mapeando a medida de Neighborhood Validation. . . . . . . . . . . . . . . . . . . . . . . . 82 


\section{Lista de Tabelas}

3.1 Conjuntos de dados utilizados no estudo com usuários. . . . . . . . . . . . 27

3.2 Parametrização utilizada na geração das projeções para o estudo experimental. . . . . . . . . . . . . . . . . . . . . . 28

3.3 Mapeamentos dos quatro conjuntos de dados obtidos com as quatro técnicas de projeção multidimensional consideradas. As cores nos mapas indicam as classes dos pontos. . . . . . . . . . . . . . . . . . . 29

3.4 Porcentagem de participantes que ranquearam corretamente $k$ vizinhos em cada um dos 30 estímulos. A média e o desvio padrão são apresentados na última linha da tabela. . . . . . . . . . . . . . . . . . . . . . . . . . 31

3.5 Porcentagem de participantes que identificaram corretamente, para cada um dos 30 estímulos, o conjunto formado por $k$ vizinhos mais próximos, $1 \leqslant k \leqslant 9$. A média e o desvio padrão são apresentados na última linha da tabela. Em destaque estão os maiores valores nas cinco primeiras escolhas.

4.1 Conjuntos de dados utilizados na avaliação experimental. . . . . . . . . . . . 54

4.2 Comparação do rank médio de cada método de identificação de agrupamentos, separados por categoria. . . . . . . . . . . . . . 55

4.3 Comparação do rank médio dos melhores métodos de identificação de agrupamentos, em cada categoria. . . . . . . . . . . . . 55

4.4 Resultados da comparação estatística (método na linha vs. método na coluna). Símbolos em verde indicam valores positivos da comparação estatística, em vermelho indicam valores negativos. Símbolos preenchidos indicam diferença significativa $(p$-value menor que 0.01) . . . . . . . . . . 56

5.1 Sumário das medidas propostas. . . . . . . . . . . . . . . . 58

5.2 Notação . . . . . . . . . . . . . . . . . . . . . . . . . . 59

5.3 Conjuntos de dados. . . . . . . . . . . . . . . . . . . . . . . . 68 
5.4 Matriz de distâncias organizadas por classes e matriz de confusão para o conjunto de dados Optdigits. . . . . . . . . . . . . . . . . . . 68

5.5 Projeções do Optdigits. Na linha 1, com os pontos coloridos por classe, e nas linhas 2, 3 e 4 coloridos de acordo com a medida proposta. O mapeamento de cores para as medidas segue a escala de cores Heated Objects (quanto mais escuro, melhor). Cada célula mostra também o valor médio referente à medida em questão. . . . . . . . . . . . . . . . . . . . . . . . 69

5.6 Projeções do News2011. Na linha 1, com os pontos coloridos por classe, e nas linhas 2, 3 e 4 coloridos de acordo com a medida proposta. Cada célula mostra também o valor médio referente à medida em questão. . . . . . . . . 70

5.7 Projeções do Optdigits. Cada linha contém os pontos coloridos de acordo com a medida proposta. Cada célula mostra também o valor médio referente à medida em questão e entre parênteses os valores de precisão e

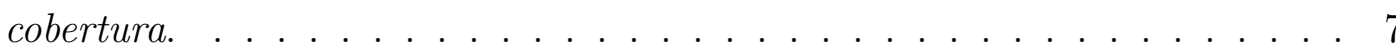

5.8 Projeções do News2011. Cada linha contém os pontos coloridos de acordo com a medida proposta. Cada célula mostra também o valor médio referente à medida em questão e entre parênteses os valores de precisão e cobertura . . . . . . . . . . . . . . . . . . . 71

5.9 Composição de classes nos 15 agrupamentos extraídos pelo algoritmo $A C$ do espaço original do conjunto de dados Optidigits. . . . . . . . . . . . . . 75

5.10 Neighborhood Validation (precisão e cobertura) para as classes do conjunto de dados Coil-20. . . . . . . . . . . . . . . . . . . . . 79

5.11 Valores das medidas propostas para as projeções do conjunto de dados Optdigits, resultantes de diferentes parametrizações da técnica $t$-SNE. . . . 80

5.12 Comparação das medidas propostas com medidas da literatura. . . . . . . 83 


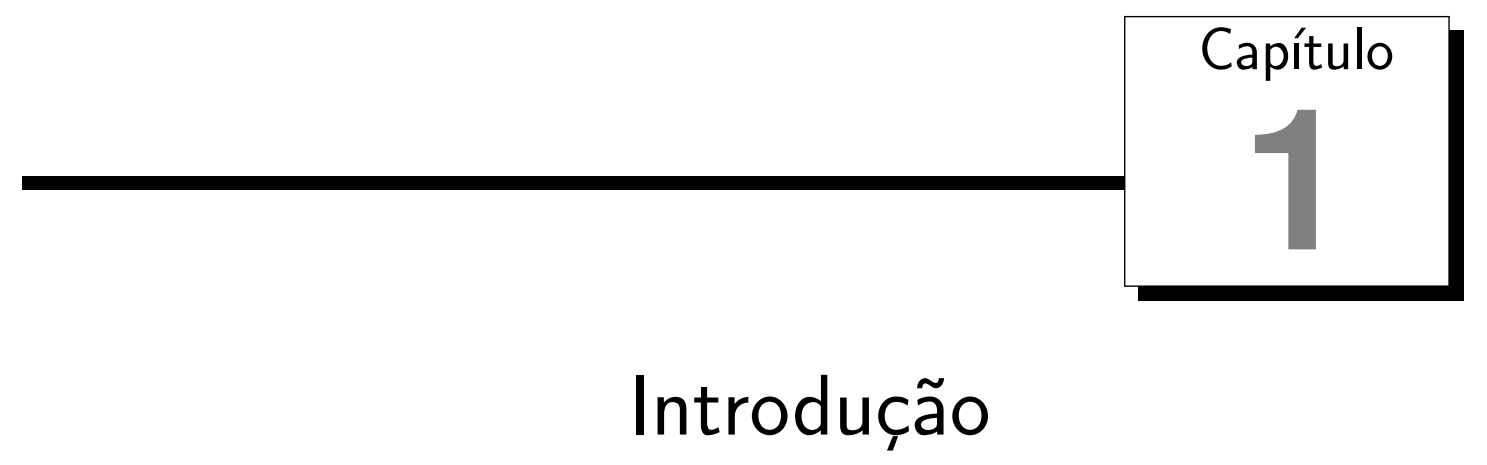

O crescimento constante dos dados, tanto em volume como em diversidade, tem recebido grande atenção e representa um desafio para os analistas. Uma pessoa pode, por exemplo, facilmente localizar uma vasta quantidade de documentos digitais sobre qualquer área de conhecimento ou assunto, porém não é fácil identificar e selecionar, neste material, as informações de interesse específicas e relevantes para quem fez a busca. Além disso, corporações deixaram de armazenar dados apenas para consultas históricas e passaram a perceber o valor das informações quando traduzidas rapidamente em conhecimento para os seus negócios.

O caminho entre a aquisição destes dados e a geração de conhecimento passa por considerável esforço devotado à pesquisa em Mineração de Dados, ou Data Mining. A mineração de dados é uma subárea da Ciência da Computação que estuda técnicas para extrair, de forma automática ou semi-automática, padrões dos dados que enriqueçam sua análise e seu uso (Fayyad et al., 1996).

De forma a contribuir com as complexas tarefas de mineração de dados, interfaces visuais adequadas podem ser utilizadas, auxiliando em tarefas de análise de dados e de aquisição de conhecimento de natureza menos sistemática e mais exploratória. A sinergia entre a mineração de dados e a área conhecida como Visualização de Informação (Card et al., 1999) tem sido explorada na Mineração Visual de Dados (Visual Data Mining) (Oliveira e Levkowitz, 2003; Börner et al., 2003), que busca integrar aos processos de mineração a capacidade humana de reconhecimento de padrões visuais. Especificamente, o que se procura é dar aos usuários um "modelo mental" adequado de um conjunto de dados, capaz de permitir que identifiquem características globais dos dados e explorem suas particularidades. No caso, por exemplo, de uma coleção de artigos científicos em uma determinada 
área de pesquisa, uma ferramenta de mineração visual pode ajudar um usuário a identificar rapidamente os principais tópicos, autores e artigos, e direcionar gradualmente a sua exploração aos aspectos de interesse para uma análise mais aprofundada. Já para um conjunto de imagens, por exemplo, tais ferramentas permitem perceber agrupamentos de imagens similares, imagens com características referentes a mais de um agrupamento, e outras análises globais, principalmente relacionadas com as distribuições de similaridade entre elas.

Para gerar modelos visuais a partir dos dados, técnicas de projeção multidimensional têm sido muito utilizadas e amplamente propostas (Sammon, 1969; Cox e Cox, 2000; Paulovich et al., 2006; Cuadros et al., 2007; Paulovich et al., 2008). Estas técnicas buscam preservar as relações de similaridade entre os dados, identificadas por alguma métrica, para gerar representações que possibilitem sua visualização. Os modelos visuais resultantes permitem identificar instâncias similares simplesmente pela sua proximidade no espaço projetado. Técnicas de projeção multidimensional têm sido cada vez mais utilizadas em análise de dados, auxiliando usuários em áreas desde computação (Gashi et al., 2009) até análise social (Martins et al., 2012), de músicas (Hamel e Eck, 2010) e na saúde (Moraes et al., 2012; Paulovich et al., 2011; Perinoto et al., 2010; Jamieson et al., 2010).

Diferentes técnicas de projeção multidimensional produzem diferentes resultados para um mesmo conjunto de dados, sendo que cada técnica adota uma estratégia específica para mapear os dados originais em um espaço geométrico de baixa dimensionalidade que permita a sua visualização. Além disso, variações na parametrização de uma mesma técnica também produz resultados distintos. Dentre as diversas técnicas de projeção multidimensional e parametrizações, a escolha da mais adequada para uma determinada tarefa não é uma atividade trivial.

Técnicas de avaliação de projeções multidimensionais são utilizadas para identificar o quanto uma projeção resultante preserva determinadas características que são úteis em uma atividade exploratória específica. Técnicas de avaliação ainda são pouco exploradas e, em geral, capturam apenas uma característica específica dos dados, por exemplo, a preservação das vizinhanças (Paulovich e Minghim, 2006; Venna e Kaski, 2001), a distribuição visual das classes (Paulovich et al., 2008) ou a preservação dos agrupamentos (Marghescu, 2006). Portanto, para avaliar uma projeção segundo diferentes propriedades é necessário implementar múltiplas técnicas de avaliação de projeções, sendo que não existe um arcabouço robusto para este fim.

Neste projeto de doutorado propomos um arcabouço para computar medidas de avaliação de projeções com enfoque na análise de vizinhança e de agrupamentos, as quais são propriedades tradicionalmente analisadas em tarefas exploratórias e também amplamente empregadas em estratégias de avaliação de projeções. Portanto, os principais objetivos deste trabalho são:

- identificar padrões na forma como os usuários observam as vizinhanças e os agrupa- 
mentos em projeções de dados multidimensionais;

- obter uma representação dos dados que favoreça a identificação automática das vizinhanças e dos agrupamentos de maneira compatível com o que é observado pelos usuários, e;

- com base na representação, propor medidas de avaliação de propriedades de vizinhanças e agrupamentos em projeções, condizentes com os padrões identificados na observação pelos usuários.

Neste processo foi conduzido um estudo de percepção para entender melhor como os usuários percebem vizinhanças e agrupamentos nas projeções. O principal padrão observado foi na análise das vizinhanças, em que a maioria dos participantes do estudo conseguiu identificar de forma similar a vizinhança de determinados pontos em cada projeção. Os padrões detectados permitiram validar a representação dos dados adotada no arcabouço, a qual é um modelo de grafo capaz de capturar características dos dados e das projeções de maneira compatível com o que foi observado pelos participantes do estudo, chamado de grafo EMST (Extended Minimum Spanning Tree). O grafo EMST é uma contribuição desse trabalho e é validado por meio de um estudo comparativo de identificação de vizinhanças e de agrupamentos, e em seguida utilizado na proposta de medidas de avaliação dessas propriedades em projeções multidimensionais.

Cinco medidas são propostas, duas delas avaliando características das projeções independentemente do espaço original dos dados, e três avaliando a preservação de propriedades do espaço original. As duas medidas propostas para caracterização das projeções avaliam aspectos distintos da capacidade de uma projeção separar visualmente as classes dos dados. Dentre as medidas de preservação de propriedades, a primeira avalia se a separação de classes observada na projeção é condizente com a separação de classes no espaço original. A segunda medida de preservação avalia a semelhança das vizinhanças de cada ponto na projeção e no espaço original. E, por fim, a última medida avalia se a projeção preserva os agrupamentos do espaço original.

As medidas propostas são inicialmente aplicadas a conjuntos de dados artificiais, favorecendo a interpretação de cada uma delas. Em seguida um estudo com dois conjuntos de dados reais é realizado para analisar o desempenho das medidas na prática. Por fim, um estudo com um terceiro conjunto de dados real é realizado, sendo um comparativo com duas medidas existentes que avaliam a preservação de vizinhança, que permitiu identificar características que distinguem as medidas propostas das demais. Os resultados indicaram que o arcabouço de avaliação de projeções proposto pode ser utilizado para uma análise ampla da qualidade de uma determinada projeção, tanto avaliando propriedades similares às propriedades que as medidas existentes já avaliam como propriedades antes não avaliadas. 
Portanto, este projeto de doutorado teve como meta principal a avaliação de projeções multidimensionais de forma condizente com a percepção de possíveis utilizadores dessas projeções. Três hipóteses foram investigadas: (i) se é possível identificar um padrão na percepção de vizinhanças e agrupamentos; (ii) se existe uma representação dos dados que favoreça a identificação automática de vizinhanças e agrupamentos; e (iii) se é possível propor um arcabouço de avaliação de projeções que permita avaliar propriedades similares às avaliadas por técnicas existentes na literatura, e também outras propriedades não consideradas por técnicas existentes.

A organização desta tese contém técnicas de projeção multidimensional e avaliação de projeções no Capítulo 2. O estudo de percepção no Capítulo 3, o qual foi aplicado a um grupo de participantes que executou tarefas referentes às projeções multidimensionais. A representação dos dados e um estudo de estratégias de identificação de vizinhança e de agrupamentos estão no Capítulo 4, o qual contém o modelo relacional proposto para representação dos dados. As medidas objetivas de avaliação de projeções multidimensionais propostas são apresentadas no Capítulo 5, que descreve as cinco medidas que são avaliadas e comparadas com outras medidas existentes. E por fim, as conclusões são discutidas no Capítulo 6, incluindo sugestões de trabalhos futuros. 


\section{- \\ Avaliação de projeções multidimensionais}

Processos de Mineração de Dados tipicamente utilizam alguma representação gráfica para apoiar tarefas de extração de informações úteis (Keim, 2002). Tal representação pode proporcionar uma interface adequada para diversas tarefas, tanto de natureza exploratória como tarefas específicas de mineração, por exemplo, classificação dos dados ou identificação de agrupamentos.

Ao interagir com uma representação visual, um usuário pode descobrir relações e padrões nos dados sem necessidade de analisar centenas deles individualmente. A título de ilustração, a Figura 2.1 representa graficamente uma coleção de 680 artigos científicos, nas áreas de Case Based Reasoning, Inductive Logic Programming, Information Retrieval e Sonification, rotulados em função dos veículos em que foram divulgadas.

A representação da Figura 2.1 funciona como um mapa, em que a proximidade entre artigos (representados pelos marcadores gráficos) é indicativa da similaridade de seus conteúdos. O mapa permite observar subáreas de pesquisa, explorar fronteiras entre áreas (i.e., abordagens relacionadas a múltiplas áreas), identificar artigos similares, entre outras possibilidades. Por simplicidade, daqui em diante, cada instância dos dados no espaço original será chamado de instância e no espaço projetado será chamado de ponto, independente do marcador gráfico utilizado para sua representação.

Estas representações visuais são, em geral, geradas por técnicas de projeção multidimensional, um caso específico de redução de dimensionalidade (Fodor, 2002; Sorzano et al., 2014). Na redução de dimensionalidade busca-se uma representação mais compacta dos dados que seja mais eficaz para uma tarefa específica. Em classificação ou identificação de agrupamentos, por exemplo, atributos irrelevantes podem ser removidos e outros atributos combinados para obter um melhor modelo de aprendizado (Kaski, 1998; Ding 


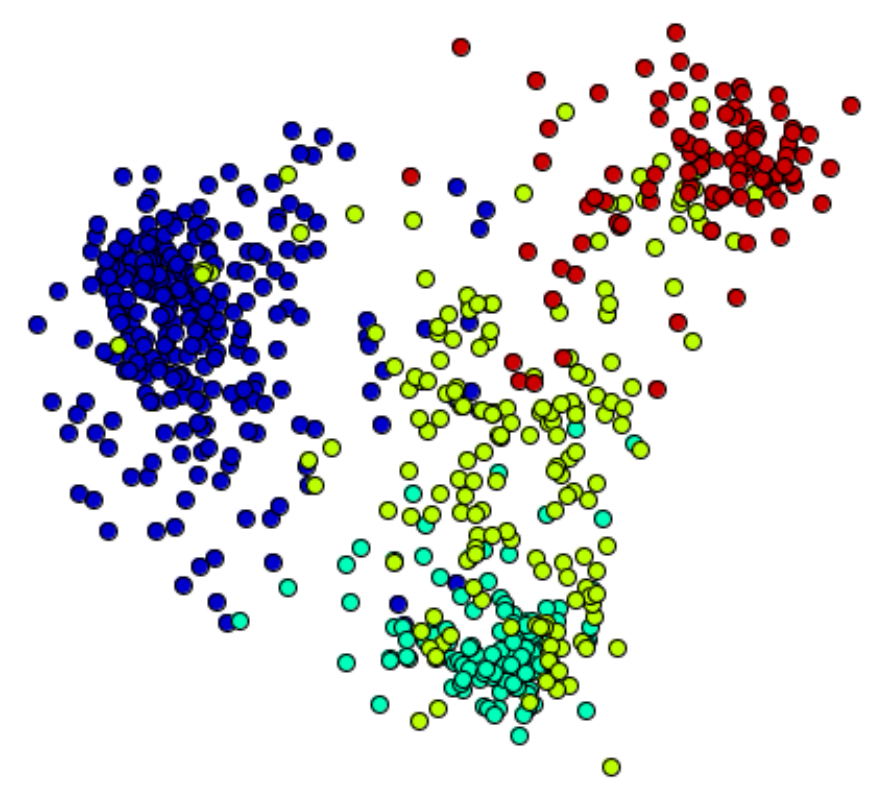

Figura 2.1: Projeção de um conjunto textual de artigos científicos. Os marcadores gráficos indicam documentos e as cores mapeiam as áreas de conhecimento.

et al., 2002; Ji e Ye, 2009). Por outro lado, em tarefas de visualização busca-se uma redução para poucos atributos, geralmente dois ou três (Roweis e Saul, 2000; Paulovich et al., 2008; van der Maaten e Hinton, 2008).

A visualização de informação tem sido cada vez mais utilizada em análise dos dados. Martins et al. (2012) utilizaram projeções multidimensionais na análise visual de redes sociais, melhorando as tradicionais visualizações de grafos com uma visualização baseada nas informações individuais das instâncias. Na Figura 2.2 é apresentada uma visualização de um conjunto de artigos científicos na área de visualização no Brasil publicadas entre 2003 e 2010, com os pontos representando autores ou artigos e as conexões indicando relações autor-artigo (autores), autor-autor (co-autores) e artigo-artigo (autores em comum). A Figura 2.2 (a) contém um exemplo de visualização de grafo, aproximando pontos conectados com uma estratégia de atração baseada em forças, e em (b) uma projeção multidimensional construída a partir de uma matriz de similaridade computada a partir das distâncias no grafo. A técnica de projeção gerou uma visualização com menos sobreposição e que favorece a análise, evidenciando por exemplo a região em verde que indica um autor (e seus artigos) que está como um "ponte" entre dois grandes grupos de pesquisa, os localizados acima e os localizados abaixo desta região verde.

Na Figura 2.3 é mostrada a visualização de usuários da rede social Orkut ${ }^{1}$. Os pontos representam os usuários e foram mapeados com base em suas informações individuais. Em (a) os usuários são coloridos por gênero e em (b) por estado civil. Estas visualizações se contrapõem às tradicionais visualizações de redes sociais, que em geral conectam usuários por alguma característica específica, como atividades esportivas em comum, e

\footnotetext{
${ }^{1}$ http://www.orkut.com/
} 


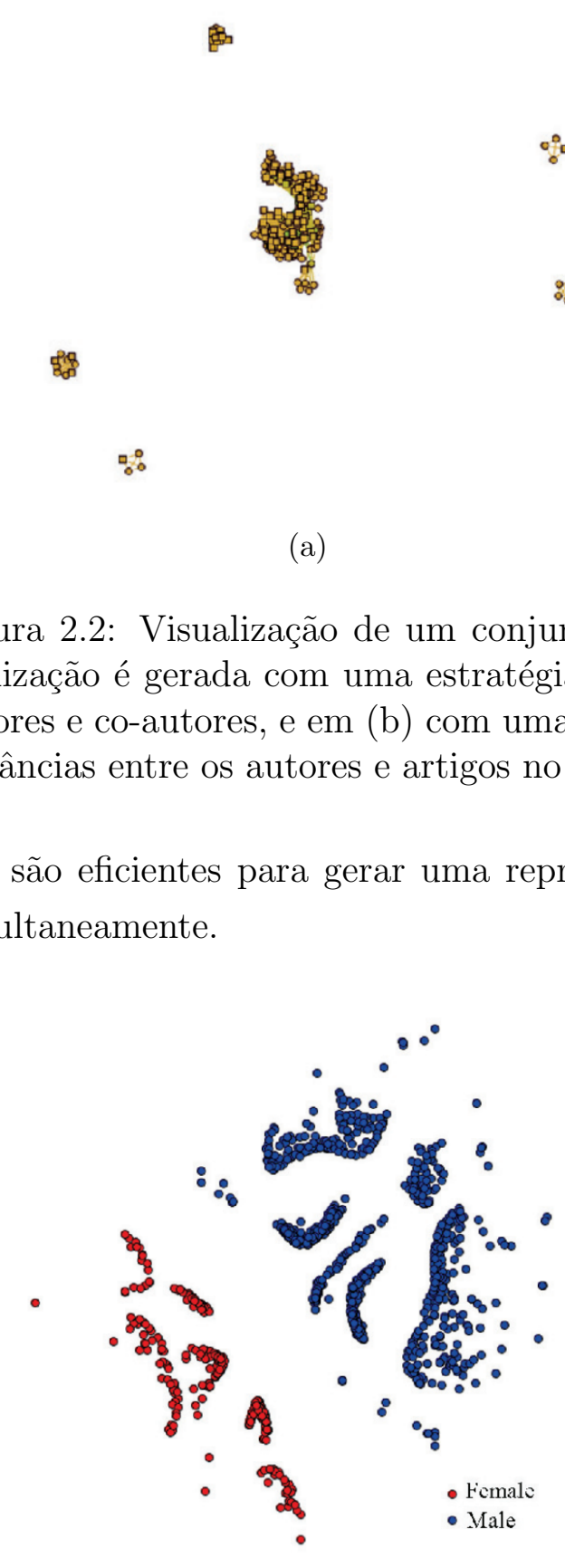

(a)

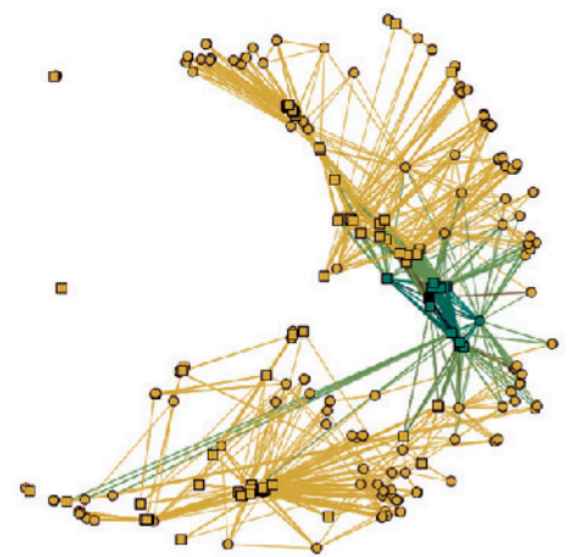

(b)

Figura 2.2: Visualização de um conjunto de autores e artigos científicos. Em (a) a visualização é gerada com uma estratégia de força baseada nas conexões que representam autores e co-autores, e em (b) com uma técnica de projeção multidimensional aplicada às distâncias entre os autores e artigos no grafo (Figura adaptada de Martins et al. (2012)).

não são eficientes para gerar uma representação visual que reflita várias características simultaneamente.

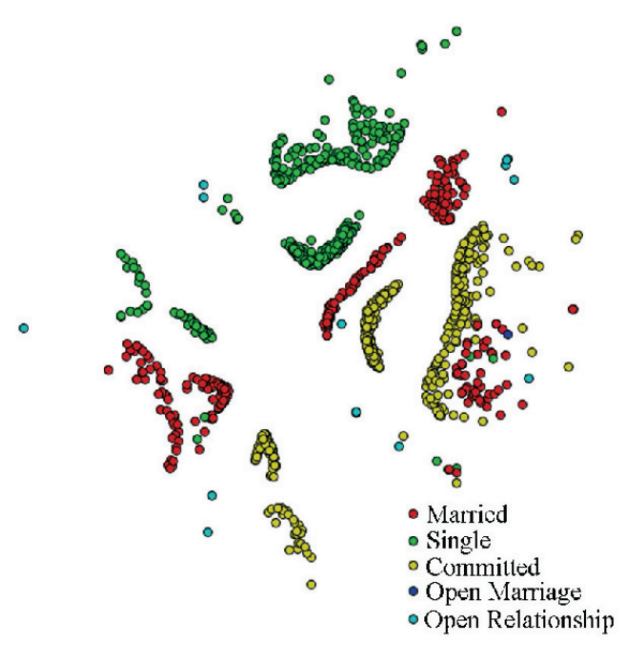

(b)

Figura 2.3: Visualização de usuários da rede social Orkut, coloridos de acordo com seu (a) gênero e (b) estado civil (Figura adaptada de Martins et al. (2012)).

Análises de projeções multidimensionais também têm sido empregadas para avaliar a qualidade de anti-vírus (Gashi et al., 2009), na extração de atributos de músicas (Hamel e Eck, 2010), e no campo da saúde, para visualizar e classificar dados de lesões mamárias (Jamieson et al., 2010), para avaliar biosensores para detecção de glicose e triglicerídeos (Moraes et al., 2012), entre outras aplicações.

De acordo com a natureza dos dados e a tarefa de análise a ser empregada pode-se considerar diferentes técnicas de projeção, pois cada técnica visa o mapeamento para 
preservar alguma característica específica, como distâncias, vizinhanças ou agrupamentos. O objetivo é fornecer ao usuário uma representação com foco na característica a ser preservada, ainda que outras características globais ou locais sejam ignoradas. Dessa forma, tipicamente outras estratégias de redução de dimensionalidade também são utilizadas com sucesso em visualização, assim como algumas técnicas de projeção também podem ser utilizadas em outras tarefas.

Técnicas de projeção requerem alguma medida de dissimilaridade de conteúdo (que pode ser aproximada por uma função de distância) entre as instâncias. Uma boa técnica, aliada a uma medida de dissimilaridade adequada, preserva informações importantes sobre as relações entre as instâncias, e permite gerar mapas que facilitam a visualização e exploração destas informações, como o ilustrado na Figura 2.1, 2.2 e 2.3.

Idealmente, características observadas na projeção devem refletir características existentes no espaço original, como por exemplo a distribuição dos pontos, a proximidade entre eles e os agrupamentos visuais. Porém, a alta dimensionalidade dos dados acarreta uma grande perda de informação na redução para duas ou três dimensões, resultando em uma projeção que muitas vezes pode não refletir características reais dos dados.

Ainda há muitos desafios para que se obtenha projeções realmente efetivas do ponto de vista de usuários finais. As necessidades funcionais variam muito conforme o domínio de aplicação, tarefas e perfis de usuários, e soluções genéricas raramente são ótimas. Adicionalmente, o suporte oferecido ao usuário deve ir muito além de funcionalidades básicas associadas à representação visual. É necessário, cada vez mais, incorporar algoritmos analíticos ao processo exploratório e, da mesma forma, incorporar recursos exploratórios aos algoritmos analíticos para direcionar processos de mineração (Thomas e Cook, 2005).

A seguir são introduzidas técnicas de projeção multidimensional, apresentadas estratégias de avaliação da qualidade das projeções resultantes e, por fim, discute-se como combinar as estratégias de avaliação com a percepção dos usuários. Por conveniência, chamaremos de técnicas de projeção multidimensional tanto as técnicas propostas especificamente com o intuito de apoiar tarefas de exploração visual quanto as técnicas de redução de dimensionalidade que também são aplicadas para visualização de dados.

\subsection{Técnicas de projeção multidimensional}

Técnicas de projeção multidimensional representam um conjunto de dados, definido como $X=\left\{x_{1}, x_{2}, \ldots, x_{n}\right\}$, em duas ou três dimensões, $Y=\left\{y_{1}, y_{2}, \ldots, y_{n}\right\}$, que podem ser diretamente visualizados. Os pontos pertencentes a representação dos dados projetados são denotados como $y_{i}=\left[y_{i 1}, y_{i 2}\right]$ (no caso de duas dimensões), enquanto os pontos no espaço original são denotados como $x_{i}=\left[x_{i 1}, x_{i 2}, \ldots, x_{i m}\right]$.

Paulovich (2008) categoriza as técnicas de projeção multidimensional em três grandes grupos: Force-Direct Placement (FDP); Multidimensional Scaling (MDS); e técnicas de 
redução de dimensionalidade.

O grupo de técnicas denominado Force-Direct Placement (FDP) é baseado na idéia de forças geradas entre os pontos por um modelo de molas, as quais ligam cada ponto a todos os outros. O modelo é aplicado iterativamente para aproximar ou repelir os pontos até o sistema como um todo atingir uma posição de equilíbrio. Algumas variações são o Force Scheme (FS) (Tejada et al., 2003), o Least Square Projection (LSP) (Paulovich et al., 2008), o ProjClus (Paulovich e Minghim, 2006) e o Glimmer (Ingram et al., 2009).

O Multidimensional Scaling (MDS) é uma abordagem que visa mapear os pontos preservando as distâncias definidas no espaço original. Técnicas de MDS podem ser divididas em duas classes (Cox e Cox, 2000), o MDS métrico e o MDS não-métrico. Na primeira classe busca-se preservar as distâncias do espaço original, e na segunda classe busca-se manter as relações entre as distâncias, de forma que um par $\left(x_{i}, x_{j}\right)$ de pontos mais próximos entre si do que um par $\left(x_{k}, x_{l}\right)$ no espaço original se mantenham mais próximos no espaço reduzido, mas sem necessariamente preservar as distâncias. Dentre as técnicas MDS mais conhecidas há o Classical Scaling (Young e Householder, 1938), o Isometric Feature Mapping (ISOMAP) (Tenenbaum, 1998), o Sammon's Mapping (SM) (Sammon, 1969), e o $t$-SNE (van der Maaten e Hinton, 2008).

As técnicas de redução de dimensionalidade não se baseiam na análise de propriedades específicas, como vizinhança ou agrupamento, e buscam uma representação que capture o conteúdo original dos dados de acordo com algum critério (Fodor, 2002). No contexto de gerar representações visuais, utiliza-se técnicas de redução de dimensionalidade para um espaço de dimensionalidade igual a 1,2 ou 3. Técnicas bastante usuais neste contexto são o Principal Component Analysis (PCA) (Pearson, 1901; Jolliffe, 2002) e o FastMap (Faloutsos e Lin, 1995).

Considerando o conjunto de artigos científicos introduzido no Capítulo 2, na Figura 2.4 são apresentadas projeções obtidas com quatro diferentes técnicas: Glimmer, ISOMAP, $L S P$ e $P C A$. Observa-se que há diferenças significativas entre os resultados obtidos por cada uma, devido a cada técnica possuir uma parametrização específica e adotar abordagens distintas para construir a representação bidimensional.

Em se tratando de recursos para apoiar a exploração visual das projeções, há uma grande diversidade de estratégias, em geral envolvendo a aplicação de algoritmos analíticos típicos da mineração de dados, como a detecção de agrupamentos, a identificação de outliers e a análise de densidade. Técnicas adequadas de mineração, combinadas com representações visuais, podem guiar o usuário em processos exploratórios.

Algoritmos de mineração de dados também são tipicamente utilizados na validação das projeções geradas, como, por exemplo, variações do algoritmo $k$-Nearest Neighbors para análise de vizinhança (Paulovich et al., 2008) e identificação de agrupamentos para avaliar a preservação dos grupos (Marghescu, 2006). Padrões observados nas projeções devem representar padrões dos dados no espaço original, para que o usuário de fato identi- 


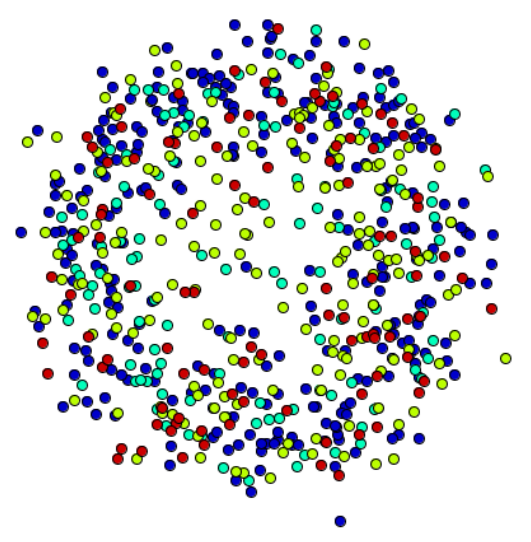

(a) Glimmer

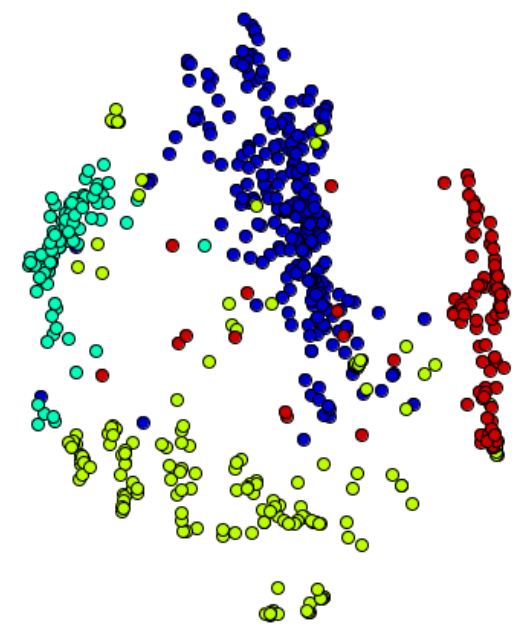

(c) LSP

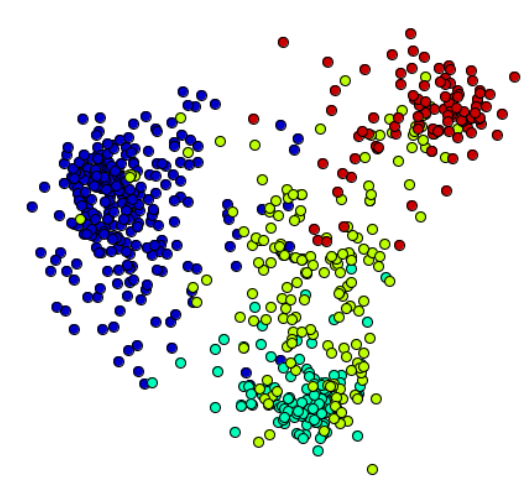

(b) ISOMAP

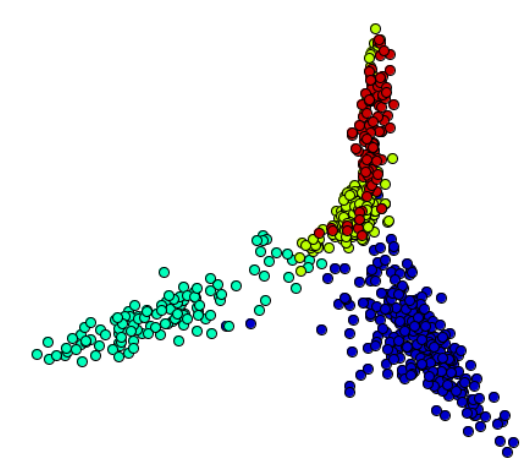

(d) PCA

Figura 2.4: Quatro projeções do conjunto de artigos científicos $C B R$, utilizando as técnicas (a) Glimmer, (b) ISOMAP, (c) $L S P$ e (d) PCA.

fique características que condizem com a realidade. Esta tarefa de avaliação de projeções multidimensionais é discutida a seguir.

\subsection{Avaliação de projeções multidimensionais}

Embora as projeções multidimensionais sejam eficientes para apoiar tarefas de análise de dados, é importante que elas representem adequadamente os dados para uma determinada tarefa. Isso significa que, para usuários com diferentes objetivos, diferentes técnicas de projeção podem ser mais adequadas.

Definir qual técnica representa melhor os dados originais, ou qual é mais eficiente para uma determinada tarefa, não é trivial. A interpretação de uma projeção é altamente subjetiva e analistas precisam de ajuda para interpretar corretamente características observadas.

Há algumas medidas qualitativas e quantitativas para avaliar e comparar múltiplos aspectos das projeções. As medidas qualitativas tipicamente apresentam alguma repre- 
sentação visual que facilita a compreensão da projeção. Medidas quantitativas permitem avaliações objetivas do comportamento global ou local de uma projeção em relação a uma determinada propriedade, como por exemplo, a preservação das distâncias ou das vizinhanças, ou a capacidade de segregação das classes. Além disso, é possível gerar representações gráficas que mapeiam os valores de qualidade individuais dos pontos, evidenciando a variação de valores de uma dada medida, nas diferentes regiões da projeção.

\subsubsection{Medidas qualitativas para interpretação de projeções}

As medidas qualitativas ajudam a interpretar características específicas dos dados ou da projeção de forma subjetiva. Estas medidas comumente são utilizadas para dar uma idéia prévia de propriedades dos dados em seu espaço original, antes de empregar alguma medida de avaliação quantitativa.

Um histograma de distância, exemplificado na Figura 2.5 (a), mostra a distribuição das distâncias entre os pares de instâncias computadas no espaço original. A matriz de similaridade, mostrada na Figura 2.5 (b), revela se as classes dos dados são bem formadas. É mostrada como uma grade com $N$ linhas e colunas, sendo $N$ o número de instâncias, com a cor da célula $(i, j)$ refletindo a similaridade entre duas instâncias. As linhas e as colunas são ordenadas pelas classes, e assim as bordas que se formam revelam se instâncias de uma classe são altamente separada das demais. A Figura 2.5 (c) mostra um diagrama de Shepard das distâncias entre pontos computadas no espaço original e no espaço projetado. Idealmente, uma projeção com mínima perda resulta em um gráfico com os pontos sobre uma linha diagonal, indicando que as distâncias foram totalmente preservadas.

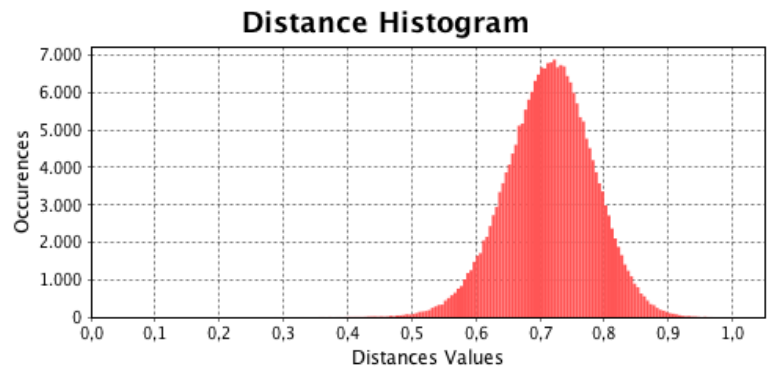

(a)

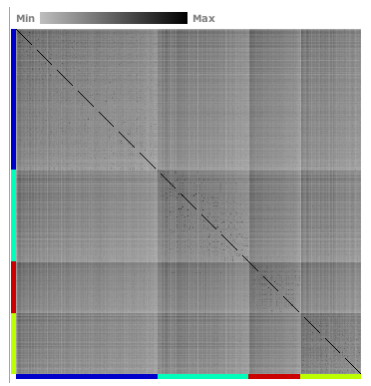

(b)

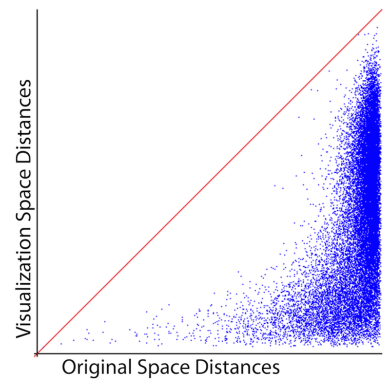

(c)

Figura 2.5: Representações visuais para auxiliar usuários na compreensão dos dados, ilustrada para o conjunto de dados $C B R$. Em (a) é apresentado um histograma de distância, em (b) uma matriz de similaridade, e em (c) um diagrama de Shephard. Em (a) e (b) as distâncias foram computadas no espaço original, e o diagrama em (c) refere-se a projeção mostrada na Figura 2.1.

Embora úteis para transmitir uma visão global de determinadas propriedades, tais representações não transmitem informações sobre outras propriedades relevantes para uma avaliação da qualidade da projeção, ou sua fidelidade a algum aspecto dos dados no espaço 
original.

\subsubsection{Funções de stress}

Funções de stress são clássicas para avaliar a capacidade de preservação de distâncias de uma projeção. Tais medidas fornecem um valor global da qualidade com base no quanto as relações de distância foram preservadas.

Morrison e Chalmers (2004) utilizaram stress para comparar projeções obtidas com diversas técnicas e variações de parâmetros. Duas destas funções são descritas nas Equações 2.1 (Sammon, 1969) e 2.2 (Kruskal, 1964), e "medem" a perda de informação introduzida no processo. Nas Equações as notações $\delta\left(x_{i}, x_{j}\right)$ e $d\left(y_{i}, y_{j}\right)$ denotam a distância entre duas instâncias no espaço original e entre dois pontos na projeção, respectivamente. $\mathrm{O}$ valor dessas funções, que varia entre $[0,1]$, indica a perda e permite comparar projeções, sendo que um menor valor indica a melhor projeção.

$$
\begin{gathered}
S_{1}=\frac{1}{\sum_{i<j} d\left(x_{i}, x_{j}\right)} \sum_{i<j} \frac{\left(d\left(y_{i}, y_{j}\right)-\delta\left(x_{i}, x_{j}\right)\right)^{2}}{d\left(x_{i}, x_{j}\right)} \\
S_{2}=\sqrt{\frac{\sum_{i<j}\left(\delta\left(x_{i}, x_{j}\right)-d\left(y_{i}, y_{j}\right)\right)^{2}}{\sum_{i<j} \delta\left(x_{i}, x_{j}\right)^{2}}}
\end{gathered}
$$

Apesar de bastante utilizada, é comum encontrar exemplos de incompatibilidade entre os resultados de stress e a interpretação visual da qualidade das projeções. Isso porque funções de stress semelhantes podem levar a diferentes avaliações de qualidade, e mesmo uma projeção que não preserva bem as distâncias pode apresentar excelentes valores de stress (Paulovich, 2008).

\subsubsection{Medidas de propriedades visuais das projeções}

Em avaliação de projeções uma classe bastante explorada de medidas busca mensurar propriedades visuais sem considerar o espaço original. Esta classe de medidas não busca avaliar se determinadas propriedades dos dados estão sendo preservadas, mas apenas o quanto uma determinada propriedade pode ser observada na projeção. Tais medidas, as quais chamaremos de medidas de caracterização da projeção, em geral estão relacionadas com a desordem visual (clutter) ou com a separação visual das classes.

Em visualização de informação é comum a dificuldade de identificar padrões visualmente devido a desordem visual. Peng et al. (2004) propõem uma estratégia para organizar um conjunto de gráficos de dispersão scatterplot de acordo com uma medida de desordem, auxiliando o usuário a identificar a visualização mais apropriada. Estratégias aplicáveis na avaliação dessas visualizações podem ser estendidas para projeções.

De forma mais genérica, Wilkinson et al. (2005) também propõem medidas relativas a 
matrizes scatterplot para extrair informações da distribuição do pontos, como presença de outliers e identificação de variações relacionadas ao formato das nuvens de pontos. Para isso, constroem uma representação em forma de grafo a partir de uma árvore geradora mínima, ou seja, um grafo conexo de menor custo possível, e propõem medidas baseadas tanto na árvore geradora mínima como no fecho convexo dos pontos. Medidas baseadas em área são fortemente dependentes da distribuição dos pontos e podem sofrer grande influência de pequenas mudanças. Ainda assim os autores ilustram todas as medidas propostas, porém sem validá-las comparando com a percepção dos usuários.

Dentre as medidas de caracterização de projeções há as medidas supervisionadas, que operam sobre dados rotulados. A curva Neighborhood Hit (Paulovich et al., 2008) é uma representação gráfica baseada em vizinhança que quantifica a capacidade de segregação das classes pela projeção. A curva é gerada calculando para um dado ponto pertencente à classe $l$, quantos de seus $k$ vizinhos mais próximos também pertencem à classe $l$, e uma média dos valores de todos os pontos é computada. Os valores variam entre $[0,1]$, e quanto maiores mais perceptíveis são os agrupamentos visuais que refletem as classes na projeção gerada. A curva é obtida ao variar $k$, como ilustrado na Figura 2.6.

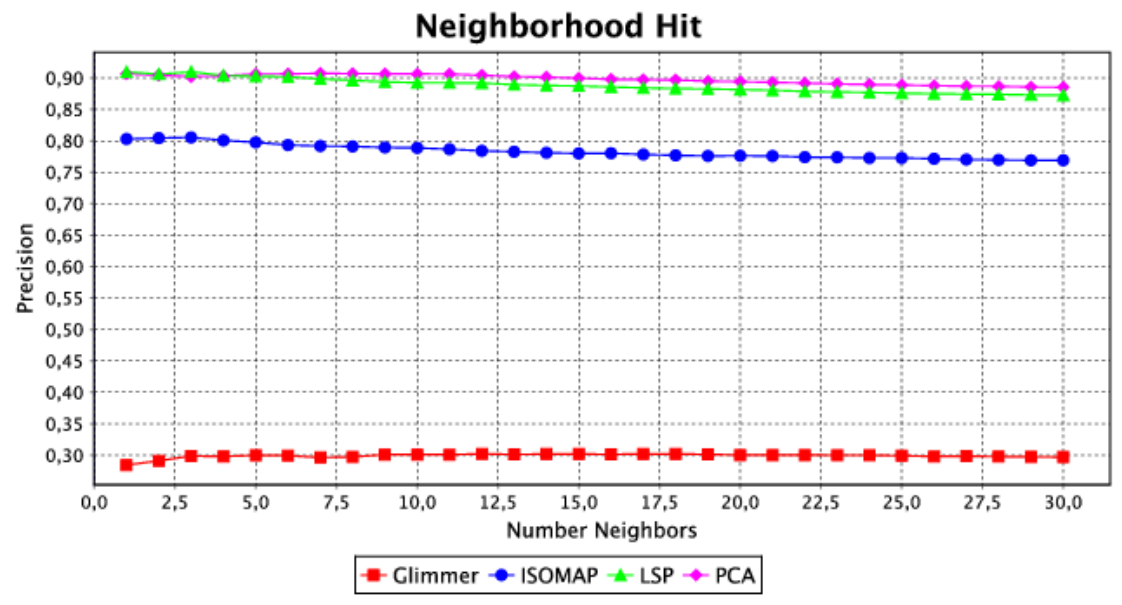

Figura 2.6: Gráfico da métrica Neighborhood Hit para as quatro projeções da Figura 2.4, relativas ao conjunto de dados $C B R$, com $k$ variando de 1 a 30 .

No entanto, a curva é altamente afetada pelas fronteiras entre classes, pois pontos próximos das fronteiras de uma classe serão possivelmente mais próximos de pontos de outras classes. Tais pontos terão baixos valores de Neighborhood Hit, ainda que tenham sido posicionados corretamente na projeção. Além disso, a curva não avalia se a projeção preserva uma separação de classes existente nos dados originais e nem o quanto as relações de distância foram preservadas.

Também avaliando a separação visual das classes, Sips et al. (2009) propõem duas medidas quantitativas. A primeira, denominada distance consistency, considera o centróide de cada classe para verificar a separação, analisando se cada ponto está mais próximo do centróide de sua respectiva classe. A segunda medida, denominada distribution consis- 
tency, considera a entropia da distribuição espacial das classes na projeção. Para isso, trata a projeção como uma matriz de pixels e a entropia é calculada em cada pixel segundo os pontos nele contidos. Regiões contendo pontos de uma mesma classe apresentam máximo valor de consistência, com base na entropia, cujo valor será menor em regiões que misturam pontos de diferentes classes.

A medida distance consistency possui como principal limitante a dependência de um formato circular dos grupos de pontos da mesma classe, pois calcula a distância para o centróide. A medida distribution consistency é fortemente dependente do tamanho do pixel, que se mal definido pode resultar em boa separação de classes mesmo em projeções que misturam diferentes classes.

Tatu et al. (2009) propõem uma estratégia para ordenar um conjunto de projeções candidatas com base na separação das classes. Os pontos de cada classe são considerados separadamente, construindo uma representação contínua com uma função de densidade baseada nas vizinhanças locais. As representações contínuas resultantes de cada classe são inspecionadas para identificar a sobreposição de classes a partir da estimativa de sobreposição em cada pixel. A medida requer a definição do número de vizinhos para gerar a representação contínua, bem como a definição do tamanho do pixel para calcular a sobreposição das classes.

As medidas supervisionadas assumem que interessa ao usuário a separação visual das classes, mesmo que estas não estejam separadas no espaço original. A seguir, são apresentadas medidas que comparam a projeção com o espaço original, identificando propriedades preservadas.

\subsubsection{Medidas de preservação de vizinhanças}

O ideal é que padrões observados em uma projeção reflitam a realidade dos dados no espaço original, por exemplo as vizinhanças dos pontos. Medidas de preservação de vizinhanças buscam avaliar se a projeção mapeia os dados preservando características de proximidade entre os pontos.

A curva Neighborhood Preservation (Paulovich e Minghim, 2006) avalia a preservação da vizinhança com base na intersecção das vizinhanças de cada ponto na projeção e no espaço original. Para cada ponto, são identificados quantos dos seus $k$ vizinhos mais próximos na projeção (para um determinado valor de $k$ ) estão também entre seus $k$ vizinhos mais próximos no espaço original. A curva é obtida variando $k$, conforme ilustrado na Figura 2.7 para as quatro projeções da Figura 2.4. Esta medida é adequada para comparar projeções, mas não como uma medida independente de qualidade.

Venna e Kaski (2001) também propõem métricas de qualidade baseadas na preservação de vizinhanças. Porém, os autores não consideram diretamente a proporção preservada dos $k$ vizinhos, mas verificam aonde realmente foram posicionados os $k$ vizinhos que deveriam 


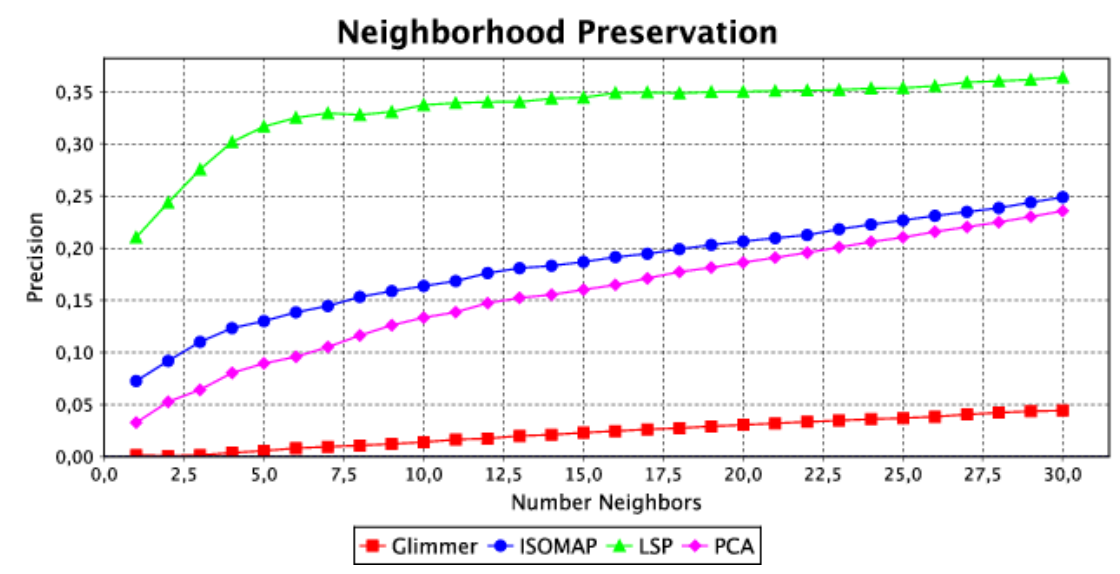

Figura 2.7: Exemplo de gráfico Neighborhood Preservation para as quatro projeções da Figura 2.4, com $k$ variando de 1 a 30 .

estar na vizinhança de um ponto. A característica de um ponto ser deslocado, na projeção, da sua vizinhança no espaço original, é chamada pelos autores de pontos ausentes, e o contrário, pontos que passam a integrar a vizinhança na projeção são chamados de falsos positivos.

Os autores propõem duas medidas, uma que avalia os pontos ausentes e outra os falsos positivos. A primeira medida, chamada de Confiabilidade, avalia a precisão da vizinhança dos pontos na projeção com base na ocorrência de falsos positivos na vizinhança de cada ponto. A medida é definida pela Equação 2.3, na qual $r\left(x_{i}, x_{j}\right)$ representa o ranking da proximidade da instância $x_{j}$ em relação à instância $x_{i}$ no espaço original, e $U_{k}\left(x_{i}\right)$ denota os $k$ pontos da vizinhança de $x_{i}$ na projeção que não pertencem à sua vizinhança original. $\mathrm{Na}$ expressão, a fração $\frac{2}{N k(2 N-3 k-1)}$ como fator de normalização entre 0 e 1 , sendo $N$ o número de instâncias.

$$
C V(k)=1-\frac{2}{N k(2 N-3 k-1)} \sum_{i=1}^{N} \sum_{x_{j} \in U_{k}\left(x_{i}\right)}\left(r\left(x_{i}, x_{j}\right)-k\right)
$$

A segunda medida, chamada de Preservação, avalia se as instâncias mais próximas no espaço original são mantidas próximas na projeção. A medida é descrita, de forma similar à anterior, pela Equação 2.4, porém considera $V_{k}\left(x_{i}\right)$, as $k$ instâncias da vizinhança original de $x_{i}$ que não estão na sua vizinhança na projeção, e $\hat{r}\left(x_{i}, x_{j}\right)$ o ranking da proximidade do ponto $x_{j}$ ao ponto $x_{i}$ no espaço projetado.

$$
P V(k)=1-\frac{2}{N k(2 N-3 k-1)} \sum_{i=1}^{N} \sum_{x_{j} \in V_{k}\left(x_{i}\right)}\left(\hat{r}\left(x_{i}, x_{j}\right)-k\right)
$$

A partir do ranking dos pontos é possível conduzir análises locais e globais variando o tamanho das vizinhanças. Os autores demonstram que algumas técnicas de projeção multidimensional apresentam melhor comportamento local, obtendo maior precisão para 
baixos valores de $k$, e outras melhor comportamento global, considerando vizinhanças maiores.

Também considerando o ranking de vizinhança dos pontos, Lee e Verleysen (2009) propuseram um arcabouço para avaliar a qualidade de técnicas de redução de dimensionalidade. Este arcabouço utiliza uma matriz de co-ranking, ou matriz $Q$, que é alimentada com a comparação do ranking das distâncias de cada instância a todas as demais, no espaço original e na projeção. A matriz resultante contabiliza o número de deslocamentos no ranking das instâncias no espaço original em relação aos seus respectivos rankings na projeção. Portanto, cada célula na posição $(i, j)$ da matriz de co-ranking informa quantas instâncias na posição $i$ dos rankings no espaço original foram para a posição $j$ no espaço projetado. Cada célula diagonal $(i, i)$ contém o número de instâncias que coincidiram na posição $i$ em ambos os espaços. Em um cenário ideal, no qual uma projeção mantém a posição exata dos pontos nos rankings, a matriz contém o valor $N$ em todas as células diagonais e, consequentemente, nenhum valor nas demais células.

Formalmente, dado o ranking das instâncias no espaço original representado por $\rho_{i j}=$ $\mid\left\{k: \delta\left(x_{i}, x_{k}\right)<\delta\left(x_{i}, x_{j}\right)\right.$ or $\left(\delta\left(x_{i}, x_{k}\right)=\delta\left(x_{i}, x_{j}\right)\right.$ and $\left.\left.k<j\right)\right\} \mid$ e o ranking dos pontos na projeção representado de forma similar por $r_{i j}=\mid\left\{k: d\left(x_{i}, x_{k}\right)<d\left(x_{i}, x_{j}\right)\right.$ or $\left(d\left(x_{i}, x_{k}\right)=\right.$ $d\left(x_{i}, x_{j}\right)$ and $\left.\left.k<j\right)\right\} \mid$, calculamos a matriz de co-ranking como uma junção de histogramas de rankings, definida na Equação 2.5.

$$
Q=\left[q_{k l}\right]_{1 \leqslant k, l \leqslant N-1} \operatorname{com} q_{k, l}=\mid\left\{(i, j): \rho_{i j}=k \text { and } r_{i j}=l\right\} \mid
$$

A informação mais relevante está no canto superior esquerdo da matriz, na linha 1 e coluna 1, que representa a quantidade de instâncias que está na primeira posição nos rankings do espaço original e também da projeção, e conforme se aumenta a linha e a coluna a informação torna-se menos relevante. Dessa forma, os autores propõem um corte nas primeiras $K$ linhas e colunas da matriz para avaliar a preservação de vizinhança (Lee e Verleysen, 2009). Este corte define quatro blocos principais, delimitados pela linha e coluna $K$, e os autores discutem estratégias de avaliação somando-se os elementos do bloco superior esquerdo e variando a forma como se considera os demais blocos. A estratégia mais explorada equivale a avaliar a proporção dos $K$ vizinhos de cada instância que coincide nos espaços original e projetado, chamada de medida $Q_{N X}$ em referência à matriz de co-ranking e aos extrusions $(X)$ e intrusions $(N)$, que referem-se, respectivamente, aos pontos ausentes e aos falsos positivos (Figura 2.8).

Em um trabalho posterior, Lee e Verleysen (2010) estendem o estudo e propõem uma maneira de obter o $K$ apropriado. Para isso, variam o valor de $K$ e consideram como o mais apropriado, $K_{\max }$, aquele que maximiza a medida $Q_{N X}$. Com base neste $K_{\max }$ é então proposta uma medida para avaliar a preservação local, a medida $Q_{\text {local }}$, e outra para preservação global, a medida $Q_{g l o b a l}$. A medida local é uma média de $Q_{N X}$ variando-se $K$ 


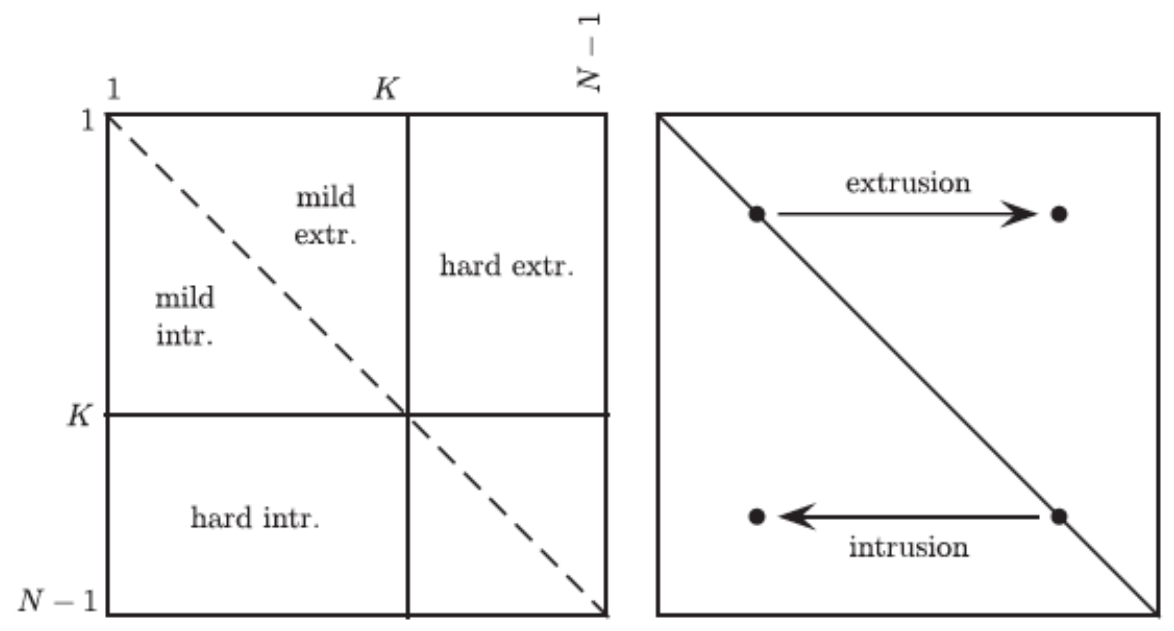

Figura 2.8: Ilustração da matriz de co-ranking com o corte em $K$ (esquerda) e com a perda identificada como extrusions ou intrusions, nos quais os pontos saem da posição ideal na diagonal principal (Figura extraída de Mokbel et al. (2013)).

de 1 até $K_{\max }$, e a global uma média variando-se de $K_{\max }$ até $N-1$.

Ainda com base no arcabouço de co-ranking, Mokbel et al. (2013) propuseram uma extensão da medida $Q_{N X}$, chamada de $Q_{N D}$, que visa evitar que altos valores de $K$ acarretem a aceitação de uma grande variação da posição nos rankings do espaço original e do espaço projetado. Ou seja, além de limitar a vizinhança considerada, nesta medida parametrizada por $K_{s}$, há também um parâmetro $K_{t}$ que controla o máximo permitido para um ponto se deslocar no ranking, permitindo avaliar valores mais altos de $K_{s}$ sem necessidade de ser tão permissivo no deslocamento de cada ponto. Portanto, segundo a matriz $Q$, o parâmetro $K_{s}$ controla a profundidade avaliada na matriz e $K_{t}$ avalia os valores das células horizontalmente, referentes ao deslocamento no ranking, no qual o deslocamento permitido limita-se no número de células, linha a linha, para a diagonal principal (Figura 2.9).
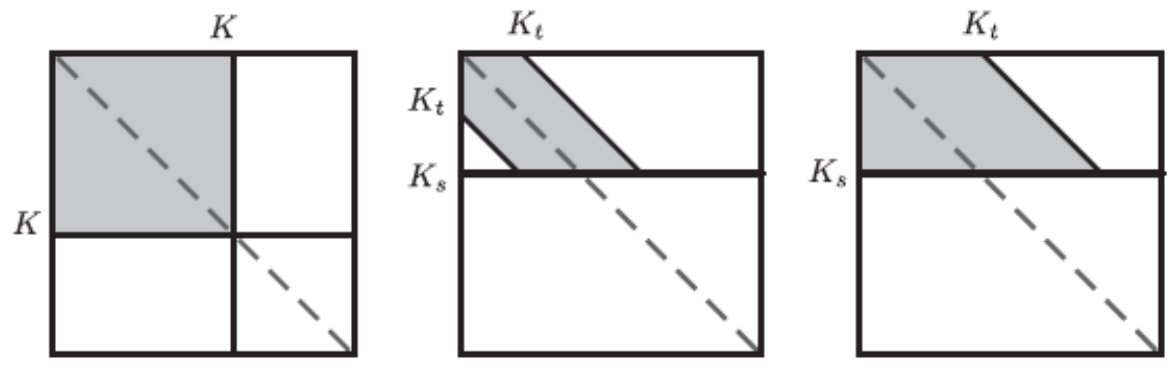

Figura 2.9: Ilustração das células consideradas na matriz de co-ranking com um corte em $K$ (Lee e Verleysen, 2009) (área cinza na imagem (a)) e as variações propostas por Mokbel et al. (2013) ilustradas em dois cenários distintos (b) e (c). Em (b) e (c) observa-se o limite vertical dado por $K_{s}$ e o limite horizontal dado por $K_{t}$, mostrado nas duas paralelas diagonais (Figura extraída de Mokbel et al. (2013)). 
As medidas derivadas do arcabouço co-ranking apresentam as limitações típicas das demais técnicas baseadas em $K$ vizinhanças. Elas não observam as características individuais de cada ponto, considerando vizinhanças de mesmo tamanho em todos os pontos. Também são sensíveis a variações na distribuição e densidade dos dados.

Combinando conceitos de recuperação de informação e visualização de informação, Venna et al. (2010) propõem uma definição para tarefas de visualização baseadas na análise de similaridade. Os autores denotam como $P_{i}$ a vizinhança de uma instância $x_{i}$, a qual é dada por um conjunto de instâncias próximas a $x_{i}$, e, de forma análoga, a vizinhança de um ponto $y_{i}$ como $Q_{i}$. As vizinhanças $P_{i}$ e $Q_{i}$ podem conter tanto uma quantidade fixa de instâncias mais próximos a $x_{i}$ e $y_{i}$ como as instâncias contidas em um raio de vizinhança previamente estabelecido.

Com base em $P_{i}$ e $Q_{i}$, Venna et al. (2010) definem três variáveis para avaliação de projeções. A primeira indica o número de elementos presentes em ambos os conjuntos, os verdadeiros positivos de $x_{i}$, denotados por $N_{T P, i}$. A segunda variável é o número de elementos em $Q_{i}$ que não estão em $P_{i}$, os falsos positivos, $N_{F P, i}$. E a terceira indica o número de elementos em $P_{i}$ que não estão em $Q_{i}$, ou os elementos ausentes, $N_{M I S S, i}$.

Os autores mapeiam estas variáveis nas tradicionais medidas de precisão e cobertura usadas em recuperação de informação, conforme as Equações 2.6 e 2.7. As medidas de precisão e cobertura podem ser ponderadas pelo usuário para indicar em uma avaliação quantitativa composta.

$$
\begin{gathered}
\operatorname{precis} \tilde{a} o(i)=\frac{N_{T P, i}}{\left|Q_{i}\right|}=1-\frac{N_{F P, i}}{\left|Q_{i}\right|} \\
\operatorname{cobertura}(i)=\frac{N_{T P, i}}{\left|P_{i}\right|}=1-\frac{N_{M I S S, i}}{\left|P_{i}\right|}
\end{gathered}
$$

Os autores afirmam que a principal limitação de considerar uma vizinhança fixa é que todas as violações de vizinhança são penalizadas igualmente. Para contornar este problema, Venna et al. (2010) propõem substituir o conjunto fixo de vizinhos, chamado de vizinhança binária, por uma vizinhança probabilística, definida pela probabilidade de um usuário observar um ponto $y_{j}$ dado que está observando um ponto $y_{i}$. A definição da probabilidade de cada ponto ser observado é dada em função da sua distância ao ponto referência, incluindo uma variável que controla o decaimento da probabilidade conforme a distância aumenta, priorizando pontos próximos.

Com base nesta vizinhança probabilística, outras medidas de precisão e cobertura são propostas comparando-se as distribuições de probabilidade nos espaços original e projetado. Porém, estas novas medidas são de difícil interpretação, pois não possuem um limite superior e os valores dependerão do conjunto de dados. Por isso, os autores propõem outra alteração, substituindo a distância do ponto $y_{j}$ para o ponto referência $y_{i}$ utilizada para obter as probabilidades pela posição de $y_{j}$ no ranking de distâncias de $y_{i}$, resultando 
em medidas similares às baseadas no arcabouço de co-ranking (Lee e Verleysen, 2009).

\subsubsection{Medidas de preservação de agrupamentos}

Agrupamentos dos dados também são frequentemente analisados em tarefas de exploração visual de projeções multidimensionais. É comum a projeção exibir grupos de pontos e é necessário avaliar se e como estes agrupamentos visuais refletem a distribuição dos dados no espaço original.

Marghescu (2006) adota uma abordagem na qual os dados são particionados e a qualidade dos agrupamentos obtidos é avaliada. São propostas medidas para comparar a estrutura $G^{R^{2}}$ de agrupamentos obtidos na projeção com uma estrutura $G^{R^{m}}$ de agrupamentos obtidos no espaço original. Os autores utilizaram o algoritmo de agrupamento K-médias (MacQueen, 1967), que apresenta bom desempenho quando aplicado a grandes conjuntos de dados (Shindler et al., 2011). Para cada par de instâncias há quatro situações possíveis:

- $S S$ - ambas as instâncias estão no mesmo grupo, tanto em $G^{R^{2}}$ como em $G^{R^{m}}$;

- $S D$ - as instâncias estão no mesmo grupo em $G^{R^{2}}$, mas em diferentes grupos em $G^{R^{m}}$

- $D S$ - as instâncias estão no mesmo grupo em $G^{R^{m}}$, mas em diferentes grupos em $G^{R^{2}}$

- $D D$ - ambas as instâncias estão em diferentes grupos, tanto em $G^{R^{2}}$ como em $G^{R^{m}}$.

Sendo $a, b, c$ e $d$ a quantidade de pares de instâncias em $S S, S D, D S$ e $D D$, respectivamente, então $a+b+c+d=H$ é o total possível de pares. Com isso, os seguintes índices estatísticos permitem medir a correspondência entre $G^{R^{2}}$ e $G^{R^{m}}$ (Theodoridis e Koutroumbas, 2006):

- Estatística Radial: $R=\frac{a+d}{H}$

- Coeficiente de Jaccard: $J=\frac{a}{a+b+c}$

- Índice de Fowlkes and Malloes: $F M=\sqrt{\frac{a}{a+b} * \frac{a}{a+c}}$

Para todos os índices, altos valores indicam alta correspondência. Porém, tal abordagem possui duas limitações. Em primeiro lugar, uma estrutura de agrupamentos extraída por um algoritmo específico não necessariamente é fiel aos dados, e depois, relações intra e inter-grupos são completamente ignoradas.

Os mesmos autores propõem ainda três abordagens baseadas na medida estatística Hubert's $\Gamma$ (Marghescu, 2006, 2007), que avalia a correspondência entre variáveis aleatórias, nesse caso, a correspondência entre duas matrizes geradas a partir dos dados de 
diferentes formas. As Equações 2.8 e 2.9 descrevem a medida estatística Hubert's $\Gamma$ e sua medida normalizada $\hat{\Gamma}$, com $\mu_{X}, \mu_{Y}, \sigma_{X}$ e $\sigma_{Y}$ representando as médias e as variâncias de duas matrizes $X$ e $Y$, respectivamente.

$$
\begin{gathered}
\Gamma=\frac{1}{H} \sum_{i=1}^{N-1} \sum_{j=i+1}^{N} X(i, j) * Y(i, j) \\
\hat{\Gamma}=\frac{\frac{1}{H} \sum_{i=1}^{N-1} \sum_{j=i+1}^{N}\left(X(i, j)-\mu_{X}\right) *\left(Y(i, j)-\mu_{Y}\right)}{\sigma_{X} \sigma_{Y}}
\end{gathered}
$$

Altos valores de $\Gamma$ (ou altos valores absolutos de $\hat{\Gamma}$ ) indicam alta correspondência entre as matrizes. Os autores propõem então, três abordagens baseadas nessa medida, considerando diferentes formações para as matrizes $X$ e $Y$.

A primeira abordagem (Marghescu, 2006) visa uma avaliação externa, verificando se instâncias de diferentes agrupamentos estão realmente distantes. Para isso, a matriz $X$ é uma matriz de proximidade, obtida dos dados originais, na qual cada posição armazena a distância entre duas instâncias. A matriz $Y$ é uma matriz binária, baseada em agrupamentos obtidos por alguma técnica de extração de agrupamentos (no trabalho é usado o $K$-médias), na qual cada posição contém o valor 1 caso os dois pontos estejam em agrupamentos distintos na projeção, e 0 caso contrário.

A segunda abordagem (Marghescu, 2007) busca avaliar não somente as distâncias entre instâncias em diferentes agrupamentos, mas também no mesmo agrupamento. Para isso, mantém a matriz de proximidade $X$, mas a matriz $Y$ é uma matriz de proximidade dos dados projetados. Na terceira abordagem (Marghescu, 2007) os autores aprimoram a primeira, também realizando uma validação externa. A matriz de proximidades $X$ é mantida, e a matriz $Y$ agora indica a distância entre os agrupamentos, dada pela distância entre seus centróides. Portanto, a matriz $Y$ armazena em cada posição a distância entre os agrupamentos a que cada ponto pertence.

Ao comparar as matrizes aplicando a estatística Hubert's $\Gamma$, verifica-se a correspondência entre as distâncias no espaço original e no espaço projetado. Os autores demonstram a qualidade das técnicas propostas, com as duas primeiras avaliando se uma projeção manteve as relações inerentes aos dados, ou seja, se manteve as relações de proximidade entre as instâncias vizinhas no espaço original. A terceira abordagem avalia a estrutura dos dados, verificando a proximidade entre os agrupamentos.

Este processo de comparação matricial, além de depender de um algoritmo de identificação de agrupamentos e partir da premissa de que tal estrutura existe nos dados, também é altamente sensível aos agrupamentos identificados em ambos os espaços. Se um agrupamento identificado na projeção contém exatamente dois agrupamentos identificados no espaço original, a medida será fortemente prejudicada. O mesmo pode ocorrer nos casos em que as distâncias são comparadas diretamente, como na terceira abordagem, já que 
dados de alta dimensionalidade têm uma distribuição de distâncias bastante distinta da distribuição da projeção, principalmente em decorrência da "maldição de dimensionalidade" (Bellman, 1961), impossibilitando uma comparação consistente.

\subsection{Medidas de avaliação de projeção e a percepção dos usuários}

As medidas de avaliação de projeção discutidas expressam aspectos relevantes dos mapeamentos, permitindo comparar técnicas e projeções em termos de propriedades relevantes para a interpretação da projeção, como vizinhanças e agrupamentos. No entanto, sua efetividade não está necessariamente relacionada com a forma como os usuários percebem as projeções.

Buscando entender se as medidas condizem com as observações dos usuários, Sedlmair et al. (2012) elaboraram uma taxonomia de fatores de separação de agrupamentos visuais nas projeções e conduziram um estudo qualitativo sistemático comparando observações humanas com medidas numéricas de qualidade. Os fatores de separação de agrupamentos foram categorizados em quatro grupos, chamados de escala, distância, forma e posição. Com projeções representando estas diferentes categorias os autores realizaram um estudo qualitativo com os usuários, e descobriram que as medidas propostas em Sips et al. (2009) e Tatu et al. (2009) não levaram a julgamentos confiáveis em cerca de 50\% dos casos. Eles avaliaram estas medidas, que são baseadas em centróides e em pixels, e mostraram que elas não são efetivas para capturar agrupamentos com diferentes propriedades visuais, como grupos de diferentes tamanhos, formas ou densidades.

Uma alternativa é não apenas fornecer um resultado quantitativo aos usuários, mas também mapear as medidas de qualidade na própria projeção de maneira a auxiliá-los a entender características de algumas regiões com base nestas medidas quantitativas. Lespinats e Aupetit (2011) propuseram uma estratégia para colorir uma projeção destacando as duas principais distorções observadas, os pontos ausentes e os falsos positivos. Para isso os autores associam a cada ponto a área da respectiva célula Voronoi, subdividindo a área bidimensional em regiões, e utilizam um mapeamento de cores para indicar a ausência de distorção, ou a presença de uma ou ambas as distorções. A Figura 2.10 ilustra este mapeamento de cores em duas projeções do conjunto de dados Optical Recognition of Handwritten Digits (Optdigits) do repositório $\mathrm{UCI}^{2}$, geradas pelas técnicas $P C A$ e $I S O$ $M A P$. Neste mapeamento a cor verde indica pontos ausentes, a cor roxa indica falsos positivos, cores próximas de preto indicam a ausência de pontos ausentes e falsos positivos e cores próximas do branco indicam que não há distorções. Com base nestas imagens, os usuários podem avaliar melhor o comportamento de diferentes regiões da projeção em relação à preservação destas propriedades.

Analogamente, Martins et al. (2014) propuseram visualizações iterativas para apoiar a

\footnotetext{
${ }^{2}$ UCI KDD Archive, http://archive.ics.uci.edu/ml/datasets/Optical+Recognition+of+Handwritten+Digits
} 


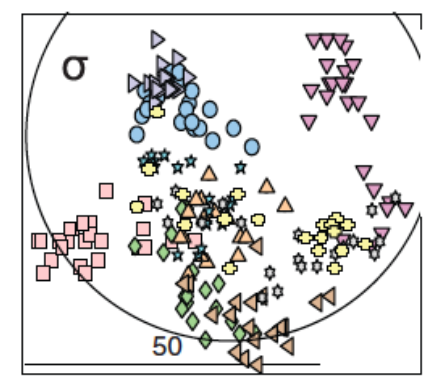

(a) $P C A$

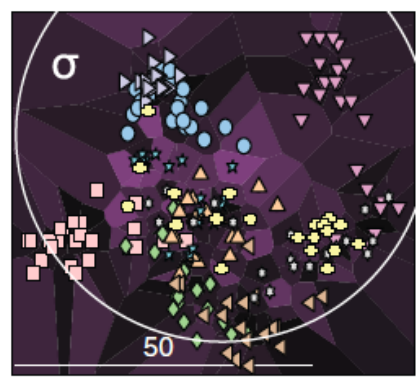

(b) $P C A$

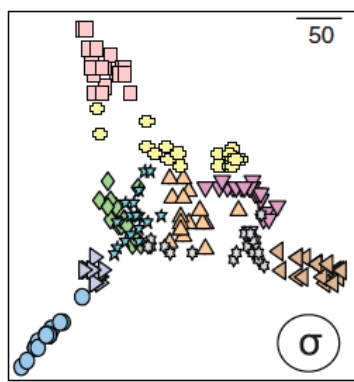

(c) ISOMAP

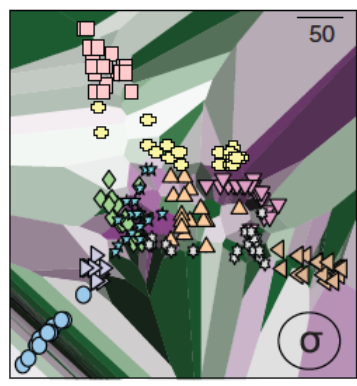

(d) ISOMAP

Figura 2.10: Projeções (a) PCA e (c) ISOMAP do Optdigits, e seus respectivos mapeamentos de cores proposto por Lespinats e Aupetit (2011) em (b) e (d). As cores indicam a presença de pontos ausentes (cor verde) e falsos positivos (cor roxa). O parâmetro $\sigma$ define o raio de vizinhança considerado (Figura extraída de Lespinats e Aupetit (2011)).

identificação de pontos ausentes e falsos vizinhos. Os autores criam uma visualização com os pontos coloridos de acordo com seu erro, incluindo uma configuração que considera o erro na vizinhança do ponto sugerindo uma função de densidade contínua, como mostrado na Figura 2.11, facilitando a análise em áreas ao invés de pontos específicos.

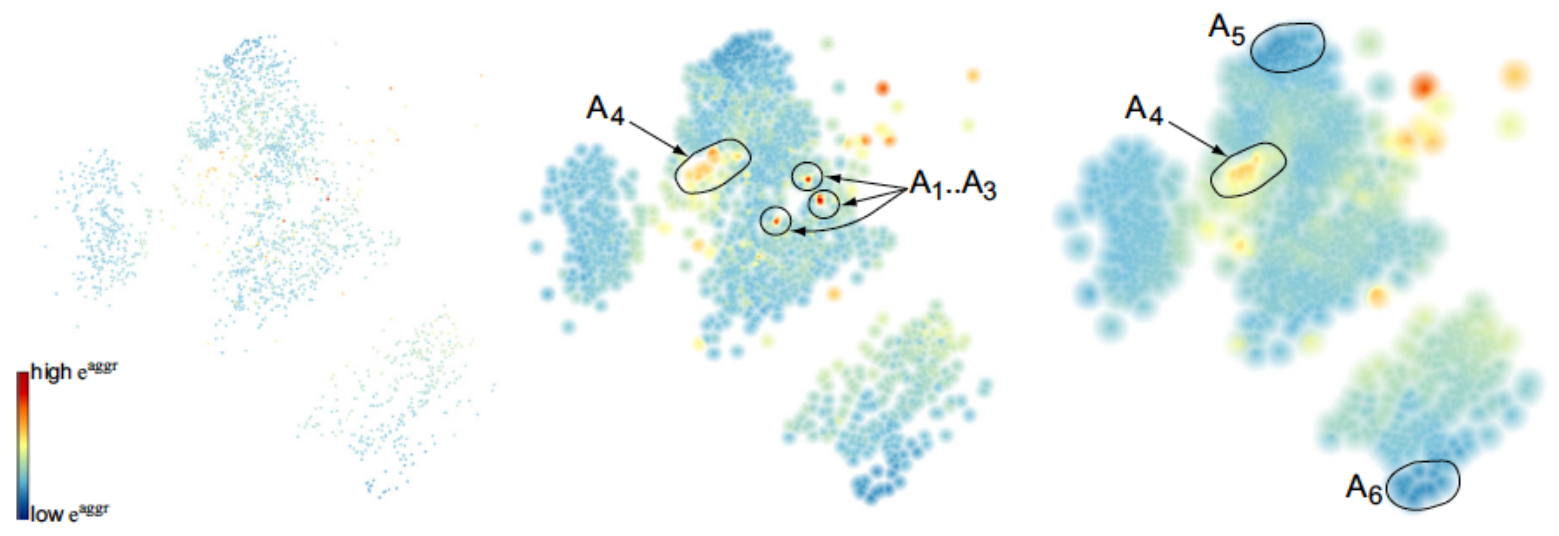

Figura 2.11: Exemplo de mapeamento visual proposto por Martins et al. (2014), no qual os pontos são coloridos segundo o respectivo erro (chamado de $e^{a g g r}$ ) e o mapeamento é configurado para exibir o erro em uma vizinhança usando uma função de densidade, permitindo a visualização por área e não por ponto específico. Em destaque são mostradas algumas regiões com alto erro $\left(A_{1}\right.$ a $\left.A_{4}\right)$ e com baixo erro $\left(A_{5}\right)$ (Figura extraída de Martins et al. (2014)).

Outra visualização iterativa proposta por Martins et al. (2014) considera os pontos conectados por uma triangulação Delaunay. Os autores consideram medidas de erro com base nas conexões, separadas em erro de falsa vizinhança e erro de pontos ausentes, também mapeados em cores. Na Figura 2.12 é exemplificado este mapeamento em (a), para o erro de falsa vizinhança, e em (b) é mostrada uma estratégia de identificação da vizinhança ausente de um ponto selecionado, o qual é conectado aos seus vizinhos mais próximos no espaço original utilizando a técnica de edge bundling (Hurter et al., 2012). 


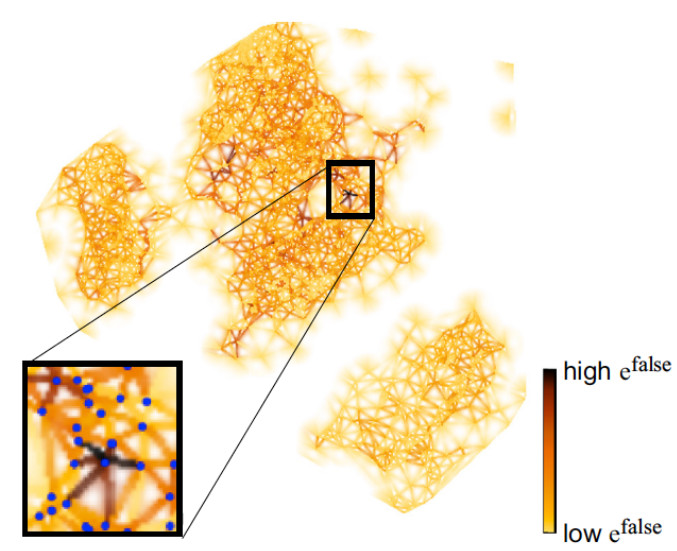

(a)

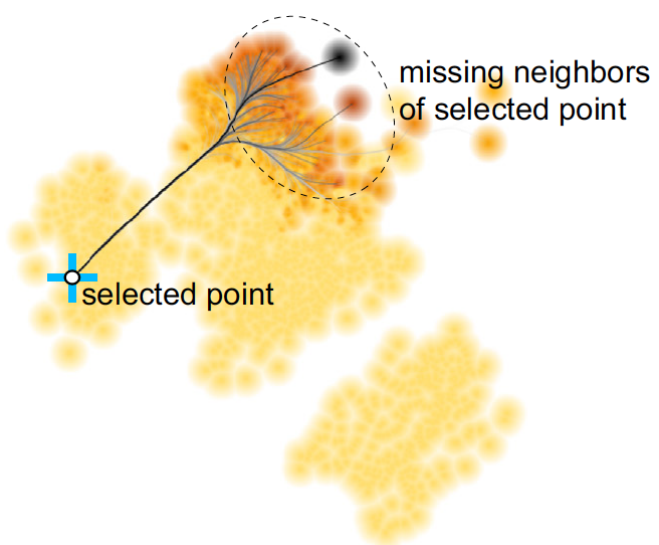

(b)

Figura 2.12: Visualização iterativa proposta por Martins et al. (2014), que utiliza uma triangulação Delaunay para cálculo e exibição do erro. Em (a) as cores indicam as falsas vizinhanças de cada ponto e em (b) os pontos ausentes, com a vizinhança real destacada pela técnica de edge bundling (Figura extraída de Martins et al. (2014)).

Tais estratégias de visualização, quando combinadas com boas medidas de avaliação, são úteis para identificar a qualidade de uma projeção multidimensional. Porém, como citado por Sedlmair et al. (2012), variações nas propriedades visuais dos grupos, como densidade, escala e formatos, prejudicam fortemente a efetividade de muitas medidas. Além disso, a dependência de parâmetros dificilmente mensuráveis é também uma forte limitação. Cientes destas lacunas, nos capítulos seguintes buscamos entender melhor algumas características da percepção dos usuários e propomos novas medidas para avaliar projeções. 



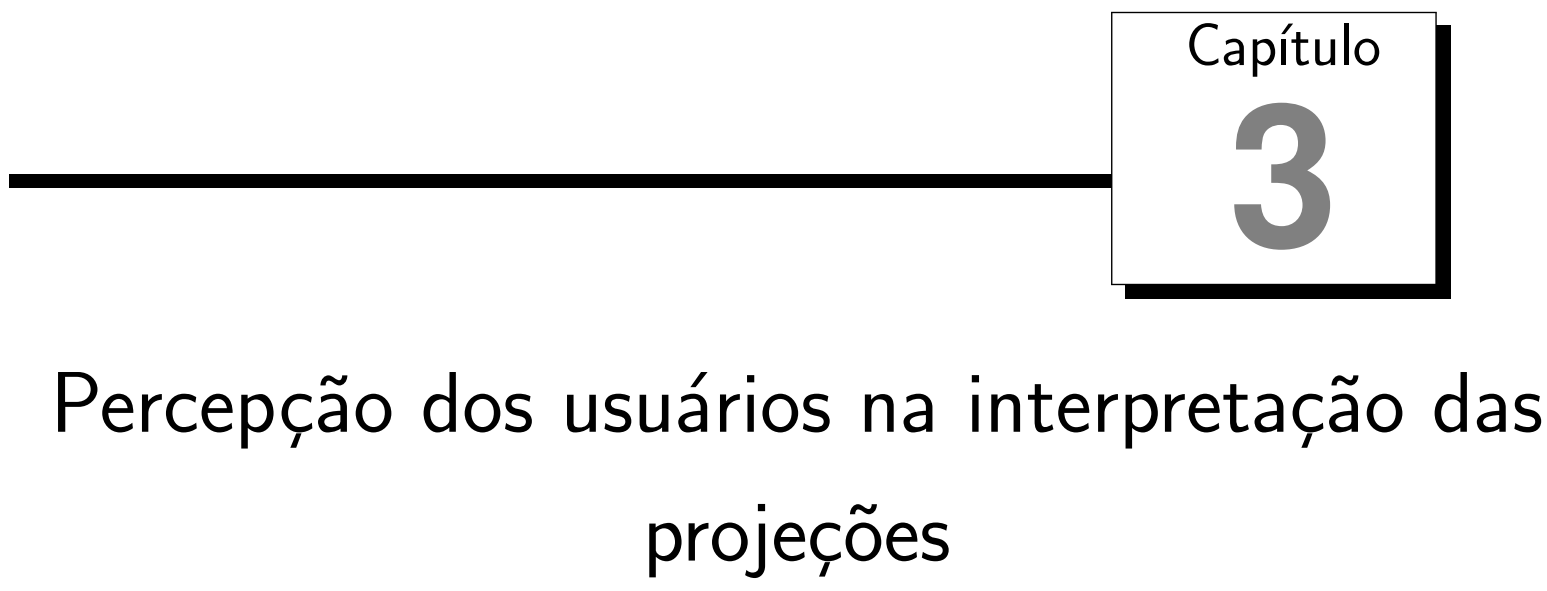

Várias medidas qualitatitivas e quantitativas foram propostas para avaliar projeções multidimensionais, porém, poucos trabalhos reportam estudos com usuários para entender características importantes a serem identificadas na projeção e como os usuários observam estes mapeamentos. Dentre os trabalhos que propuseram as medidas de avaliação de projeção citadas no Capítulo 2, apenas dois compararam as medidas propostas com resultados de estudos com usuários. Sips et al. (2009) e Tatu et al. (2009) conduziram estudos para verificar se medidas propostas de separação visual de classes produzem resultados condizentes com a percepção dos usuários. Ainda com base nesses dois trabalhos, Sedlmair et al. (2012) realizaram um estudo para verificar se estas medidas são eficazes na presença de diferentes propriedades visuais, como grupos de diferentes tamanhos, formas ou densidades, identificando que em metade dos casos não produziram resultados condizentes com a percepção dos usuários.

Porém, não conhecemos nenhum estudo amplo que busque identificar a capacidade dos usuários perceberem diversas propriedades, como vizinhança de pontos e agrupamentos. Como parte deste trabalho conduzimos um estudo visando identificar como os participantes observam e percebem as projeções geradas por diferentes técnicas e inferem informações sobre os dados a partir delas. Este estudo foi realizado em colaboração com o grupo de pesquisa do Prof. Dr. Lars Linsen, da Jacobs University, em Bremen (Alemanha), local onde foi realizado um estágio sanduíche durante o primeiro semestre de 2012.

Na Seção 3.1 é apresentada a configuração do estudo, na qual definimos as projeções utilizadas, as tarefas apresentadas e a forma de aplicação. Nas Seções 3.2 e 3.3 analisamos 
detalhadamente as tarefas referentes a vizinhanças e agrupamentos, respectivamente.

\subsection{Configuração do estudo com usuários}

O estudo foi conduzido com o objetivo de entender melhor como os usuários observam as projeções. Portanto, foram escolhidas cuidadosamente as técnicas utilizadas e as tarefas apresentadas aos participantes. As técnicas de projeção selecionadas devem ser representativas de diferentes estratégias de mapeamento. As tarefas devem abordar aspectos relevantes para a proposta de medidas de avaliação de projeções. Participaram do estudo estudantes de graduação e pós-graduação em Matemática Aplicada e Ciência da Computação com diferentes níveis de conhecimento sobre projeções. Todos participaram de uma introdução de 20 minutos sobre o tema.

Para este estudo, selecionamos quatro técnicas de projeção multidimensional, representativas de técnicas clássicas e mais recentes que capturam diferentes comportamentos dos dados: PCA (Jolliffe, 2002), ISOMAP (Tenembaum et al., 2000), LSP (Paulovich et al., 2008) e Glimmer (Ingram et al., 2009). Também foi utilizada uma estratégia de mapeamento de pontos baseada em árvores, chamada árvore NJ (Paiva et al., 2011), porém os resultados relativos às árvores não são considerados nesta análise.

Utilizamos quatro conjuntos de dados, dois textuais e dois de imagens (Tabela 3.1). Os textuais são referidos como $C B R$ e KDViz. O $C B R$ foi introduzido no Capítulo 2, e contém 680 artigos científicos em quatro diferentes tópicos, Case-Based Reasoning, Inductive Logic Programming, Information Retrieval e Sonification, com o número de documentos desbalanceado entre as classes ${ }^{1}$. Para descrever cada documento do corpus $C B R$ foram selecionados 1.423 termos para compor o modelo vetorial. De forma similar, o KDViz é um conjunto textual coletado de um repositório na internet ${ }^{1}$ contendo artigos científicos em quatro áreas, com 1.624 instâncias, 520 dimensões e quatro classes altamente desbalanceadas.

Os conjuntos de imagens são chamados Corel e Medical. O Corel ${ }^{2}$ contém 1.000 fotografias em 10 diferentes temas, cada uma representada por um vetor de 150 descritores SIFT (Li e Wang, 2003). O Medical foi fornecido por um colaborador e possui 540 imagens médicas obtidas por ressonância magnética, cada imagem representada por 28 descritores.

Para os conjuntos textuais a dissimilaridade foi computada pela distância de Cosseno, e para os conjuntos de imagens pela distância Euclidiana e distância de Cosseno, dependendo da qualidade visual da projeção obtida em relação a sobreposição de pontos. Os parâmetros utilizados para gerar as projeções foram os valores padrões das implementações utilizadas e são detalhados na Tabela 3.2, sendo que os mapeamentos resultantes são mostrados na Tabela 3.3. Pelo fato das projeções serem apresentadas aos participantes

\footnotetext{
${ }^{1}$ http://vicg.icmc.usp.br/infovis2/DataSets

${ }^{2}$ UCI KDD Archive, http://kdd.ics.uci.edu
} 
Tabela 3.1: Conjuntos de dados utilizados no estudo com usuários.

\begin{tabular}{rrrrr}
\hline Nome & Conteúdo & Classes & \#Instâncias & \#Atributos \\
\cline { 1 - 1 } CBR & artigos científicos & 4 & 680 & 1.423 \\
KDViz & artigos científicos & 4 & 1.624 & 520 \\
Corel & fotografias & 10 & 1.000 & 150 \\
Medical & imagens médicas & 12 & 540 & 28 \\
\cline { 1 - 1 } Distribuição das classes: & & \\
CBR: $40 \% ; 27 \% ; 18 \% ; 15 \%$ & & \\
KDViz: $76 \%, 12 \%, 9 \%, 3 \%$ & & \\
Corel: 10 classes distribuídas igualmente & \\
Medical: 12 classes distribuídas igualmente & & \\
\hline
\end{tabular}

com as cores modificadas de acordo com a tarefa, as diferentes representações visuais serão referidas como estímulos daqui em diante.

Para definir as tarefas a serem apresentadas aos participantes foram identificadas tarefas típicas do uso de projeções. Quatro grupos principais foram definidos: o primeiro é relativo a capacidade de identificar padrões globais, como agrupamentos e outliers; o segundo é relativo à identificação de padrões com base em um conjunto referência, como vizinhos mais próximos; o terceiro envolve a comparação de diferentes agrupamentos; e o quarto grupo aborda a capacidade de identificar propriedades em agrupamentos. A seguir, cada tarefa é detalhada:

- Grupo 1:

Tarefa 1: Estimar o número de agrupamentos.

Tarefa 2: Estimar o número de subgrupos de um dado agrupamento.

Tarefa 3: Estimar o número de outliers.

- Grupo 2:

Tarefa 4: Identificar o agrupamento mais próximo a um dado agrupamento.

Tarefa 5: Identificar o agrupamento mais próximo a um dado ponto.

Tarefa 6: Identificar e ordenar os $k$ pontos mais próximos a um dado ponto.

- Grupo 3:

Tarefa 7: Ordenar os agrupamentos por densidade.

- Grupo 4:

Tarefa 8: Estimar o número de pontos em uma seleção.

Para cada tarefa os estímulos foram preparados eliminando cores nas tarefas referentes ao número de agrupamentos e mantendo apenas as cores necessárias nas demais. Os 
Tabela 3.2: Parametrização utilizada na geração das projeções para o estudo experimental.

\begin{tabular}{|c|c|c|}
\hline \multirow{4}{*}{$C B R$} & Glimmer & distância: Cosseno \\
\hline & ISOMAP & $\begin{array}{l}\text { número de vizinhos: } 10 \\
\text { distância: Cosseno }\end{array}$ \\
\hline & $L S P$ & $\begin{array}{l}\text { número de iterações: } 50 \\
\text { fração do delta: } 8 \\
\text { número de pontos de controle: } 67 \\
\text { número de vizinhos: } 10 \\
\text { distância: Cosseno }\end{array}$ \\
\hline & $P C A$ & distância: Cosseno \\
\hline \multirow{4}{*}{ KDViz } & Glimmer & distância: Cosseno \\
\hline & ISOMAP & $\begin{array}{l}\text { número de vizinhos: } 10 \\
\text { distância: Cosseno }\end{array}$ \\
\hline & $L S P$ & $\begin{array}{l}\text { número de iterações: } 50 \\
\text { fração do delta: } 8 \\
\text { número de pontos de controle: } 162 \\
\text { número de vizinhos: } 10 \\
\text { distância: Cosseno }\end{array}$ \\
\hline & $P C A$ & distância: Cosseno \\
\hline \multirow{4}{*}{ Corel } & Glimmer & distância: Euclidiana \\
\hline & ISOMAP & $\begin{array}{l}\text { número de vizinhos: } 10 \\
\text { distância: Cosseno }\end{array}$ \\
\hline & $L S P$ & $\begin{array}{l}\text { número de iterações: } 50 \\
\text { fração do delta: } 8 \\
\text { número de pontos de controle: } 100 \\
\text { número de vizinhos: } 10 \\
\text { distância: Cosseno }\end{array}$ \\
\hline & $P C A$ & distância: Euclidiana \\
\hline \multirow{4}{*}{ Medical } & Glimmer & distância: Euclidiana \\
\hline & ISOMAP & $\begin{array}{l}\text { número de vizinhos: } 10 \\
\text { distância: Euclidiana }\end{array}$ \\
\hline & $L S P$ & $\begin{array}{l}\text { número de iterações: } 50 \\
\text { fração do delta: } 8 \\
\text { número de pontos de controle: } 100 \\
\text { número de vizinhos: } 10 \\
\text { distância: Euclidiana }\end{array}$ \\
\hline & $P C A$ & distância: Euclidiana \\
\hline
\end{tabular}




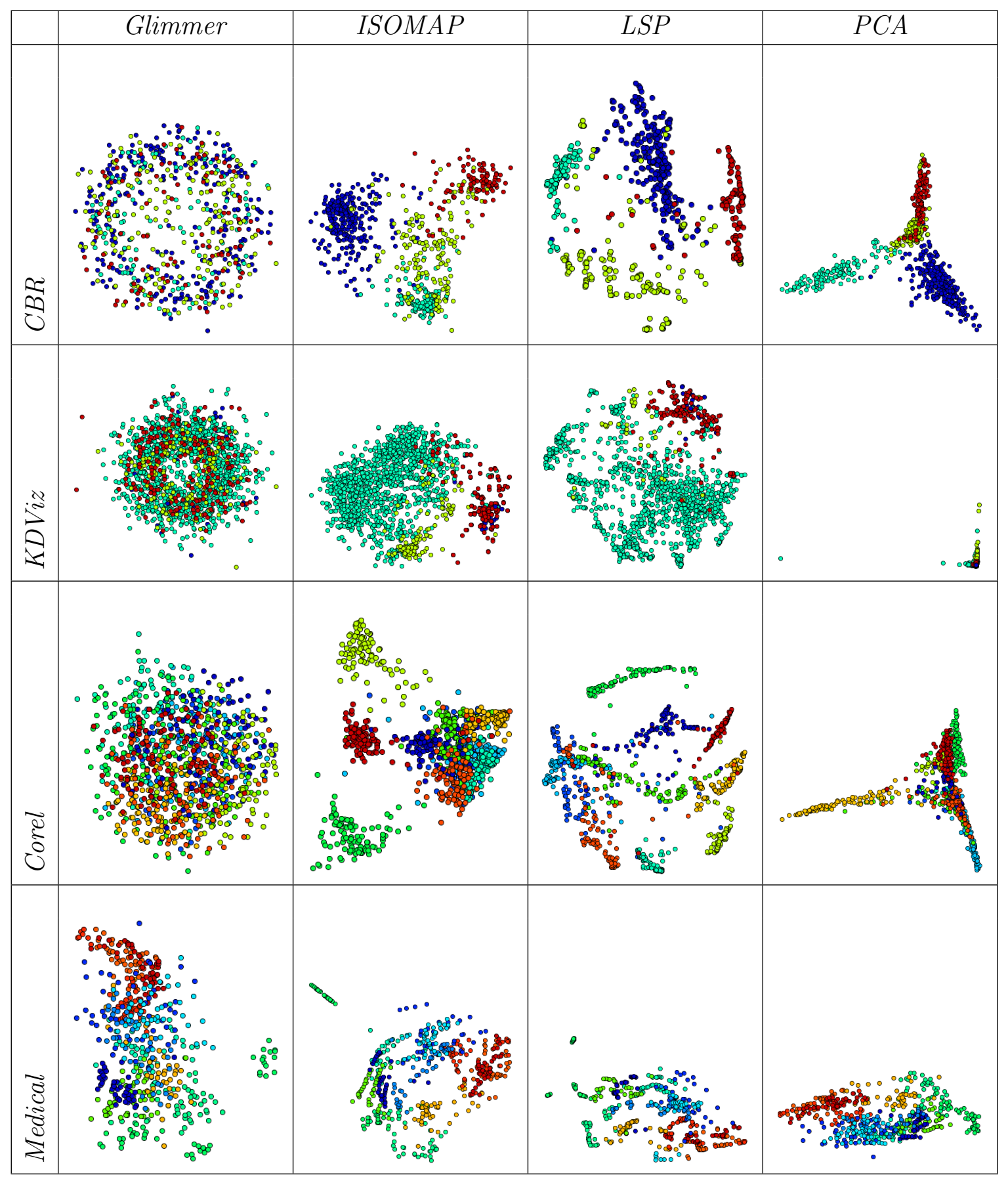

Tabela 3.3: Mapeamentos dos quatro conjuntos de dados obtidos com as quatro técnicas de projeção multidimensional consideradas. As cores nos mapas indicam as classes dos pontos. 
estímulos são apresentados por até 30 segundos, tempo definido após um estudo piloto com 8 estudantes, os quais demoraram em média 7,7 segundos por resposta, com o maior tempo de resposta igual a 24,75 segundos. Depois de responder o participante define sua confiança na resposta dada (muito baixa, baixa, média, alta, muito alta).

O estudo foi conduzido no Brasil e a análise dos resultados realizada parte no Brasil e parte na Alemanha, em parceria com o Prof. Dr. Lars Linsen e sua então aluna de doutorado Ronak Etemadpour. Os resultados estão sendo publicados no IEEE Transactions on Visualization and Computer Graphics (TVCG) (Etemadpour et al., 2014).

A maioria das medidas de avaliação descritas no Capítulo 5 avalia a qualidade de uma projeção com base nas vizinhanças ou nos agrupamentos. Estas são tarefas comuns na exploração visual de projeções e as mantivemos como foco neste estudo. Portanto, dentre as tarefas aplicadas aos participantes duas são diretamente de interesse para este trabalho de doutorado, a Tarefa 6 relativa à identificação de vizinhanças e a Tarefa 1 relativa à identificação de agrupamentos. Estas duas tarefas nos permitem identificar como os usuários percebem vizinhanças e agrupamentos. A seguir descrevemos em detalhes as respostas referentes a ambas, e os padrões identificados.

\subsection{Análise da percepção de vizinhanças}

Na Tarefa 6, referente à identificação de vizinhança, o objetivo foi avaliar a capacidade dos participantes identificarem os pontos mais próximos a um dado ponto. Ao ordenar os pontos mais próximos a um ponto de referência, percebe-se o quão precisamente um observador conseguiu distinguir relações de proximidade em uma vizinhança.

Os estímulos apresentados aos participantes mostram apenas o ponto de referência e mais 9 pontos coloridos de maneira diferenciada, e foi solicitado que o participante ordenasse os pontos em relação à distância ao ponto de referência destacado. A Figura 3.1 ilustra a tela apresentada.

Para esta tarefa foram gerados 30 estímulos alternando tanto as projeções como os pontos de referência e as cores dos demais pontos. Os estímulos foram apresentados a 45 participantes, cada um observando 19 estímulos desta tarefa específica, totalizando 855 respostas. Estas respostas foram analisadas sob duas perspectivas distintas, a primeira avaliando a capacidade dos participantes ranquearem os nove vizinhos mais próximos, e a segunda avaliando a capacidade dos participantes identificarem um conjunto de $k$ vizinhos mais próximos, $1 \leqslant k \leqslant 9$.

De modo a sumarizar as respostas segundo a primeira perspectiva analisada, são apresentadas na Tabela 3.4 a porcentagem dos participantes que foram capazes de ranquear corretamente os $k$ pontos mais próximos, $1 \leqslant k \leqslant 9$, em cada um dos 30 estímulos.

O erro nesta análise é acumulado e, portanto, a porcentagem de participantes que foi capaz de identificar do primeiro ao $i$-ésimo ponto é sempre maior ou igual a porcentagem 
Tabela 3.4: Porcentagem de participantes que ranquearam corretamente $k$ vizinhos em cada um dos 30 estímulos. A média e o desvio padrão são apresentados na última linha da tabela.

\begin{tabular}{|l|c|c|c|c|c|c|c|c|c|c|}
\hline & \multicolumn{10}{|c|}{ número de vizinhos ranqueados corretamente } \\
\hline estímulo & $1 \leqslant k \leqslant 1$ & $1 \leqslant k \leqslant 2$ & $1 \leqslant k \leqslant 3$ & $1 \leqslant k \leqslant 4$ & $1 \leqslant k \leqslant 5$ & $1 \leqslant k \leqslant 6$ & $1 \leqslant k \leqslant 7$ & $1 \leqslant k \leqslant 8$ & $1 \leqslant k \leqslant 9$ \\
\hline estímulo 1 & $64 \%$ & $59 \%$ & $32 \%$ & $18 \%$ & $9 \%$ & $0 \%$ & $0 \%$ & $0 \%$ & $0 \%$ \\
estímulo 2 & $52 \%$ & $48 \%$ & $30 \%$ & $13 \%$ & $9 \%$ & $4 \%$ & $0 \%$ & $0 \%$ & $0 \%$ \\
estímulo 3 & $86 \%$ & $86 \%$ & $82 \%$ & $68 \%$ & $59 \%$ & $18 \%$ & $9 \%$ & $9 \%$ & $9 \%$ \\
estímulo 4 & $96 \%$ & $91 \%$ & $87 \%$ & $65 \%$ & $39 \%$ & $13 \%$ & $9 \%$ & $9 \%$ & $9 \%$ \\
estímulo 5 & $73 \%$ & $23 \%$ & $14 \%$ & $14 \%$ & $9 \%$ & $9 \%$ & $9 \%$ & $9 \%$ & $9 \%$ \\
estímulo 6 & $0 \%$ & $0 \%$ & $0 \%$ & $0 \%$ & $0 \%$ & $0 \%$ & $0 \%$ & $0 \%$ & $0 \%$ \\
estímulo 7 & $77 \%$ & $45 \%$ & $36 \%$ & $18 \%$ & $5 \%$ & $0 \%$ & $0 \%$ & $0 \%$ & $0 \%$ \\
estímulo 8 & $87 \%$ & $83 \%$ & $57 \%$ & $30 \%$ & $26 \%$ & $4 \%$ & $0 \%$ & $0 \%$ & $0 \%$ \\
estímulo 9 & $9 \%$ & $0 \%$ & $0 \%$ & $0 \%$ & $0 \%$ & $0 \%$ & $0 \%$ & $0 \%$ & $0 \%$ \\
estímulo 10 & $4 \%$ & $0 \%$ & $0 \%$ & $0 \%$ & $0 \%$ & $0 \%$ & $0 \%$ & $0 \%$ & $0 \%$ \\
estímulo 11 & $23 \%$ & $23 \%$ & $18 \%$ & $14 \%$ & $14 \%$ & $9 \%$ & $9 \%$ & $9 \%$ & $9 \%$ \\
estímulo 12 & $52 \%$ & $48 \%$ & $48 \%$ & $48 \%$ & $26 \%$ & $22 \%$ & $17 \%$ & $17 \%$ & $17 \%$ \\
estímulo 13 & $82 \%$ & $18 \%$ & $5 \%$ & $5 \%$ & $5 \%$ & $5 \%$ & $5 \%$ & $5 \%$ & $5 \%$ \\
estímulo 14 & $91 \%$ & $26 \%$ & $26 \%$ & $13 \%$ & $13 \%$ & $13 \%$ & $9 \%$ & $9 \%$ & $9 \%$ \\
estímulo 15 & $0 \%$ & $0 \%$ & $0 \%$ & $0 \%$ & $0 \%$ & $0 \%$ & $0 \%$ & $0 \%$ & $0 \%$ \\
estímulo 16 & $26 \%$ & $13 \%$ & $4 \%$ & $4 \%$ & $4 \%$ & $4 \%$ & $4 \%$ & $4 \%$ & $4 \%$ \\
estímulo 17 & $73 \%$ & $73 \%$ & $50 \%$ & $0 \%$ & $0 \%$ & $0 \%$ & $0 \%$ & $0 \%$ & $0 \%$ \\
estímulo 18 & $96 \%$ & $91 \%$ & $48 \%$ & $0 \%$ & $0 \%$ & $0 \%$ & $0 \%$ & $0 \%$ & $0 \%$ \\
estímulo 19 & $41 \%$ & $41 \%$ & $41 \%$ & $36 \%$ & $36 \%$ & $27 \%$ & $18 \%$ & $18 \%$ & $18 \%$ \\
estímulo 20 & $35 \%$ & $35 \%$ & $35 \%$ & $26 \%$ & $26 \%$ & $17 \%$ & $13 \%$ & $13 \%$ & $13 \%$ \\
estímulo 21 & $91 \%$ & $68 \%$ & $68 \%$ & $32 \%$ & $14 \%$ & $9 \%$ & $9 \%$ & $9 \%$ & $9 \%$ \\
estímulo 22 & $91 \%$ & $87 \%$ & $83 \%$ & $65 \%$ & $22 \%$ & $17 \%$ & $13 \%$ & $9 \%$ & $9 \%$ \\
estímulo 23 & $64 \%$ & $50 \%$ & $50 \%$ & $41 \%$ & $32 \%$ & $27 \%$ & $14 \%$ & $14 \%$ & $14 \%$ \\
estímulo 24 & $70 \%$ & $65 \%$ & $65 \%$ & $22 \%$ & $13 \%$ & $9 \%$ & $4 \%$ & $0 \%$ & $0 \%$ \\
estímulo 25 & $55 \%$ & $55 \%$ & $32 \%$ & $27 \%$ & $27 \%$ & $18 \%$ & $18 \%$ & $18 \%$ & $18 \%$ \\
estímulo 26 & $22 \%$ & $17 \%$ & $17 \%$ & $9 \%$ & $4 \%$ & $4 \%$ & $4 \%$ & $4 \%$ & $4 \%$ \\
estímulo 27 & $41 \%$ & $32 \%$ & $0 \%$ & $0 \%$ & $0 \%$ & $0 \%$ & $0 \%$ & $0 \%$ & $0 \%$ \\
estímulo 28 & $30 \%$ & $22 \%$ & $9 \%$ & $4 \%$ & $0 \%$ & $0 \%$ & $0 \%$ & $0 \%$ & $0 \%$ \\
estímulo 29 & $82 \%$ & $18 \%$ & $14 \%$ & $0 \%$ & $0 \%$ & $0 \%$ & $0 \%$ & $0 \%$ & $0 \%$ \\
estímulo 30 & $91 \%$ & $43 \%$ & $4 \%$ & $4 \%$ & $0 \%$ & $0 \%$ & $0 \%$ & $0 \%$ & $0 \%$ \\
\hline média & $57 \%$ & $42 \%$ & $32 \%$ & $19 \%$ & $13 \%$ & $8 \%$ & $5 \%$ & $5 \%$ & $5 \%$ \\
desvio padrão & $(31 \%)$ & $(29 \%)$ & $(27 \%)$ & $(21 \%)$ & $(15 \%)$ & $(9 \%)$ & $(6 \%)$ & $(6 \%)$ & $6 \%)$ \\
\hline
\end{tabular}




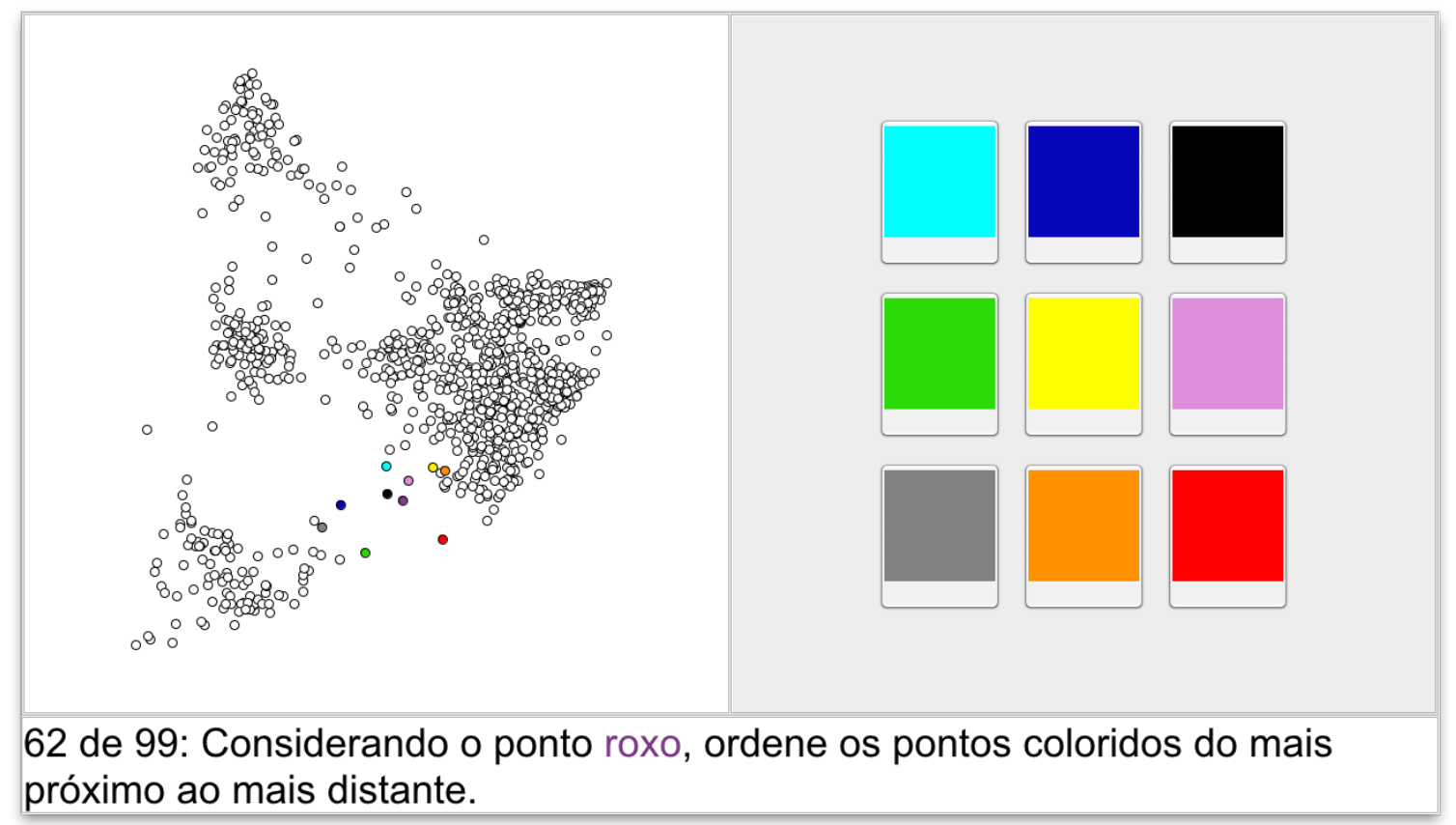

Figura 3.1: Exemplo da tarefa apresentada aos participantes, na qual é solicidado que ordene os pontos segundo a proximidade ao ponto roxo.

de participantes que foi capaz de identificar do primeiro ao $j$-ésimo ponto, com $i<j$. Este erro acumulado resulta em uma baixa porcentagem de acerto no ranqueamento a medida que o número de vizinhos aumenta. A porcentagem média de acerto é inferior a $20 \%$ a partir de $k=4$. Em metade dos estímulos nenhum participante ranqueou corretamente os 9 vizinhos mais próximos.

A segunda perspectiva analisada, com base nas mesmas 855 respostas, é referente à capacidade dos participantes identificarem um conjunto de $k$ vizinhos mais próximos, sem ranqueá-los por proximidade. Foi possível observar que os participantes tiveram grande dificuldade em ranquear os vizinhos, porém são capazes de identificar com precisão um conjunto de vizinhos mais próximos. Os resultados desta análise são apresentados na Tabela 3.5 .

Pelo fato de ter sido apresentado aos participantes um número fixo de 9 pontos é esperado que, no caso de desconsiderar a ordem, a probabilidade de acerto só aumente a partir da seleção de $k=6$ pontos, obviamente atingindo $100 \%$ de acerto na seleção dos 9 vizinhos mais próximos.

A probabilidade de selecionar aleatoriamente uma instância em 9 equivale à seleção de uma instância em um conjunto dado pela combinação matemática $C_{9,1}=\frac{9 !}{1 ! \cdot(9-1) !}=9$, ou seja, é $\frac{1}{9}=0,111$. Tal probabilidade é exatamente a mesma de selecionar 8 pontos em 9 , pois $C_{9,1}=C_{9,8}$. De forma análoga, a probabilidade de seleção de 2 pontos em 9 , igual à seleção de 7 em 9 , é $\frac{1}{C_{9,2}}=\frac{1}{C_{9,7}}=0,028$, também de 3 e de 6 , que é 0,012 , e também de 4 e de 5, ou 0,008, pois é a chance de uma seleção em 126 combinações possíveis de 4 pontos em um conjunto de 9 (Figura 3.2). Naturalmente estas probabilidades assumem 
Tabela 3.5: Porcentagem de participantes que identificaram corretamente, para cada um dos 30 estímulos, o conjunto formado por $k$ vizinhos mais próximos, $1 \leqslant k \leqslant 9$. A média e o desvio padrão são apresentados na última linha da tabela. Em destaque estão os maiores valores nas cinco primeiras escolhas.

\begin{tabular}{|c|c|c|c|c|c|c|c|c|c|}
\hline & \multicolumn{9}{|c|}{ número de vizinhos identificados corretamente } \\
\hline estímulo & $1 \leqslant k \leqslant 1$ & $1 \leqslant k \leqslant 2$ & $1 \leqslant k \leqslant 3$ & $1 \leqslant k \leqslant 4$ & $1 \leqslant k \leqslant 5$ & $1 \leqslant k \leqslant 6$ & $1 \leqslant k \leqslant 7$ & $1 \leqslant k \leqslant 8$ & $1 \leqslant k \leqslant 9$ \\
\hline estímulo 1 & $64 \%$ & $59 \%$ & $32 \%$ & $41 \%$ & $45 \%$ & $27 \%$ & $18 \%$ & $50 \%$ & $100 \%$ \\
\hline estímulo 2 & $52 \%$ & $52 \%$ & $35 \%$ & $22 \%$ & $35 \%$ & $13 \%$ & $26 \%$ & $48 \%$ & $100 \%$ \\
\hline estímulo 3 & $86 \%$ & $86 \%$ & $82 \%$ & $68 \%$ & $59 \%$ & $23 \%$ & $55 \%$ & $68 \%$ & $100 \%$ \\
\hline estímulo 4 & $96 \%$ & $91 \%$ & $87 \%$ & $65 \%$ & $39 \%$ & $22 \%$ & $52 \%$ & $61 \%$ & $100 \%$ \\
\hline estímulo 5 & $73 \%$ & $23 \%$ & $55 \%$ & $59 \%$ & $50 \%$ & $50 \%$ & $59 \%$ & $59 \%$ & $100 \%$ \\
\hline estímulo 6 & $0 \%$ & $87 \%$ & $74 \%$ & $83 \%$ & $78 \%$ & $65 \%$ & $65 \%$ & $78 \%$ & $100 \%$ \\
\hline estímulo 7 & $77 \%$ & $50 \%$ & $45 \%$ & $59 \%$ & $36 \%$ & $14 \%$ & $9 \%$ & $68 \%$ & $100 \%$ \\
\hline estímulo 8 & $87 \%$ & $87 \%$ & $57 \%$ & $52 \%$ & $61 \%$ & $17 \%$ & $35 \%$ & $65 \%$ & $100 \%$ \\
\hline estímulo 9 & $9 \%$ & $41 \%$ & $64 \%$ & $45 \%$ & $68 \%$ & $73 \%$ & $73 \%$ & $45 \%$ & $100 \%$ \\
\hline estímulo 10 & $4 \%$ & $0 \%$ & $70 \%$ & $35 \%$ & $87 \%$ & $83 \%$ & $61 \%$ & $17 \%$ & $100 \%$ \\
\hline estímulo 11 & $23 \%$ & $91 \%$ & $86 \%$ & $86 \%$ & $36 \%$ & $23 \%$ & $36 \%$ & $95 \%$ & $100 \%$ \\
\hline estímulo 12 & $52 \%$ & $91 \%$ & $87 \%$ & $91 \%$ & $39 \%$ & $22 \%$ & $35 \%$ & $87 \%$ & $100 \%$ \\
\hline estímulo 13 & $82 \%$ & $18 \%$ & $64 \%$ & $36 \%$ & $45 \%$ & $45 \%$ & $36 \%$ & $50 \%$ & $100 \%$ \\
\hline estímulo 14 & $91 \%$ & $26 \%$ & $87 \%$ & $48 \%$ & $65 \%$ & $61 \%$ & $52 \%$ & $65 \%$ & $100 \%$ \\
\hline estímulo 15 & $0 \%$ & $9 \%$ & $9 \%$ & $64 \%$ & $27 \%$ & $59 \%$ & $59 \%$ & $77 \%$ & $100 \%$ \\
\hline estímulo 16 & $26 \%$ & $43 \%$ & $43 \%$ & $70 \%$ & $65 \%$ & $57 \%$ & $61 \%$ & $87 \%$ & $100 \%$ \\
\hline estímulo 17 & $73 \%$ & $86 \%$ & $55 \%$ & $9 \%$ & $0 \%$ & $14 \%$ & $18 \%$ & $27 \%$ & $100 \%$ \\
\hline estímulo 18 & $96 \%$ & $91 \%$ & $48 \%$ & $22 \%$ & $4 \%$ & $35 \%$ & $35 \%$ & $57 \%$ & $100 \%$ \\
\hline estímulo 19 & $41 \%$ & $82 \%$ & $82 \%$ & $77 \%$ & $73 \%$ & $59 \%$ & $45 \%$ & $68 \%$ & $100 \%$ \\
\hline estímulo 20 & $35 \%$ & $87 \%$ & $87 \%$ & $78 \%$ & $78 \%$ & $48 \%$ & $43 \%$ & $65 \%$ & $100 \%$ \\
\hline estímulo 21 & $91 \%$ & $68 \%$ & $82 \%$ & $50 \%$ & $27 \%$ & $73 \%$ & $55 \%$ & $64 \%$ & $100 \%$ \\
\hline estímulo 22 & $91 \%$ & $87 \%$ & $87 \%$ & $70 \%$ & $26 \%$ & $74 \%$ & $61 \%$ & $43 \%$ & $100 \%$ \\
\hline estímulo 23 & $64 \%$ & $68 \%$ & $82 \%$ & $50 \%$ & $59 \%$ & $50 \%$ & $36 \%$ & $50 \%$ & $100 \%$ \\
\hline estímulo 24 & $70 \%$ & $91 \%$ & $91 \%$ & $43 \%$ & $52 \%$ & $48 \%$ & $43 \%$ & $57 \%$ & $100 \%$ \\
\hline estímulo 25 & $55 \%$ & $59 \%$ & $45 \%$ & $73 \%$ & $82 \%$ & $55 \%$ & $59 \%$ & $55 \%$ & $100 \%$ \\
\hline estímulo 26 & $22 \%$ & $52 \%$ & $39 \%$ & $74 \%$ & $70 \%$ & $48 \%$ & $57 \%$ & $52 \%$ & $100 \%$ \\
\hline estímulo 27 & $41 \%$ & $59 \%$ & $0 \%$ & $50 \%$ & $32 \%$ & $41 \%$ & $41 \%$ & $73 \%$ & $100 \%$ \\
\hline estímulo 28 & $30 \%$ & $52 \%$ & $13 \%$ & $48 \%$ & $22 \%$ & $13 \%$ & $4 \%$ & $74 \%$ & $100 \%$ \\
\hline estímulo 29 & $82 \%$ & $18 \%$ & $14 \%$ & $5 \%$ & $36 \%$ & $36 \%$ & $45 \%$ & $55 \%$ & $100 \%$ \\
\hline estímulo 30 & $91 \%$ & $43 \%$ & $4 \%$ & $4 \%$ & $22 \%$ & $30 \%$ & $61 \%$ & $74 \%$ & $100 \%$ \\
\hline média e & $57 \%$ & $60 \%$ & $57 \%$ & $53 \%$ & $47 \%$ & $43 \%$ & $45 \%$ & $61 \%$ & $100 \%$ \\
\hline desvio padrão & $31 \%$ & $28 \%$ & $29 \%$ & $24 \%$ & $23 \%$ & $21 \%$ & $17 \%$ & $17 \%$ & $0 \%$ \\
\hline
\end{tabular}


uma seleção aleatória e não devem ser normalizadores para a tarefa dada aos participantes do estudo. Mas, ainda assim, a análise deve considerar apenas os primeiros 5 vizinhos.

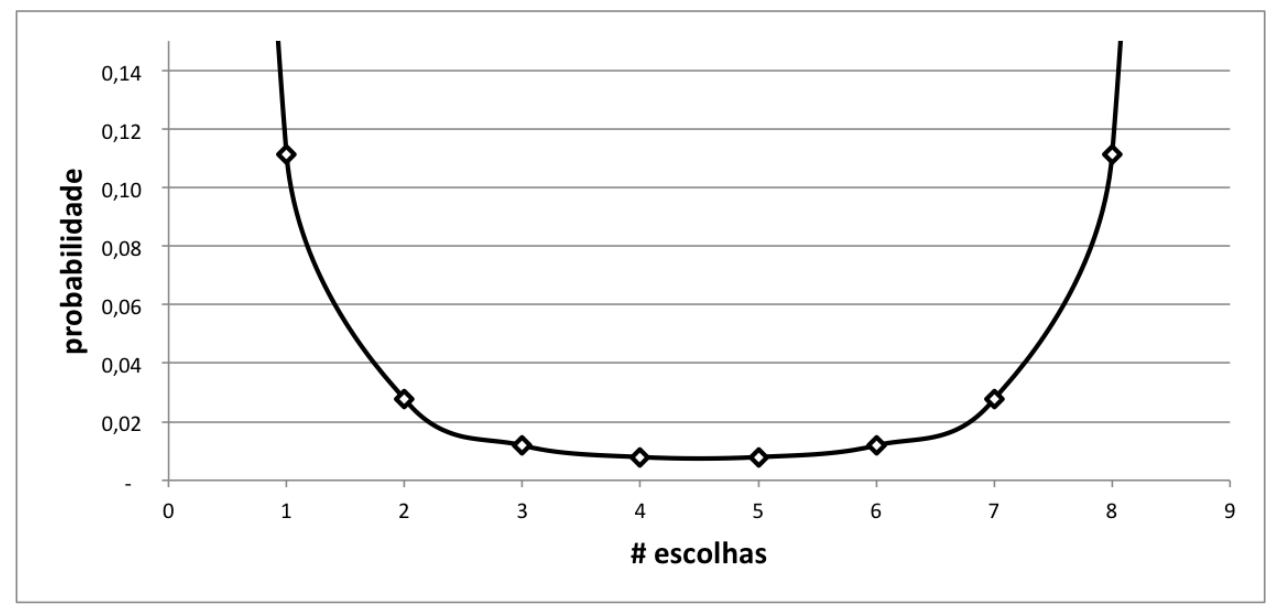

Figura 3.2: Probabilidade de seleção aleatória de um subconjunto de tamanho dado por \# escolhas, em um conjunto de 9 pontos

No gráfico na Figura 3.3 são apresentados as médias dos resultados das Tabelas 3.4 e 3.5. Observa-se que o erro acumulado da perspectiva que considera o ranqueamento reduz a porcentagem de acertos a medida que $k$ (\# escolhas) aumenta, atingindo uma porcentagem de acerto inferior a $20 \%$ a partir dos 4 vizinhos mais próximos, como já citado. Na perspectiva sem ranqueamento, a porcentagem de acerto é mais estável, entre 47 e $60 \%$ para os primeiros 5 vizinhos, e sendo quase 3 vezes maior que a obtida ranqueando os 5 vizinhos mais próximos.

Para essa perspectiva, na Tabela 3.5 está destacado o valor de $k$ que resultou na maior porcentagem de acerto dos participantes, para cada estímulo. Chamaremos este tamanho da vizinhança com maior acerto dos participantes de vizinhança "ideal", para o respectivo estímulo. Como referência, na Figura 3.3 é mostrada uma linha tracejada indicando a porcentagem média de participantes que identificou corretamente a vizinhança "ideal" em cada estímulo (limitado a 5 escolhas, devido à probabilidade de acerto). A média de acertos é de $80 \%$, com um desvio padrão de $12 \%$, o que indica que em média 4 a cada 5 participantes foram capazes de identificar a vizinhança "ideal" de cada ponto.

Dentre os 30 estímulos utilizados foram selecionados dois com características específicas para observarmos em detalhes, apresentados na Figura 3.4. O estímulo 12 foi selecionado porque grande parte dos participantes acertaram os 2 e os 4 primeiros vizinhos $(91 \%$ dos participantes), e o estímulo 23 que apresentou o menor desvio padrão na porcentagem de participantes que acertou de 1 a 5 vizinhos, ou seja, o desempenho dos participantes ao identificar todos os 5 vizinhos foi parecido, com apenas um caso com melhor desempenho, a resposta para 3 vizinhos.

As circunferências nos estímulos indicam os raios de distância do ponto referência aos cinco vizinhos mais próximos, evidenciando a real dificuldade de ranquear os pontos 


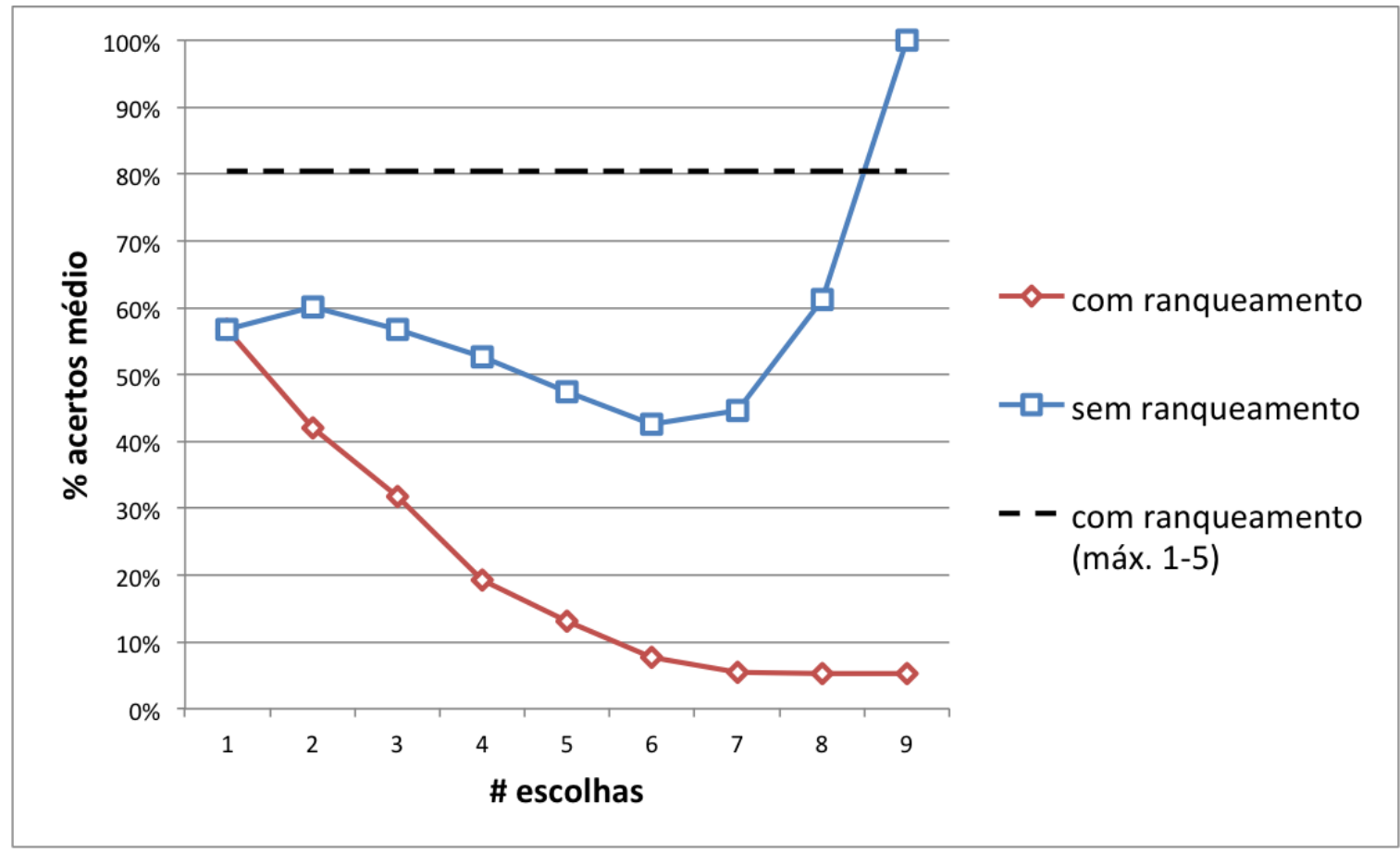

Figura 3.3: Média de acerto dos participantes nas perspectivas com e sem ranqueamento do conjunto de vizinhos. Em tracejado é apresentado o valor médio da maior porcentagem de acerto na perspectiva sem ranqueamento para cada estímulo, considerando apenas as primeiras 5 escolhas.

segundo a proximidade, problema visível quando as circunferências estão quase sobrepostas. Em vermelho destacamos a circunferência relativa às respostas dos participantes com maior porcentagem de acerto, que dá o tamanho de vizinhança "ideal", e vemos que há uma diferença significativa para a circunferência seguinte. Na Figura 3.4 (a) é mostrado inclusive a diferença significativa da quarta para a quinta vizinhança, que também é uma vizinhança "ideal", com mesma porcentagem de acerto dos participantes.

Muitas vezes os pontos próximos estão a distâncias tão parecidas do ponto referência que efetuar um ranqueamento é forçar uma informação que não é perceptível na prática, ou seja, é difícil distinguir vizinhanças com precisão nessa situação. Idealmente, poderíamos considerar a distribuição de distâncias como uma distribuição de probabilidades, como feito por Venna et al. (2010), porém, considerar a distribuição para todos os vizinhos, $1 \leqslant k \leqslant N-1$, também implicaria em avaliar a qualidade da projeção globalmente, ignorando propriedades locais de cada ponto. Neste cenário, vemos como a situação ideal que cada ponto seja associado localmente a um conjunto de pontos próximos, sem ranqueamento.

Outra observação importante é a variação do tamanho da vizinhança "ideal". Na maioria dos estímulos o tamanho da vizinhança "ideal" foi 1 ou 2 vizinhos, porém, em $30 \%$ dos casos foi igual a 3 ou mais vizinhos. Essa característica indica que não é apropriado definir uma quantidade fixa de vizinhos para todos os pontos, mas sim identificar o número 


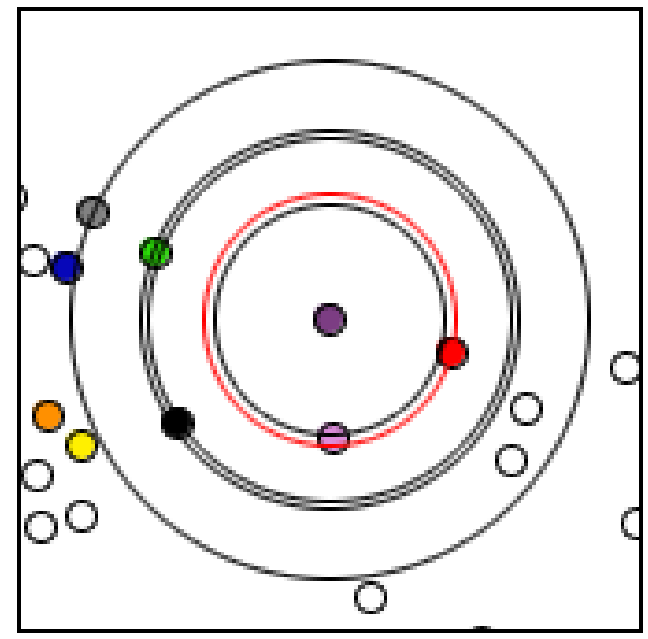

(a) estímulo 12

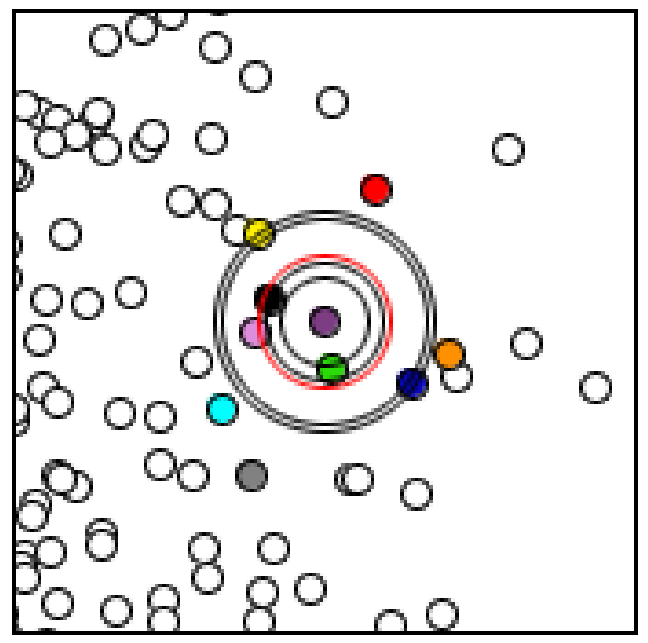

(b) estímulo 23

Figura 3.4: Ilustração dos raios de distâncias do ponto de referência aos cinco primeiros vizinhos mais próximos em dois estímulos específicos. A circunferência em vermelho indica a resposta dos participantes com maior precisão na perspectiva sem ranqueamento.

de vizinhos apropriado para cada ponto, conforme as características da região em que se encontra.

\subsection{Análise da percepção de agrupamentos}

A Tarefa 1, referente à identificação de agrupamentos, teve como objetivo analisar como os participantes do estudo percebem grupos na projeção. A tarefa apresentada aos participantes foi identificar a quantidade de agrupamentos observados em uma projeção.

Poucos trabalhos avaliam a qualidade de uma projeção com base em agrupamentos, a maioria considera vizinhanças, avaliando a separação das classes ou a preservação dos vizinhos mais próximos. Porém, a análise de agrupamentos, assim como a análise de vizinhanças, é uma tarefa comum na exploração visual dos dados.

O principal objetivo desta análise foi verificar se houve um padrão na quantidade de agrupamentos identificada nas projeções. Para isso, fazemos uma breve análise global da quantidade de agrupamentos percebida pelos participantes e, em seguida, uma análise específica por estímulo.

Um único estímulo foi gerado para cada projeção obtida por cada técnica, com todos os pontos exibidos em uma única cor. Estes estímulos foram apresentadas a dois grupos, com 22 e com 24 participantes, respectivamente. O primeiro grupo avaliou 13 estímulos e o segundo 11, totalizando 550 estímulos avaliados. A Figura 3.5 exemplifica a tarefa apresentada aos participantes.

Para esta tarefa a resposta foi o número de agrupamentos percebidos. Portanto, analisamos o resultado observando a frequência de cada quantidade de agrupamentos iden- 


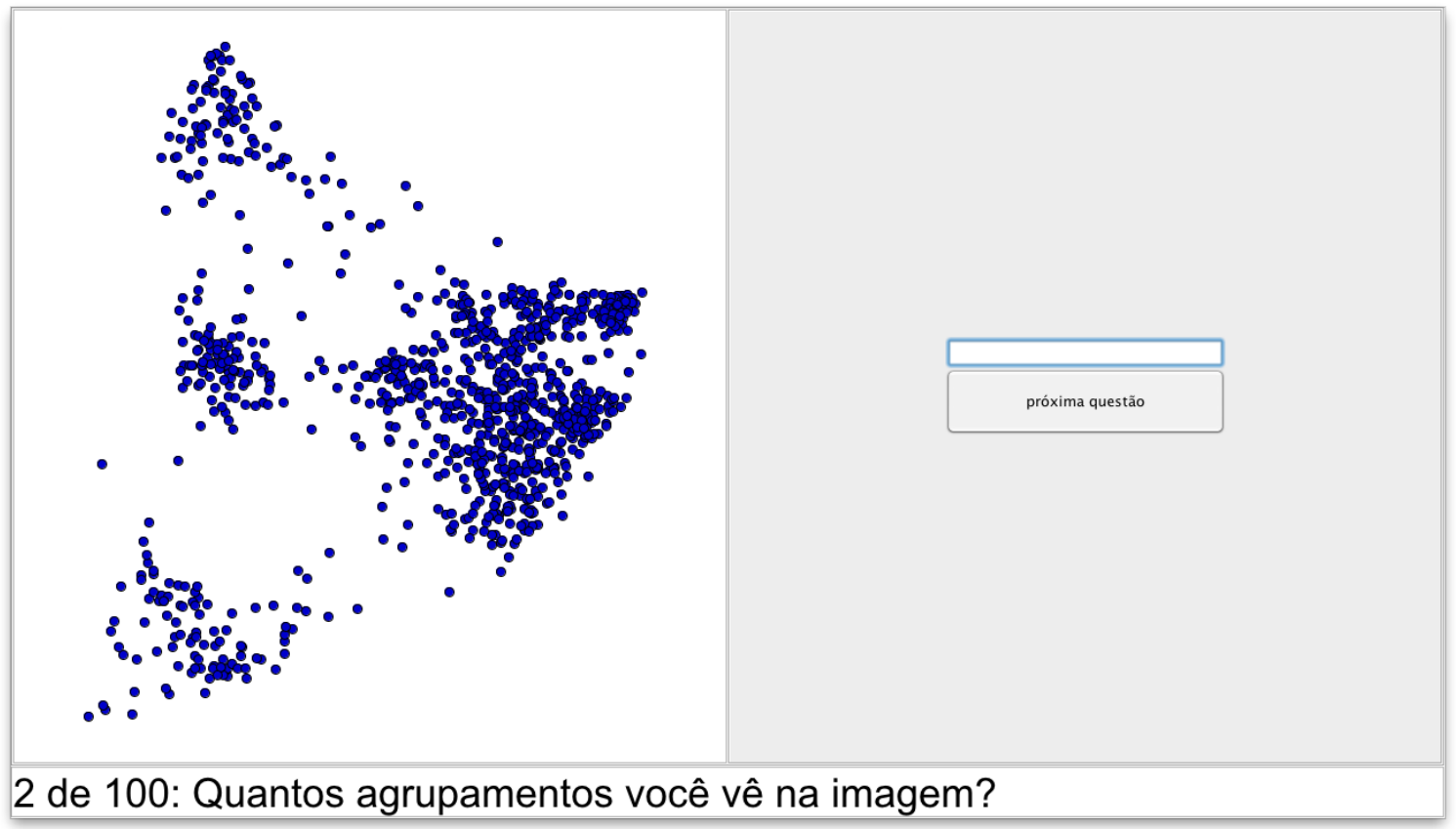

Figura 3.5: Exemplo de tarefa que solicitou ao participante indicar a quantidade de agrupamentos percebidos.

tificada. Na Figura 3.6 é apresentado o histograma das respostas relativas a todos os estímulos. Observou-se que a resposta mais frequente (34\% das ocorrências) corresponde a um único agrupamento, ou seja, o observador entende que a projeção não exibe agrupamentos perceptíveis. Esta característica é esperada, já que algumas técnicas, como a Glimmer, tendem a espalhar muito os pontos e não favorece a identificação de grupos.

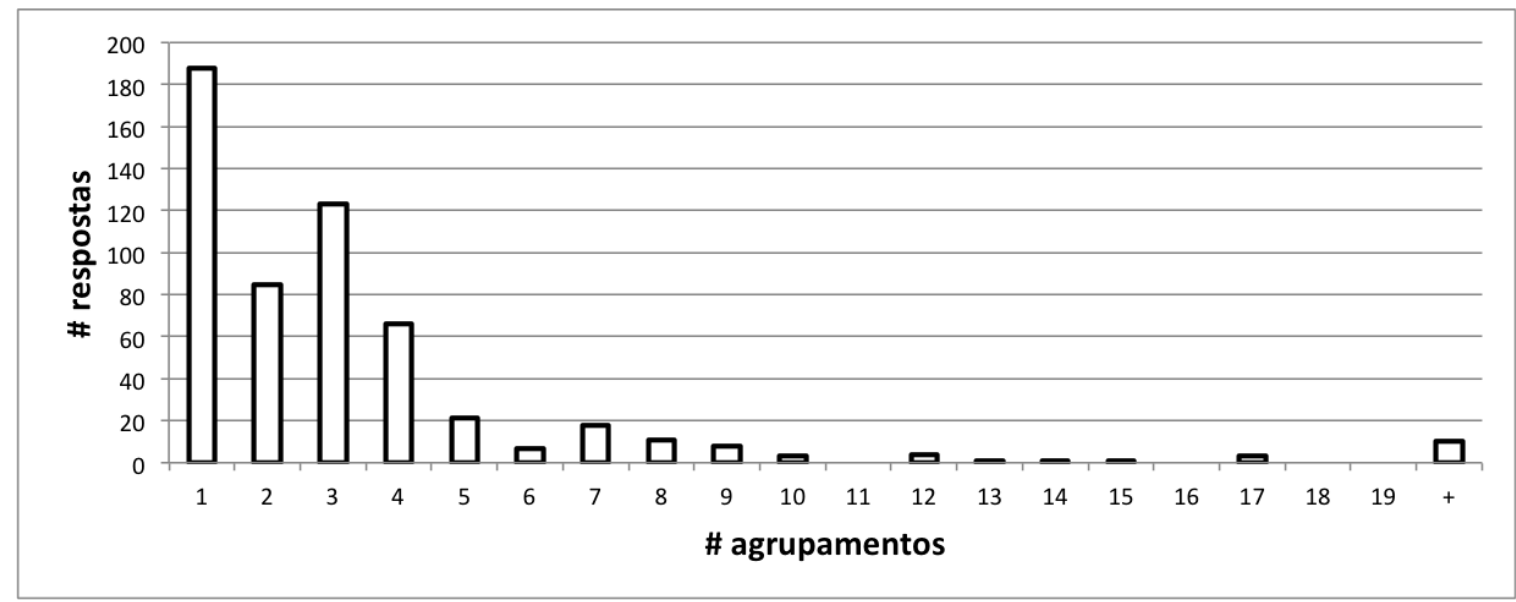

Figura 3.6: Histograma das respostas referentes à quantidade de agrupamentos.

Considerando as demais respostas, observamos uma tendência dos participantes identificarem poucos grupos. A segunda quantidade mais frequente, 3 agrupamentos, ocorreu em $22 \%$ das respostas. Porém, em 10 respostas foram identificados acima de 19 agrupamentos, mostrando a grande discrepância que pode ocorrer entre diferentes estímulos e participantes. A ausência de um valor predominante observando o conjunto de todas as 
projeções é esperada, já que as projeções apresentam distribuições de pontos bastante distintas. Por isso, é importante verificarmos as projeções individualmente para identificar se a percepção de agrupamentos nos mesmos conjuntos de dados é similar nas diferentes técnicas.

Na Figura 3.7 são apresentados os histogramas relativos a cada técnica de projeção. É possível observar que as projeções geradas pelas técnicas Glimmer e PCA obtiveram muitas respostas iguais a 1 , a primeira por espalhar demais os pontos e a segunda por juntá-los demais, ambas prejudicando a identificação de grupos.

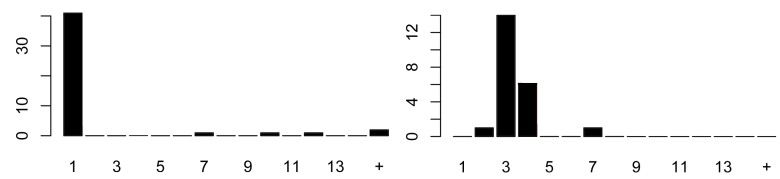

(a) CBR - Glimmer (b) $C B R-I S O M A P$

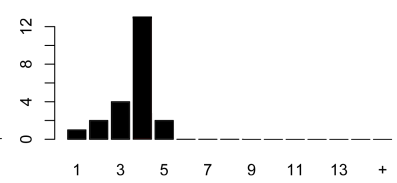

(f) $K D V i z-I S O M A P$

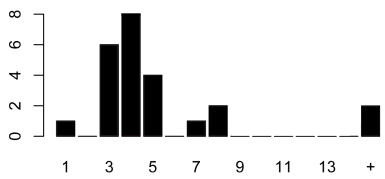

(c) $C B R-L S P$

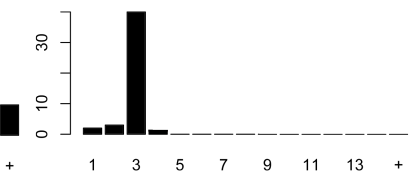

(d) $C B R-P C A$
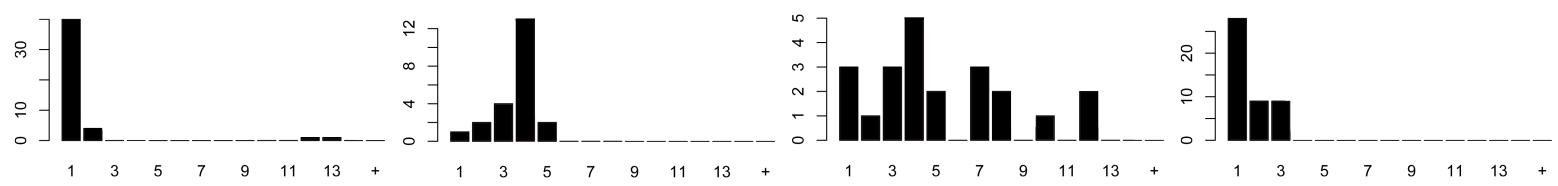

(e) KDViz - Glimmer

(g) KDViz - LSP

(h) KDViz - PCA
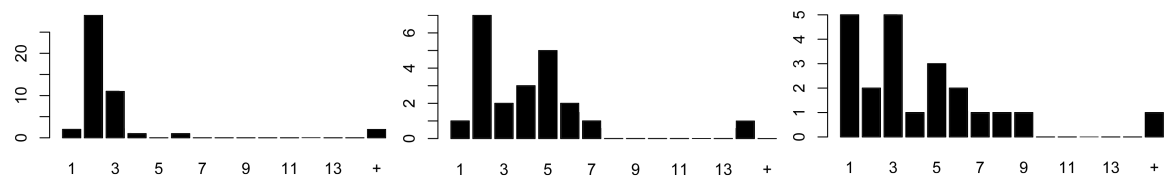

(k) Medical - LSP

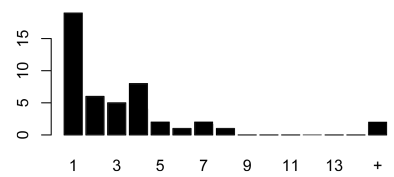

(1) Medical - PCA

(j) Medical - ISOMAP

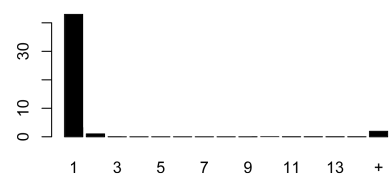

(m) Corel-Glimmer

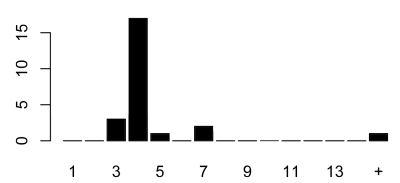

(n) Corel - ISOMAP

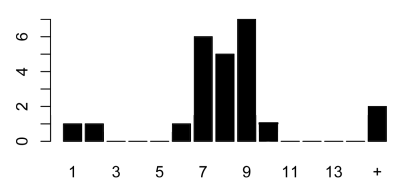

(o) Corel - LSP

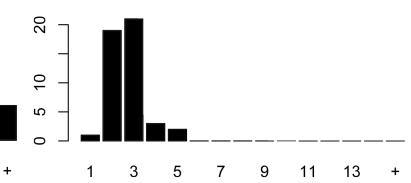

(p) Corel - PCA

Figura 3.7: Histograma das respostas referentes a quantidade de agrupamentos para cada projeção, nos quatro conjuntos de dados.

Em 5 dos 16 histogramas, a resposta mais frequente foi 1, com frequencia duas vezes maior do que a segunda mais frequente. Dos demais 11 histogramas, 5 deles apresentam uma resposta predominante entre 2 e 4 agrupamentos, e os outros 6 histogramas exibem distribuição das respostas mais variada, sem uma frequência predominante. Dentre os 5 com respostas predominantes entre 2 e 4 agrupamentos estão 3 projeções geradas com a técnica ISOMAP, dos conjuntos de dados $C B R, K D V i z$ e Corel, 1 projeção gerada com a técnica $P C A$, do $C B R$, e uma projeção obtida com a técnica Glimmer, do Medical.

Portanto, as respostas se dividiram de forma bem distribuída em 3 grupos. O primeiro, relativo a $31 \%$ das projeções, no qual os participantes não percebem uma estrutura visual de agrupamentos. O segundo, relativo a $31 \%$ projeções, no qual há uma quantidade de 
agrupamentos predominante entre os participantes. E o terceiro, com $38 \%$ das projeções, no qual os participantes percebem uma estrutura de agrupamentos, mas há grande divergência no número percebido.

Dentre as técnicas de projeção a ISOMAP resultou, para 3 dos 4 conjuntos de dados, em uma estrutura visual de agrupamentos que teve concordância da maioria dos participantes no número de grupos percebidos, enquanto as demais técnicas geraram percepções variadas entre os participantes. Também para 3 dos 4 conjuntos de dados, a técnica Glimmer gerou projeções nas quais os participantes responderam 1, indicando ausência de uma estrutura visual de agrupamentos. Por fim, a técnica com maior variação nas respostas foi a $L S P$, com respostas bem distribuídas nos números de agrupamentos percebidos.

Estes resultados mostraram que os participantes, em geral, divergiram na percepção de agrupamentos. Essa ausência de padrão para uma grande quantidade de estímulos nos motivou a realizar um estudo comparativo de técnicas de identificação de agrupamentos, apresentada na Seção 4.3, no qual não avaliamos a quantidade de agrupamentos e focamos na qualidade dos grupos identificados. 



\section{Capítulo}

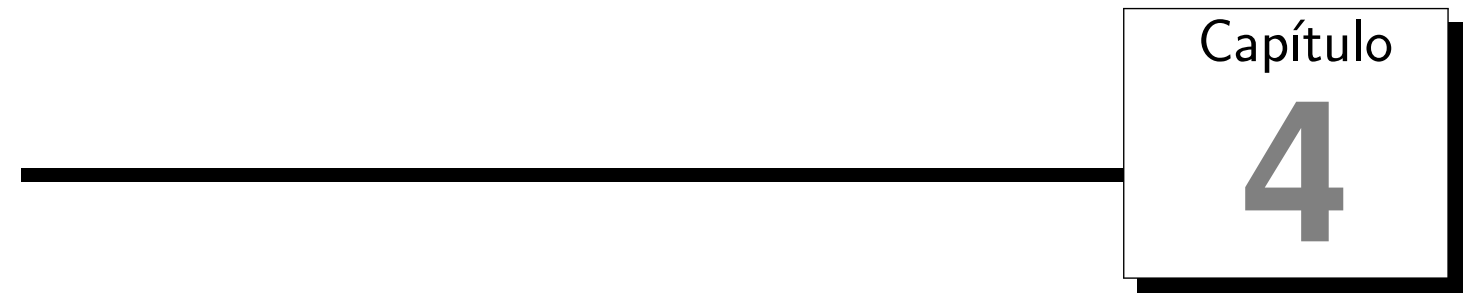

\section{Representação dos dados e identificação de vizinhanças e agrupamentos}

Com enfoque principalmente na análise de vizinhanças e de agrupamentos para avaliar projeções multidimensionais, é importante utilizar uma representação dos dados que reflita bem estas duas características. Neste Capítulo são investigadas diferentes representações dos dados para serem utilizadas nesse contexto. Para validar as representações dos dados em relação aos agrupamentos conduzimos um estudo comparativo de diferentes técnicas de identificação de agrupamentos e para validação em relação às vizinhanças utilizamos resultados do estudo de percepção apresentado no Capítulo 3. Algumas observações identificadas no estudo de percepção foram:

- para cada ponto houve, em geral, um tamanho de vizinhança que grande parte dos participantes foi capaz de identificar com alta precisão;

- não houve um tamanho fixo global de vizinhança, ou seja, o tamanho da vizinhança variou de ponto para ponto conforme a região em que se encontra;

- os participantes apresentaram grande divergência na quantidade de agrupamentos percebidos em cada projeção.

Assim, é necessário definir um modelo de representação dos dados que (i) seja capaz de identificar um tamanho de vizinhança adequado a cada ponto e (ii) possa ser utilizado na identificação de agrupamentos com boa precisão.

Estas especificações nos motivaram a explorar representações relacionais dos dados, tradicionalmente modeladas como grafos. Nestas representações, tarefas relacionadas a 
vizinhanças podem ser baseadas nos adjacentes de cada vértice no grafo e tarefas relacionadas a agrupamentos se associam a grupos de vértices altamente conectados. Além disso, as arestas de um grafo podem também guiar o usuário na interpretação do que está sendo avaliado em cada medida.

Nos últimos anos, soluções baseadas em grafos inspiraram pesquisadores da comunidade de Aprendizado de Máquina e Mineração de Dados. Técnicas baseadas em grafos são capazes de (i) capturar a estrutura topólogica dos dados; (ii) representar hierarquicamente os dados, ao particionar o grafo em subgrafos, que também podem ser divididos em subgrafos menores, e assim por diante; (iii) detectar agrupamentos com diferentes formatos e densidades; e (iv) combinar informações locais e globais dos dados (Bertini Jr. et al., 2011).

A seguir são apresentadas diferentes representações relacionais de dados obtidas por meio de modelos de grafos baseados em similaridade, incluindo a proposta de um novo modelo. Em seguida, são descritos dois estudos comparativos, o primeiro relacionado à identificação de vizinhanças e o segundo relacionado a identificação de agrupamentos.

\subsection{Representação relacional de dados}

Uma representação relacional enriquece a tradicional representação tabular dos dados agregando informação de relacionamento às informações individuais que cada instância já possui. Recentemente muitos estudos têm sido propostos relacionados à modelagem destes grafos e à sua aplicação na extração de padrões em dados (Lilian Berton, 2014).

Representações relacionais são modeladas como grafos em que as instâncias são os vértices e as arestas indicam suas relações. Para a caracterização dos grafos diversas propriedades podem ser utilizadas, algumas delas caracterizando individualmente os vértices e outras caracterizando o grafo como um todo. Observa-se que a representação via grafos também pode ser aplicada a conjuntos de dados tabular, sendo que neste caso cada instância (linha da tabela) é representada por um vértice e as arestas vão indicar alguma relação de similaridade entre as instâncias. Estes modelos são apresentados na Seção 4.1.1.

Dentre as medidas que caracterizam individualmente os vértices, conhecidas como de centralidade de vértices, podemos citar: grau, coeficiente de agrupamento, grau de excentricidade (excentricity), grau de intermediação (betweenness) e grau de proximidade (closeness). Algumas medidas que caracterizam o grafo como um todo são: grau médio, distribuição de conectividade, diâmetro, transmissão de informação, árvore geradora mínima e estrutura de comunidades (Costa et al., 2007).

O grau $g_{i}$ de um vértice $v_{i}$ é a medida mais básica relacionada a um vértice, e é dado pelo seu número de arestas incidentes. Altos valores indicam instâncias importantes na formação do grafo (hubs). Dentre as medidas de caracterização do grafo como um todo, algumas delas são simplesmente a média dos valores obtidos para os vértices individual- 
mente, como o grau médio do grafo. Outra medida baseada no grau é a distribuição de conectividade, que pode ser definida como a probabilidade de que um vértice escolhido ao acaso tenha grau $g$. Um histograma dos graus dos seus vértices define a distribuição de conectividade do grafo.

O uso adequado das propriedades descritas e, possivelmente, novas propriedades propostas, podem ter papel fundamental em atividades de mineração de dados. A seguir é descrito como gerar uma representação relacional de dados não relacionais, e em seguida é apresentado um estudo do uso de representações relacionais para análise de vizinhanças e identificação de agrupamentos.

\subsubsection{Modelos de grafos baseados em similaridade}

Modelos de grafos baseados em distância (dissimilaridades), podem ser utilizados em diferentes tarefas de mineração de dados, tais como classificação, identificação de agrupamentos e algoritmos de busca. Alguns modelos relevantes neste contexto são os grafos baseados em vizinhança e os grafos que consideram em seu processo de formação, além da vizinhança, também alguma característica estrutural, como agrupamentos ou densidades.

Um modelo bastante conhecido é a árvore geradora mínima (minimum spanning tree graph - MST), a qual é um sub-grafo de um grafo completo que inclui todos os vértices e que possui o número mínimo de arestas, ou para grafos com peso, o conjunto de arestas de custo total mínimo. Uma $M S T$ pode ser computada de um grafo completo construído a partir dos dados considerando como peso das arestas as respectivas distâncias entre os pares de instâncias.

O grafo $M S T$ é um modelo não paramétrico, mas sua forma de construção resulta em um grafo com poucas arestas e, geralmente, não preserva importantes propriedades dos dados, principalmente relacionadas com densidade.

O grafo $k N N G$ (Zhu, 2005) ( $k$ Nearest Neighbors Graph) é também um modelo tradicional. Neste modelo conecta-se cada instância aos seus $k$ vizinhos mais próximos de acordo com uma dada função de distância, na qual o parâmetro de entrada $k$ define o número de conexões. A variação do parâmetro $k$ irá produzir grafos com diferentes propriedades. Grafos conexos são geralmente utilizados para computar apropriadamente a maioria das medidas sobre grafos, particularmente as que se baseiam em caminhos no grafo, e, tipicamente, este modelo de grafo requer um alto valor de $k$ para gerar um grafo conexo.

Baseado no grafo $k N N G$, Aoyama et al. (2011) propuseram um grafo chamado $k$ degreereduced nearest neighbor graph $(k D R)$, como um método rápido de busca de similaridade aproximada. O $k D R$ difere do $k N N G$ por não ter uma aresta entre $x$ e seus vizinhos mais próximos $y \in N_{k}(x)$, com $N_{k}(x)$ denotando os $k$ vizinhos mais próximos de $x$, sem a qual um algoritmo de busca guloso pode atingir $x$ partindo de $y$ utilizando as arestas existentes. 
Portanto, o grafo $k D R$ possui um grau médio menor comparado ao grafo $k N N G$.

Um grafo $k D R$ inicia-se com a construção de um grafo $k N N G$ com $k=1$, e então adotase um procedimento incremental em $k$, até $k=k_{\max }$, o qual é fornecido antecipadamente. Inicialmente, o grafo $k D R$ é exatamente o grafo $k N N$ com $k$ igual a 1, e em seguida, para cada grafo $k N N$ com $1<k<=k_{\max }$, as arestas são verificadas e possivelmente inseridas no grafo $k D R$. Uma aresta ligando $x$ e $y$ é inserida se, no atual grafo $k D R$, a distância entre $x$ e cada adjacente de $y$ é maior do que a distância entre $x$ e $y$.

Bayá e Granitto (2011) também criaram modelos de grafo baseados nos grafos $k N N G$, visando identificar agrupamentos em dados de expressão gênica. Conectividade é uma propriedade importante destes grafos, garantindo que haja sempre uma distância finita entre todos os pares de instâncias. A construção parte do grafo $k N N G$, o qual é transformado em um grafo conexo (Penalized $k$ Nearest Neighbors Graph - PKNNG). A estratégia adotada faz com que arestas ligando vértices em diferentes componentes sejam definidas com peso significativamente menor do que arestas internas a um componente.

Quatro diferentes estratégias são consideradas para obter o grafo conexo: (i) adicionar o conjunto de arestas com custo mínimo para tornar o grafo $k N N G$ conexo, i.e., as arestas de sua árvore geradora mínima; (ii) adicionar a aresta de menor custo entre todos pares de componentes; (iii) adicionar arestas com baixo custo entre todas as instâncias de componentes distintos; e (iv) adicionar arestas entre instâncias centrais nos componentes. A primeira estratégia apresentou os melhores resultados para identificação de agrupamentos, com desempenho similar ao estado da arte de métodos de agrupamento não relacionais.

Em um trabalho anterior Motta et al. (2009) propusemos um modelo hierárquico de grafo (Hierarchical Similarity Network model - HSN), com poucas conexões entre instâncias isoladas e mais conexões em regiões densas. O modelo requer um parâmetro de entrada que controla o grau médio do grafo resultante, e a estratégia aglomerativa de construção busca otimizar a estrutura modular do grafo, mesmo que essa modularidade não seja necessariamente uma propriedade dos dados de entrada.

Dadas $N$ instâncias, um grafo inicial é formado por $N$ componentes de um único vértice, sem nenhuma aresta. Um processo aglomerativo hierárquico é iniciado para conectar pares de vértices iterativamente, dado um limiar de similaridade mínima, até atingir um grau médio definido pelo usuário. O processo de junção dos componentes utiliza um critério que considera a similaridade entre os vértices e o número de conexões entre componentes internamente. Em outras palavras, o algoritmo busca por novos componentes que tenham vértices com alta similaridade, grande número de conexões internas e poucas conexões externas. O procedimento é interrompido quando o grafo torna-se conexo.

Buscando um modelo não paramétrico adequado para tarefas de avaliação de projeções, de acordo com características levantadas no estudo de percepção conduzido, propomos neste trabalho um grafo obtido a partir da árvore gerada mínima, apresentado a seguir. 


\subsubsection{Grafo EMST}

O único modelo não paramétrico descrito foi a $M S T$, construído a partir de um grafo completo. E como já destacamos, a forma de geração do grafo MST faz com que ele não reflita algumas características dos dados, por exemplo, agrupamentos de instâncias altamente conectadas. Diante disso, introduzimos um modelo de grafo nomeado Extended Minimum Spanning Tree (EMST), o qual expande a MST inserindo conexões entre pares de vértices similares, segundo um critério que considera padrões de conexão da $M S T$.

A EMST é efetiva em capturar as variações locais nas relações de vizinhança e mapealos em padrões de conexões. O grafo é construído em dois estágios: obtida a $M S T$, a construção da EMST se inicia com um conjunto vazio de arestas no qual arestas são adicionadas segundo um padrão de conexões identificado na $M S T$. Dois valores são utilizados para computar um limiar de conexão para cada vértice, um baseado nas distâncias locais e um nas distâncias globais. Dois vértices irão se conectar somente se a distância entre eles for inferior ao limiar. A idéia é formalizada na Definição 1. O conjunto de arestas $A$ inclui as arestas da $M S T$ mais as arestas adicionais de cada vértice no grafo completo $G_{C}$ que satisfazem seu limiar. O processo completo, incluindo o cálculo do limiar de cada vértice, é detalhado no Algoritmo 1.

Definicão1 : $\operatorname{EMST}(V, A) \mid$

$$
\begin{aligned}
& V=\left\{v_{1}, \ldots, v_{N}\right\} \\
& A=\left\{\left(v_{i}, v_{j}\right) \mid\left(v_{i}, v_{j}\right) \in M S T\right\} \cup\left\{\left(v_{i}, v_{j}\right) \in G_{C} \mid \delta\left(x_{i}, x_{j}\right) \leqslant \operatorname{limiar}\left(v_{i}\right)\right\}
\end{aligned}
$$

O Algoritmo 1 descreve o processo de construção do grafo. Inicialmente é computado o grafo completo $G_{C}$ e seu correspondente $M S T\left(V, A^{\prime}\right)$. As arestas da EMST irão ser gradualmente adicionadas a um conjunto de arestas inicialmente vazio $A$. O limiar de cada vértice $v_{i}$ é computado na linha 14. $Q_{d d}$ é um fator global de distribuição de distâncias, computado a partir de $G_{C}$ com a Equação 4.1, em que $D$ é o conjunto de todas as distâncias normalizadas entre os pares de instâncias, e o desvio padrão $s d, 0 \leqslant s d \leqslant 0.5$, é tomado como um indicador de variabilidade da distribuição de distâncias, com $\max (s d)=$ 0.5 adotado como um fator de normalização. Pequenos valores de $Q_{d d}$ indicam baixa variabilidade nas distâncias entre os pares, e capturar a vizinhança das instâncias requer um critério de conectividade rigoroso, ou seja, o limiar para conectar as instâncias deve ser baixo. Valores de $Q_{d d}$ próximos a um indicam alta variabilidade nas distâncias, e o limiar de conectividade deve ser relaxado.

Portanto, o limiar é computado somando-se $Q_{d d}$ (ponderado pelo peso médio $\left\langle w^{A^{\prime}}\right\rangle$ das arestas do grafo) ao maior valor entre $w_{i j}^{G_{C}}$ e $\left\langle w^{A^{\prime}}\right\rangle$, os quais representam o fator baseado nas distâncias locais, com $w_{i j}^{G_{C}}$ sendo o menor peso dentre as arestas do vértice. O grafo final é $G_{E M S T}(V, A)$, com $A \supset A^{\prime}$. A complexidade computacional é determinada pelo 
custo de construção da $M S T$, que é $O(N \log (N))$, e das iterações nas linhas 12-16, que é $O\left(N^{2}\right)$. Portanto, a construção da EMST tem custo $O\left(N^{2}\right)$.

$$
Q_{d d}(D)=s d(D) / \max (s d)
$$

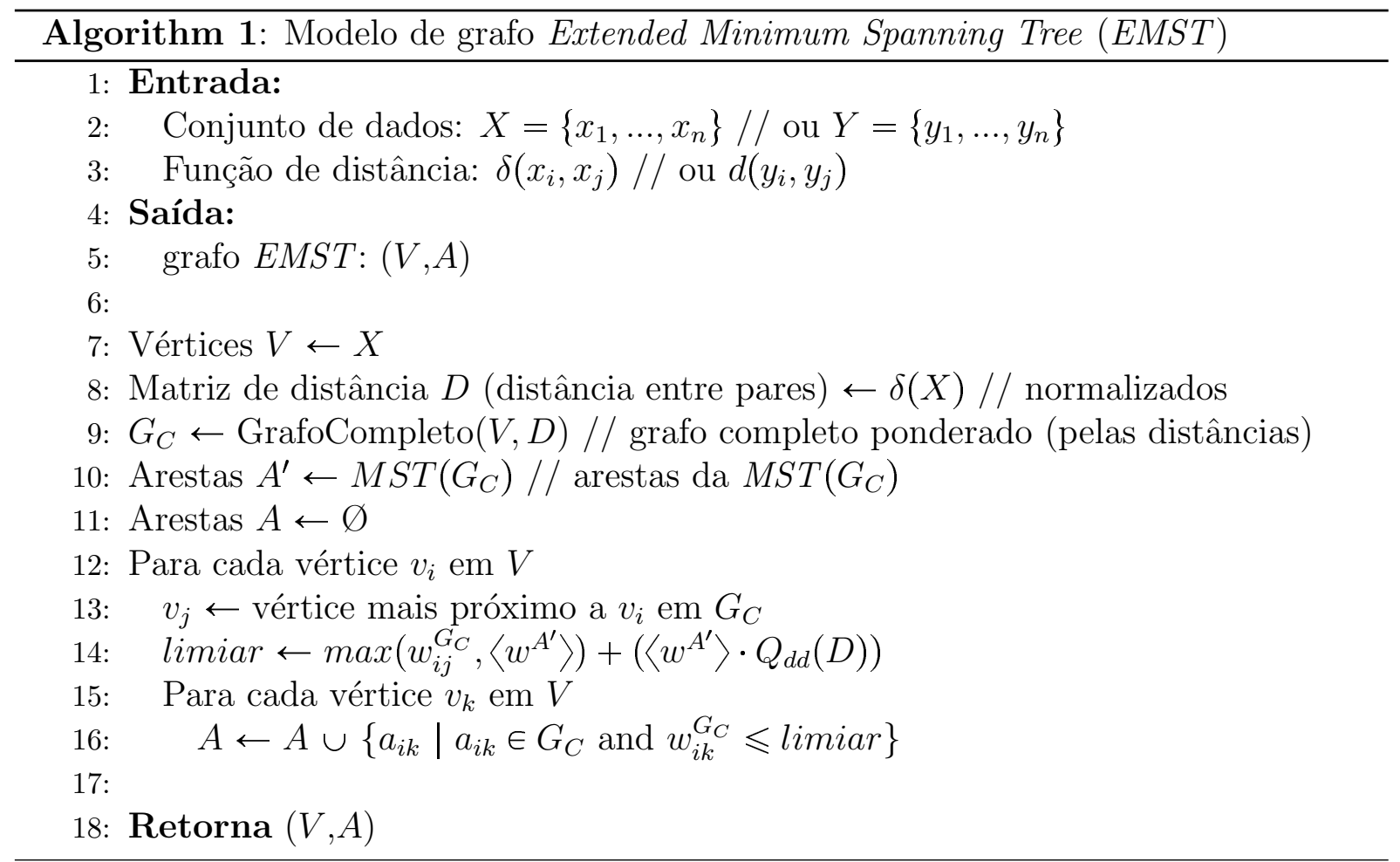

O grafo EMST resultante mantém instâncias em regiões densas altamente conectadas e instâncias esparsas fracamente conectadas. Além disso, se houver uma estrutura de agrupamentos nos dados o grafo consequentemente manterá estes grupos fortemente conectados, devido ao seu processo de inserção de arestas. Na Figura 4.1 há um exemplo de grafo EMST do conjunto de dados Iris $^{1}{ }^{1}$, o qual é formado por 150 instâncias que descrevem 3 espécies da flor (50 de cada espécie). Neste conjunto de dados cada instância é representada por 4 atributos dos quais sepal length e sepal width são utilizadas no mapeamento 2D mostrado.

A Figura 4.2 apresenta os diferentes modelos de grafo citados, relativos ainda ao Iris. É possível observar as poucas arestas existentes no grafo $M S T$ e a diferença em relação à $E M S T$, que tem mais arestas entre instâncias próximas. Também observa-se o grafo $k N N G$ desconexo para $k=3$ e com conexões entre instâncias distantes para $k=11$, e os modelos $k D R, H S N$ e EMST com grafos conexos e contendo poucas arestas entre as instâncias distantes. Portanto, vemos que os modelos geram grafos com diferentes distribuições de conexões e cada um pode ser útil em diferentes tarefas.

\footnotetext{
${ }^{1}$ http://archive.ics.uci.edu/ml/datasets/Iris
} 


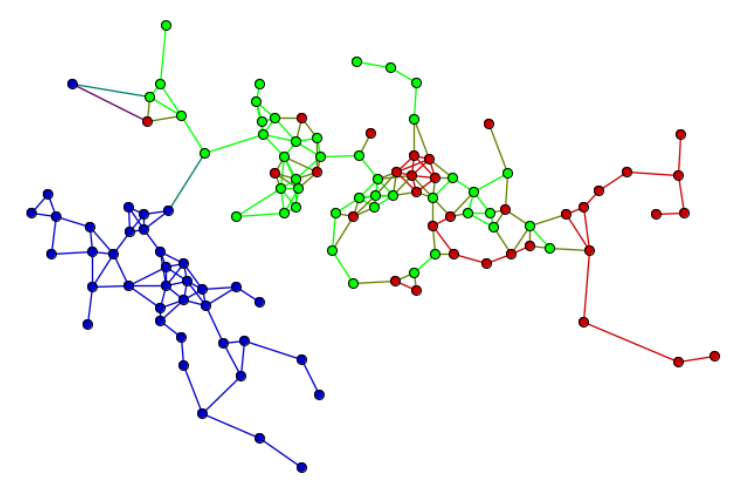

Figura 4.1: EMST para o Iris mapeado no espaço bidimensional com base nos valores dos atributos sepal length e sepal width.

\subsection{Identificação da vizinhança dos pontos}

Nesta Seção é apresentado um estudo de diferentes modelos de grafos para identificação da vizinhança apropriada para cada ponto em uma projeção. Para isso, o estudo de percepção apresentado no Capítulo 3 nos serve como base, permitindo que as vizinhanças determinadas por cada modelo de grafo sejam comparadas às vizinhanças identificadas pelos participantes do estudo. Portanto, para cada um dos 30 estímulos apresentados, com um ponto referência destacado, temos um tamanho "ideal" de vizinhança para este ponto, que corresponde ao número de vizinhos escolhido pelos participantes de forma mais precisa.

Com isso, para um dado critério de identificação de vizinhança (segundo um modelo de grafo), validamos o quanto este critério coincide com a percepção dos participantes do estudo. Aqui, utilizamos o critério $K N N$ não relacional, ou seja, para todos os pontos consideramos os $k$ vizinhos mais próximos, e os seguintes grafos: $k N N G, k D R, P K N N G$, $H S N, M S T$ e EMST. Observe que o grafo $k N N G$ é diferente do $K N N$ não relacional, pois para cada ponto irá considerar, além dos seus $k$ vizinhos mais próximos, também aqueles pontos que o incluiram como um dos $k$ vizinhos, pois é um grafo não direcionado. Os valores de $k$, nos modelos paramétricos, variaram de 1 a 5 , pois as respostas dos participantes foram restringidas em 5 .

Portanto, cada critério resulta em um tamanho de vizinhança para o ponto referência de cada um dos 30 estímulos. Idealmente, o tamanho da vizinhança deverá ser o mesmo tamanho selecionado corretamente pela maior parte dos participantes no estudo, o qual denominamos tamanho "ideal" de vizinhança, e que foi destacado na Tabela 3.5. Na Figura 4.3 é apresentada a diferença média entre a quantidade de vizinhos dada por cada critério e o tamanho "ideal" da vizinhança, considerando todos os estímulos. O valor próximo a zero indica maior qualidade do critério, com menor diferença média em relação ao tamanho "ideal". 


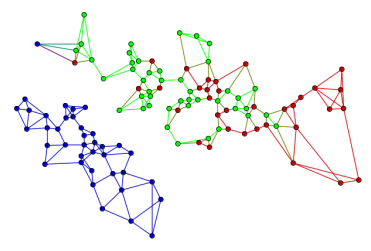

(a) $k N N G(k=3)$

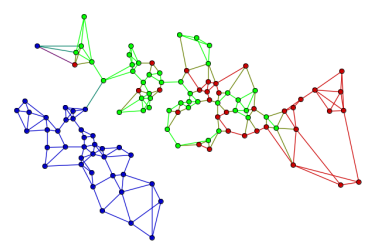

(e) $P K N N G(k=3)$

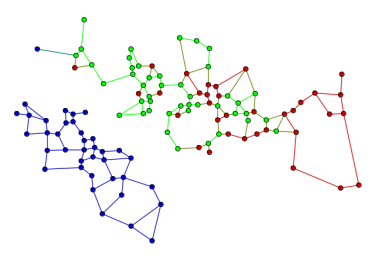

(i) $k D R(k=3)$

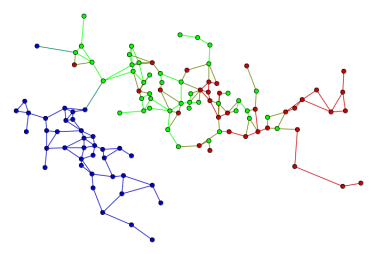

(m) HSN (input degree=3)

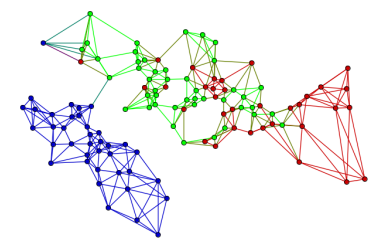

(b) $k N N G(k=5)$

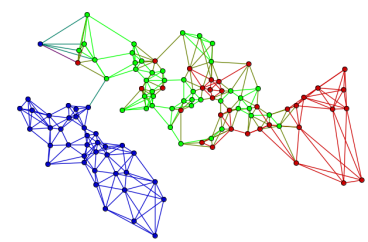

(f) $P K N N G(k=5)$

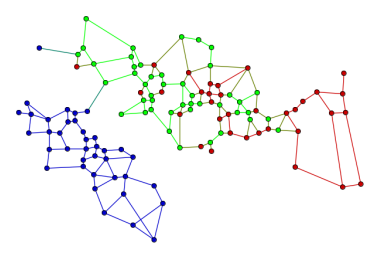

(j) $k D R(k=5)$

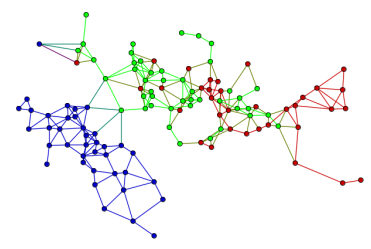

(n) $H S N$ (input degree $=5$ )

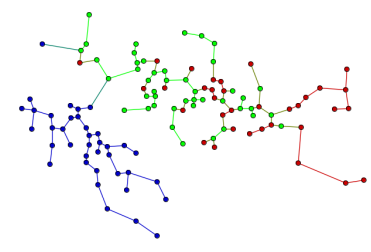

(q) $M S T$

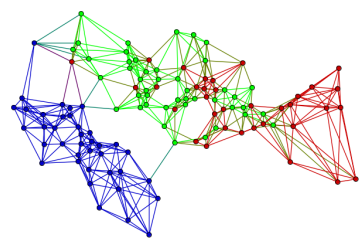

(c) $k N N G(k=7)$

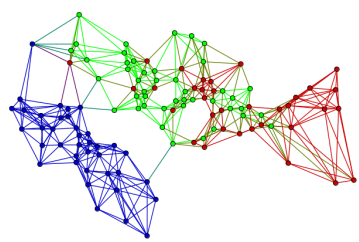

(g) $P K N N G(k=7)$

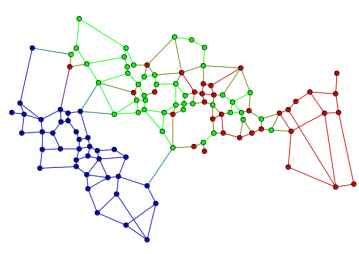

(k) $k D R(k=7)$

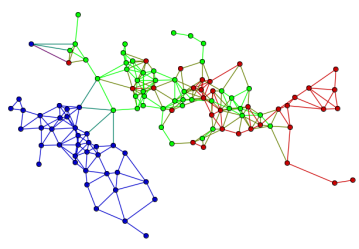

(o) HSN (input degree=7)

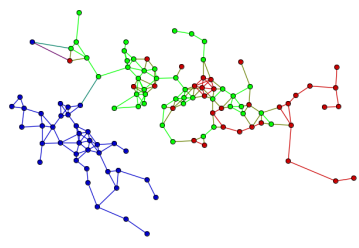

(r) $E M S T$

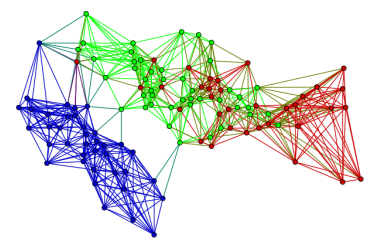

(d) $k N N G(k=11)$

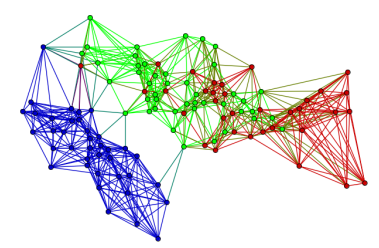

(h) $P K N N G(k=11)$

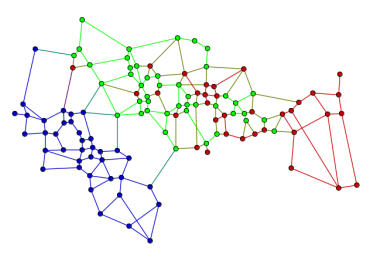

(l) $k D R(k=11)$

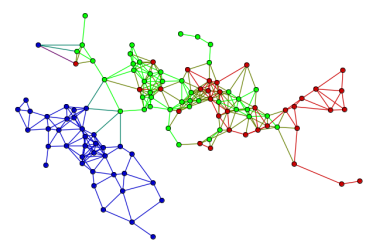

(p) $H S N$ (input degree=11)

Figura 4.2: Conjunto de dados Iris representado por diferentes modelos de grafo de similaridade. Redes $k N N$ (a-d), PKNNG (e-h), $k D R$ (i-l) e $H S N$ (m-p) com respectivos valores de entrada iguais a 3, 5, 7 e 11, e grafos não paramétricos $M S T$ (q) e $\operatorname{EMST}$ (r). As cores de cada ponto indicam a classe da instância.

Em apenas 5 dos 27 critérios a diferença ficou abaixo de 1, com o melhor caso sendo o grafo EMST, com valor 0,6. Também foi avaliado o número de vezes que cada critério identificou exatamente o tamanho "ideal" da vizinhança, e o resultado é apresentado na Figura 4.4. É possível perceber que o grafo EMST resultou no tamanho "ideal" em 17 dos 30 estímulos mostrados, enquanto o segundo melhor acertou 13 casos.

Ainda em relação à qualidade da vizinhança, podemos ignorar o tamanho "ideal" e ava- 


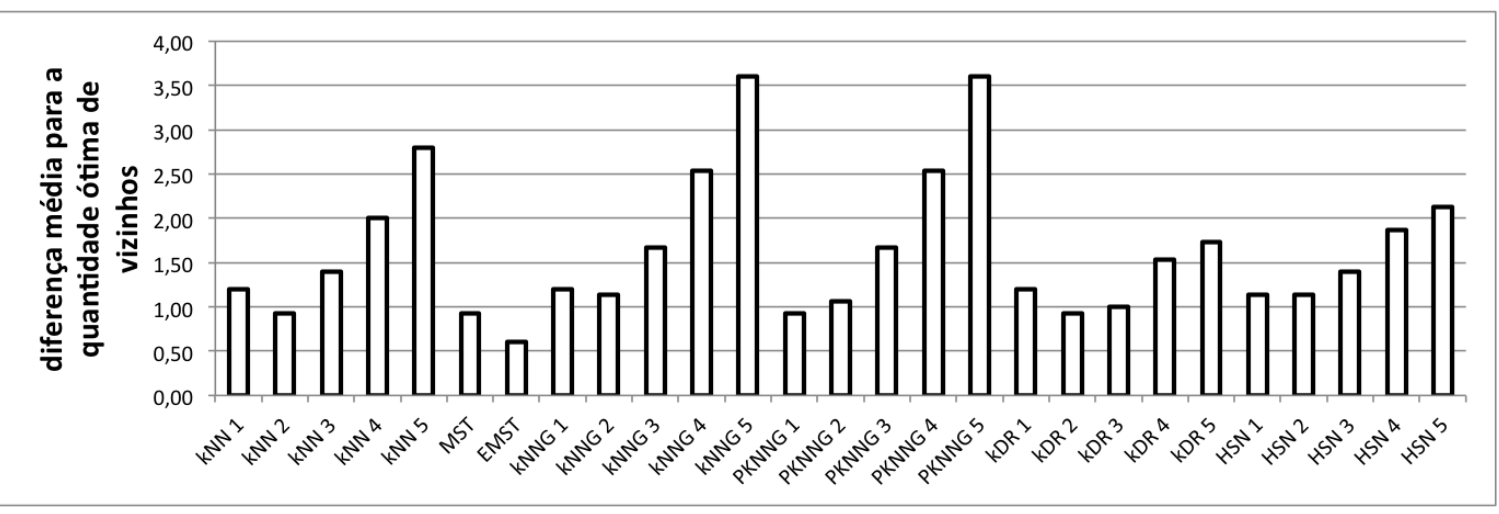

Figura 4.3: Diferença média entre o número de vizinhos dado por cada critério de identificação de vizinhança e o número mais frequente no estudo de percepção (tamanho "ideal" de vizinhança).

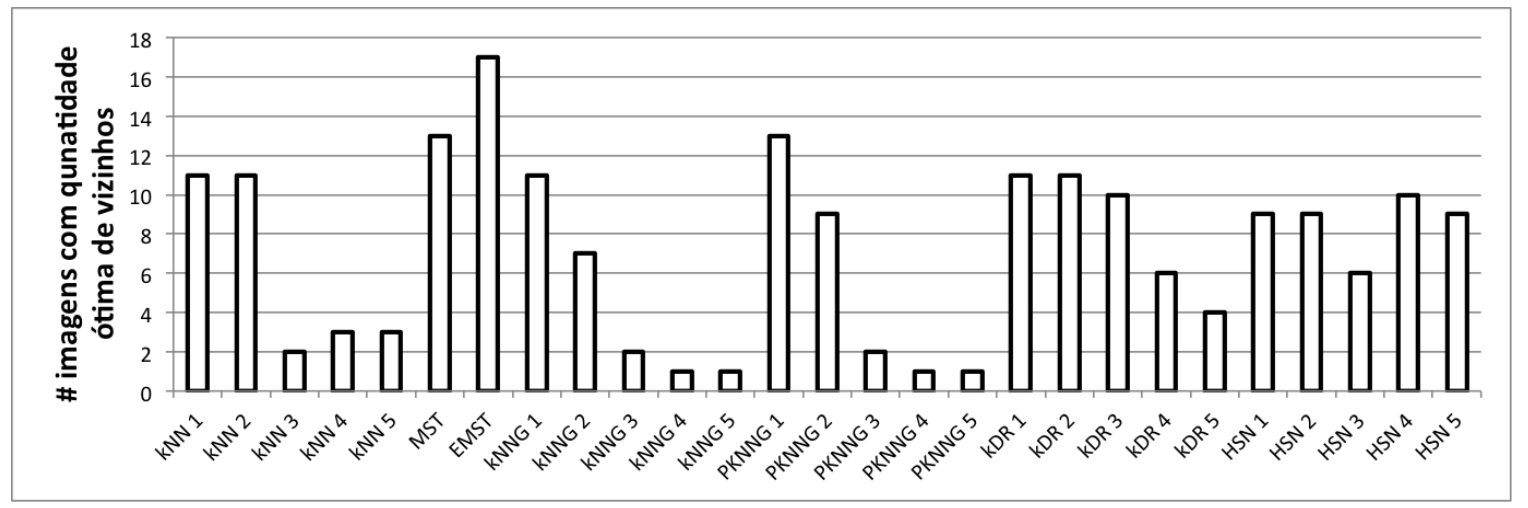

Figura 4.4: Número de estímulos em que a quantidade de vizinhos dada por cada critério de identificação de vizinhança coincidiu com o tamanho "ideal" da vizinhança.

liar diretamente a porcentagem dos participantes que acertou o número de vizinhos dado por cada critério. Ou seja, mesmo não sendo o tamanho "ideal", pode ser que o número dado pelo critério tenha uma porcentagem de acertos alta por parte dos participantes.

Na Figura 4.5 mostramos a porcentagem média de participantes que acertou a vizinhança considerando o número de vizinhos dado por cada critério. Um valor próximo a $100 \%$ indica boa coincidência do critério com as respostas dos participantes do estudo. Neste caso, também o grafo EMST apresentou o melhor valor, com $71 \%$ de acerto médio pelos participantes. É importante destacar que o valor máximo neste caso é a média da maior porcentagem de acerto em cada caso, que foi de $80 \%$, pois para atingir $100 \%$ seria preciso que em todas as projeções houvesse uma quantidade de vizinhos em que todos participantes acertaram, o que não ocorreu.

Na avaliação dos critérios de identificação de vizinhança observamos que o grafo EMST proposto é capaz de conectar cada ponto aos vizinhos mais próximos com alta precisão em relação as vizinhanças percebidas pela maioria dos participantes no estudo realizado. Outra atividade importante é a identificação de agrupamentos, detalhada a seguir. 


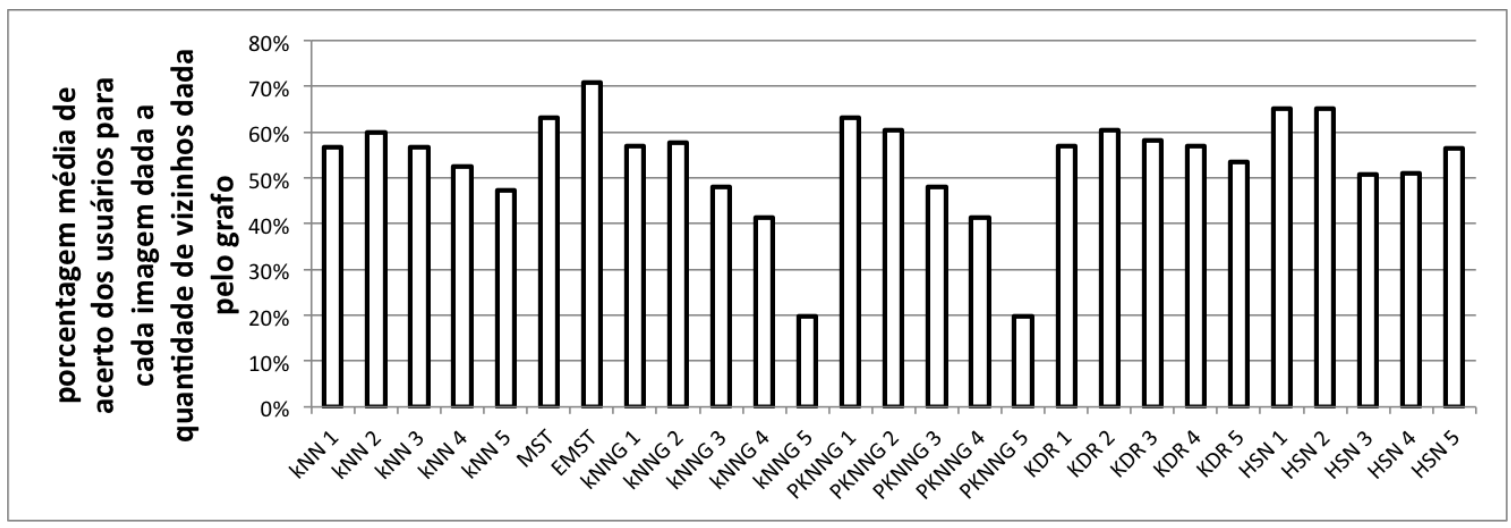

Figura 4.5: Porcentagem média de acerto dos participantes para o número de vizinhos dado por cada critério de identificação de vizinhança.

\subsection{Identificação de agrupamentos nos dados}

Identificamos que, em geral, não há um padrão na quantidade de agrupamentos percebida pelos participantes do estudo nos estímulos avaliados, havendo uma quantidade de agrupamentos predominante para apenas 31\% dos estímulos. Portanto, focamos nossa análise na qualidade dos agrupamentos identificados e não na quantidade de agrupamentos.

Nesta Seção comparamos diversos algoritmos de identificação de agrupamentos, os quais foram divididos em dois grupos principais, os não relacionais, que são mais tradicionais para identificação de agrupamentos e consideram a representação tabular dos dados, e os algoritmos relacionais, que são aplicados a grafos.

\subsubsection{Técnicas não relacionais}

Há muitos trabalhos descrevendo algoritmos não relacionais de identificação de agrupamentos, os quais podem ser divididos em duas categorias principais, os particionais e os hierárquicos (Jain e Dubes, 1988). Algoritmos particionais subdividem os dados em um conjunto de agrupamentos mutualmente independentes, ou seja, geram um único particionamento dos dados. Algoritmos hierárquicos, por outro lado, visam obter uma sequência de partições aninhadas.

K-Means (MacQueen, 1967) é possivelmente o mais conhecido algoritmo particional, e opera na identificação de uma partição ótima dos dados buscando uma minimização do critério de soma do erro quadrático. O algoritmo começa escolhendo arbitrariamente $k$ grupos protótipos (centroides). Então, cada instância $x_{i}$ é adicionada ao cluster $C_{i}$ com o centroide mais próximo. Após este processo ter sido realizado para as $N$ instâncias, os protótipos de cada grupo são atualizados calculando a média de todas as suas instâncias. A atribuição de instâncias aos agrupamentos e a atualização dos centroides continua iterativamente até que os agrupamentos se tornem estáveis. A complexidade deste algoritmo é 
aproximadamente linear, $O(N k d t)$, com $k$ sendo o número de agrupamentos, $d$ o número de dimensões e $t$ o número de iterações.

A classe de algoritmos hierárquicos pode ser dividida em duas, os aglomerativos e os divisivos (Jain e Dubes, 1988). Nos aglomerativos, cada instância é inicialmente considerada em um único grupo. A cada etapa, algoritmos aglomerativos agrupam os dois grupos mais próximos, até restar um único grupo. Os algoritmos divisivos, por outro lado, começam com todas instâncias em um único grupo e subdividem sucessivamente até todos os grupos terem uma única instância. Os algoritmos aglomerativos são mais populares, devido a menor complexidade $\left(O\left(N^{2}\right)\right.$ por passo) comparado aos métodos divisivos $\left(O\left(2^{N}\right)\right.$ por passo).

Os algoritmos aglomerativos mais conhecidos são o Single Link, Complete Link e Average Link, distintos pelo processo de atualização da matriz de distâncias em cada passo. Quando um novo grupo $C_{n e w}$ é formado pela junção de dois grupos $C_{i}$ e $C_{j}$, o algoritmo atualiza a matriz de distâncias calculando a distância de $C_{\text {new }}$ a todos os demais agrupamentos. Em um algoritmo Single Link, a distância calculada na atualização da matriz entre um grupo qualquer $C_{k}$ e o novo grupo $C_{\text {new }}$ é a menor distância possível entre uma instância pertencente a $C_{k}$ e uma pertencente a $C_{n e w}$; no algoritmo Complete Link, a distância é maior possível entre uma instância pertencente a $C_{k}$ e uma pertencente a $C_{n e w}$; e no algoritmo Average Link, é a distância média entre os pontos dos dois agrupamentos.

Na categoria de algoritmos divisivos, o Bisecting K-Means é muito popular (Savaresi e Boley, 2004). O algoritmo consiste em aplicar iterativamente o algoritmo K-Means para subdividir um grupo em dois, gerando partições aninhadas do conjunto de dados. Este processo é repetido até cada grupo ter apenas uma instância.

Nos algoritmos não relacionais de identificação de agrupamentos, o usuário deve escolher um número apropriado de grupos para particionar os dados. Um particionamento pode ser obtido tanto pela aplicação direta dos algoritmos para uma dada quantidade de grupos ou por um corte no dendograma obtido por um algoritmo hierárquico. Medidas de qualidade da estrutura de agrupamentos podem ser utilizadas para auxiliar a busca pela quantidade ideal de agrupamentos. Considerando que a única informação a respeito das instâncias são os atributos (ou seja, nenhuma informação de classe é fornecida), medidas de validação permitem comparar particionamentos obtidos por diferentes algoritmos (Vendramin et al., 2010). Três medidas bem conhecidas são (Vendramin et al., 2010): Calinski-Harabasz Index, Dunn's Index e Silhouette Width Criterion, que avaliam as partições em termos de considerações geométricas em relação a quão compactos e separados estão os agrupamentos. Estas medidas permitem avaliar múltiplas configurações de um algoritmo em particular considerando diferentes números de agrupamentos. A configuração que maximiza a medida de avaliação pode ser considerada como a melhor partição gerada por um dado algoritmo. 


\subsubsection{Técnicas relacionais}

Newman (2003) define estrutura de comunidades como uma propriedade de grafos que possuem grupos de vértices em que as instâncias de cada grupo são fortemente relacionados entre si e fracamente relacionados com instâncias de outros grupos. Existem diversas estratégias para identificar estruturas de comunidades em grafos (Rodrigues, 2007): (i) métodos espectrais analisam os autovetores de matrizes derivadas do grafo (Newman, 2006); (ii) métodos divisivos removem iterativamente as conexões entre as comunidades buscando maximizar a modularidade (Girvan e Newman, 2002; Radicchi et al., 2004); (iii) métodos aglomerativos são baseados na idéia de similaridade entre vértices da mesma comunidade (Newman, 2004; Clauset et al., 2004; Pons e Latapy, 2004; Reichardt e Bornholdt, 2006; Raghavan et al., 2007); (iv) métodos de maximização de modularidade (Duch e Arenas, 2005); e (v) métodos locais, que ignoram as informações globais do grafo (Clauset, 2005; Bagrow e Bollt, 2005).

Para avaliar a qualidade de uma divisão particular do grafo em comunidades, Newman (2003) propõe a medida de modularidade $Q$. Para um grafo dividido em $c$ comunidades é construída uma matriz $F$ de $c$ linhas e $c$ colunas, cujos elementos na diagonal principal, $f_{i i}$, fornecem a fração das conexões entre os vértices na mesma comunidade, e os elementos $f_{i j}$ representam a fração de arestas que conectam ao menos um vértice na comunidade $i$. A modularidade $Q$ é obtida pela Equação 4.2. Quando $Q=1$ o grafo já é inicialmente formado por módulos desconectados e valores altos de $Q$ são obtidos para grafos com estrutura modular definida.

$$
Q=\sum_{i}\left[f_{i i}-\left(\sum_{j} f_{i j}\right)^{2}\right]
$$

A medida de modularidade $Q$ permite que algoritmos de identificação de comunidades em grafos não necessitem previamente da quantidade de agrupamentos. A seguir, é apresentado um estudo comparativo que considera a medida $Q$ para avaliar a qualidade dos agrupamentos identificados.

\subsubsection{Estudo comparativo de técnicas relacionais e não relacionais}

A maioria das contribuições que comparam algoritmos de identificação de agrupamentos avaliam o desempenho em aplicações específicas. Jiang et al. (2004) apresentam um levantamento de algoritmos não relacionais de identificação de agrupamento em dados de expressão de gênica. Zhao e Karypis (2004) comparam diferentes usos de algoritmos de particionamento.

Na medida em que surgiram algoritmos de detecção de agrupamentos em grafos relevantes contribuições são identificadas principalmente na análise de grafos com diferentes atributos. Danon et al. (2005) comparam 16 métodos de detecção de comunidades em 
dados artificiais, analisando a precisão e o custo computacional, concluindo que o método Fast Greedy (Newman, 2004) atinge um bom compromisso entre precisão e custo. Lancichinetti e Fortunato (2009) avaliaram diversos métodos em grafos do mundo real com diferentes propriedades. O método baseado em caminhos aleatórios proposto por Rosvall e Bergstrom (2008) apresentou bom desempenho e versatilidade, podendo ser aplicado a grafos com peso e direcionalidade nas arestas.

As contribuições citadas, no entanto, avaliam exclusivamente métodos não relacionais ou métodos relacionais de identificação de agrupamento. Aqui são comparadas estratégias baseadas em grafos com as tradicionais estratégias não relacionais, com foco em quão homogêneo são os agrupamentos considerando as classes já conhecidas dos dados. Os resultados deste estudo comparativo foram apresentados no 28th Annual ACM Symposium on Applied Computing (SAC'13) no artigo intitulado Comparing relational and non-relational algorithms for clustering propositional data (Motta et al., 2013).

A avaliação foi conduzida sobre 23 conjuntos numéricos do repositório do $\mathrm{UCI}^{2}$ e 10 conjuntos de dados textuais ( 2 do UCI, 5 do projeto CLUTO $^{3}$ e 3 de um repositório da Internet $\left.^{4}\right)$. Um resumo destes conjuntos de dados é apresentado na Tabela 4.1, informando o número de instâncias, atributos e classes.

Para o estudo comparativo foram considerados algoritmos não relacionais aglomerativo hierárquicos (Single, Average e Complete Link), divisivo hierárquico (Bisecting K-Means) e particional (K-Means). Estes métodos requerem um número de grupos como entrada, e o desempenho foi medido em todos conjuntos de dados variando o número de grupos de 2 a 50. As medidas Sillhouette Coefficient, Dunn's Index e Calinski-Harabasz Index foram aplicadas para identificar a melhor estrutura de agrupamentos para cada método, gerando 15 combinações a serem comparadas.

Também foram avaliadas abordagens relacionais de identificação de agrupamentos considerando os seguintes grafos: $k N N G, k D R, P K N N G, H S N, M S T$ e EMST. Para os quatro primeiros modelos, que são paramétricos, os valores de entrada ( $k$ para os três primeiros e grau para $H S N$ ) considerados foram 3, 5, 7 e 11. Para cada grafo, foram aplicados os métodos de identificação de comunidades Fast Greedy (Newman, 2004) e Adaptive Clustering (Ye et al., 2008), e a medida de modularidade $Q$ (Newman, 2004) para identificar a melhor estrutura de agrupamentos. Portanto, com 18 grafos e 2 métodos de identificação de agrupamentos, foram produzidas 36 possíveis combinações.

A validação dos agrupamentos obtidos foi conduzida com três medidas externas de avaliação: Rand Index (Rand, 1971), Adjusted Rand Index (Hubert e Arabie, 1985) e F-Score Measure (Rijsbergen, 1979; Larsen e Aone, 1999). Estas medidas atribuem um valor para a estrutura de agrupamentos resultante de acordo com o grau de pureza, ou

\footnotetext{
${ }^{2}$ http://archive.ics.uci.edu/ml/

${ }^{3} \mathrm{http}: / /$ glaros.dtc.umn.edu/gkhome/views/cluto

${ }^{4}$ http://vicg.icmc.usp.br/infovis2/DataSets
} 
Tabela 4.1: Conjuntos de dados utilizados na avaliação experimental.

\begin{tabular}{|c|c|c|c|}
\hline dataset & \# instâncias & \# atributos & \# classes \\
\hline balance & 625 & 4 & 3 \\
\hline blood-transf. & 748 & 4 & 2 \\
\hline cleveland & 298 & 13 & 5 \\
\hline diabetes & 768 & 8 & 2 \\
\hline ecoli & 336 & 7 & 8 \\
\hline glass & 214 & 10 & 6 \\
\hline habermans & 306 & 3 & 2 \\
\hline heart-statlog & 270 & 13 & 2 \\
\hline ionosphere & 351 & 34 & 2 \\
\hline iris & 150 & 4 & 3 \\
\hline isolet & 1559 & 617 & 26 \\
\hline libras & 360 & 90 & 15 \\
\hline madelon & 600 & 500 & 2 \\
\hline mult-features & 2000 & 649 & 10 \\
\hline musk-v1 & 476 & 166 & 2 \\
\hline satimg & 500 & 36 & 6 \\
\hline sonar & 208 & 60 & 2 \\
\hline spectf & 267 & 44 & 2 \\
\hline vehicle & 846 & 18 & 4 \\
\hline vertebral & 310 & 6 & 3 \\
\hline vowels & 990 & 10 & 11 \\
\hline wine & 178 & 13 & 3 \\
\hline$z 00$ & 101 & 16 & 7 \\
\hline Amazon & 1500 & 10000 & 50 \\
\hline$C N A E-9$ & 1080 & 856 & 9 \\
\hline reo & 1504 & 2886 & 13 \\
\hline re1 & 1657 & 3758 & 25 \\
\hline $\operatorname{tr23}$ & 204 & 5832 & 6 \\
\hline $\operatorname{tr31}$ & 927 & 10128 & 7 \\
\hline $\operatorname{tr} 41$ & 878 & 7454 & 10 \\
\hline$C B R$ & 675 & 1423 & 4 \\
\hline KDViz & 1624 & 520 & 4 \\
\hline News2011 & 1771 & 3731 & 23 \\
\hline
\end{tabular}

seja, de acordo com a capacidade do método de gerar agrupamentos que representam as classes, estabelecendo uma relação direta entre agrupamentos e classes. Para viabilizar esta avaliação consideramos conjuntos de dados com classes, utilizando as instâncias de uma mesma classe como agrupamentos de forma similar a outros autores (Sedlmair et al., 2012; Klein et al., 2002; Wagstaff e Cardie, 2000).

Para facilitar a interpretação dos resultados foi efetuada uma filtragem preliminar das alternativas. Em uma análise foram comparados os resultados obtidos em cada categoria (aglomerativo hierárquico, divisivo hierárquico, particional e baseados em grafos) para 
identificar os mais representativos. Para cada categoria foi obtida a posição média no ranking para cada medida de avaliação, como mostrado na Tabela 4.2. Nas abordagens relacionais, o modelo de grafo $k N N G$ não foi considerado, pois sua principal limitação, que é possuir uma quantidade mínima de agrupamentos por possibilitar grafos desconexos, é resolvida no grafo $P K N N G$, e estes dois modelos são muito similares. Dentre os dois métodos de identificação de agrupamentos em grafos, o Adaptive Clustering é o único apresentado, pois em geral apresentou melhores resultados que o Fast Greedy.

Tabela 4.2: Comparação do rank médio de cada método de identificação de agrupamentos, separados por categoria.

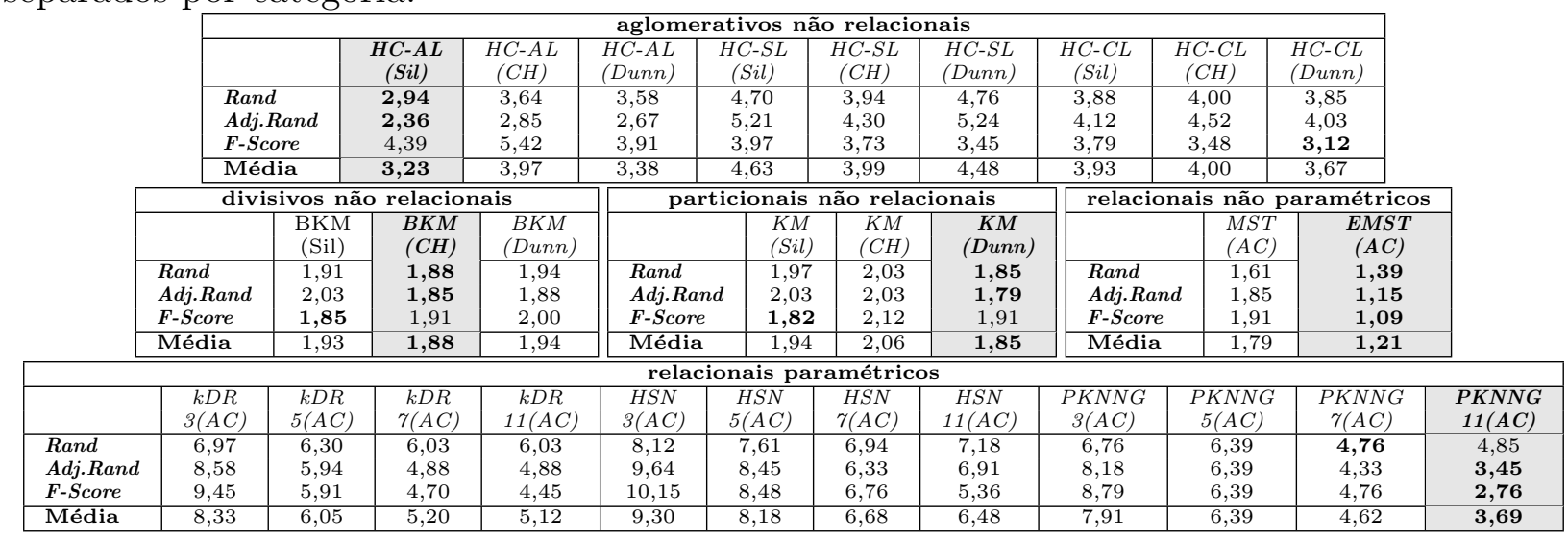

A análise aponta o Average Link como o melhor método hierárquico aglomerativo. Para este algoritmo, a partição obtida utilizando o Sillhouette Coefficient foi superior à obtida utilizando Dunn's Index e Calinski-Harabasz Index. Para o algoritmo divisivo hierárquico (Bisecting K-Means), partições obtidas utilizando Calinski-Harabasz Index apresentam os melhores resultados. Para o algoritmo particional (K-Means), partições obtidas com o Dunn's Index tiveram melhores resultados. Finalmente, o modelo de grafo PKNNG apresentou os melhores resultados para os modelos de grafos paramétricos, para $k=11$. O modelo EMST obteve melhores resultados comparado ao outro modelo não paramétrico $M S T$.

Tabela 4.3: Comparação do rank médio dos melhores métodos de identificação de agrupamentos, em cada categoria.

\begin{tabular}{|l|c|c|c|c|c|}
\hline & $\begin{array}{c}H C-A L \\
(\text { Sil })\end{array}$ & $\begin{array}{c}\text { BKM } \\
(\text { CH })\end{array}$ & $\begin{array}{c}\text { KM } \\
(\text { Dunn) }\end{array}$ & $\begin{array}{c}\text { PKNNG } \\
\text { 11(AC) }\end{array}$ & $\begin{array}{c}E M S T \\
(A C)\end{array}$ \\
\hline Rand & 3,24 & 3,85 & 3,36 & $\mathbf{2 , 0 3}$ & 2,48 \\
Adj.Rand & 3,30 & 3,88 & 3,64 & $\mathbf{1 , 7 3}$ & 2,45 \\
F-Score & 3,18 & 3,12 & 3,55 & $\mathbf{2 , 2 4}$ & 2,91 \\
\hline Média & 3,24 & 3,62 & 3,52 & $\mathbf{2 , 0 0}$ & 2,62 \\
\hline
\end{tabular}

Como resumo final, os métodos selecionados são comparados entre si: (i) $H C$-AL (Sil), indicando o aglomerativo hierárquico utilizando Average Link e a validação com base no Sillhouette Coefficient; (ii) KM (Dunn) como o método K-Means com máximo Dunn's Index; (iii) BKM (CH) como o Bisecting K-Means com máximo Calinski-Harabasz Index; 
Tabela 4.4: Resultados da comparação estatística (método na linha vs. método na coluna). Símbolos em verde indicam valores positivos da comparação estatística, em vermelho indicam valores negativos. Símbolos preenchidos indicam diferença significativa ( $p$-value menor que 0.01).

\begin{tabular}{|c|c|c|c|c|c|}
\hline & $\begin{array}{c}P K N N G \\
11(A C)\end{array}$ & $\begin{array}{c}E M S T \\
(A C)\end{array}$ & $\begin{array}{c}H C-A L \\
(S i l)\end{array}$ & $\begin{array}{c}\text { KM } \\
\text { (Dunn) }\end{array}$ & $\begin{array}{l}B K M \\
(C H)\end{array}$ \\
\hline \multicolumn{6}{|l|}{ Rand Index } \\
\hline$P K N N G 11(A C)$ & - & $\triangle$ & $\mathbf{z}$ & 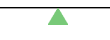 & 7 \\
\hline $\operatorname{EMST}(A C)$ & $\nabla$ & - & $\boldsymbol{\Delta}$ & $\Delta$ & $\boldsymbol{\Delta}$ \\
\hline$H C-A L(S i l)$ & $\nabla$ & $\boldsymbol{\nabla}$ & - & $\triangle$ & $\triangle$ \\
\hline$K M($ Dunn $)$ & $\boldsymbol{\nabla}$ & $\boldsymbol{\nabla}$ & $\nabla$ & - & $\triangle$ \\
\hline$B K M(C H)$ & $\nabla$ & $\nabla$ & $\nabla$ & $\nabla$ & - \\
\hline \multicolumn{6}{|c|}{ Adjusted Rand Index } \\
\hline$P K N N G 11(A C)$ & - & $\Delta$ & $\Delta$ & 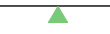 & $\Delta$ \\
\hline $\operatorname{EMST}(A C)$ & $\boldsymbol{\nabla}$ & - & $\Delta$ & $\Delta$ & $\Delta$ \\
\hline$H C-A L(S i l)$ & $\nabla$ & $\nabla$ & - & $\triangle$ & $\triangle$ \\
\hline$K M($ Dunn $)$ & $\boldsymbol{\nabla}$ & $\boldsymbol{\nabla}$ & $\nabla$ & - & $\triangle$ \\
\hline$B K M(C H)$ & $\nabla$ & $\nabla$ & $\nabla$ & $\nabla$ & - \\
\hline \multicolumn{6}{|l|}{ F-Score } \\
\hline$P K N N G 11(A C)$ & - & $\pi$ & $\triangle$ & Z & $\triangle$ \\
\hline $\operatorname{EMST}(A C)$ & $\boldsymbol{\nabla}$ & - & $\triangle$ & $\Delta$ & $\Delta$ \\
\hline$H C-A L(S i l)$ & $\nabla$ & $\nabla$ & - & $\triangle$ & $\triangle$ \\
\hline$K M($ Dunn $)$ & $\nabla$ & $\nabla$ & $\nabla$ & - & $\nabla$ \\
\hline$B K M(C H)$ & $\nabla$ & $\nabla$ & $\nabla$ & $\triangle$ & - \\
\hline
\end{tabular}

(iv) PKNNG11 (AC) como o grafo PKNNG com $k=11$ e o método Adaptive Clustering; e (v) EMST (AC) como o modelo de grafo não paramétrico.

Os métodos selecionados em cada categoria foram então comparados e os resultados são mostrados na Tabela 4.3. Métodos relacionais produziram melhores resultados, com PKNNG11 apresentando leve vantagem quando comparado ao grafo EMST. O teste pareado Wilcoxon's foi aplicado com $\alpha=0.01$ para identificar se há diferença significativa no desempenho dos algoritmos. Os resultados são dados na Tabela 4.4.

Observa-se que, em relação às medidas Rand Index and Adjusted Rand Index, métodos baseados em grafos apresentam melhores resultados com diferença estatística comparados aos métodos não relacionais. Ambas as abordagens apresentaram melhor desempenho na medida F-Score, com PKNNG (AC) apresentando alta diferença significativa. Dentre os métodos baseados em grafos, PKNNG (AC) foi superior ao método $\operatorname{EMST}(A C)$ em todas as medidas de avaliação. Quando comparados os métodos não relacionais, nenhum método predominou em relação aos demais.

Com base no estudo de identificação de vizinhanças e neste de agrupamentos vemos que o grafo EMST é o modelo de rede mais eficiente para mapeamento dos dados e eficaz na utilização para análise destas duas características. Na identificação de agrupamentos o grafo EMST teve um desempenho inferior ao $P K N N G$, mas ainda atingiu bons resultados, o que não ocorreu com o grafo $P K N N G$ aplicado à identificação de vizinhanças. 


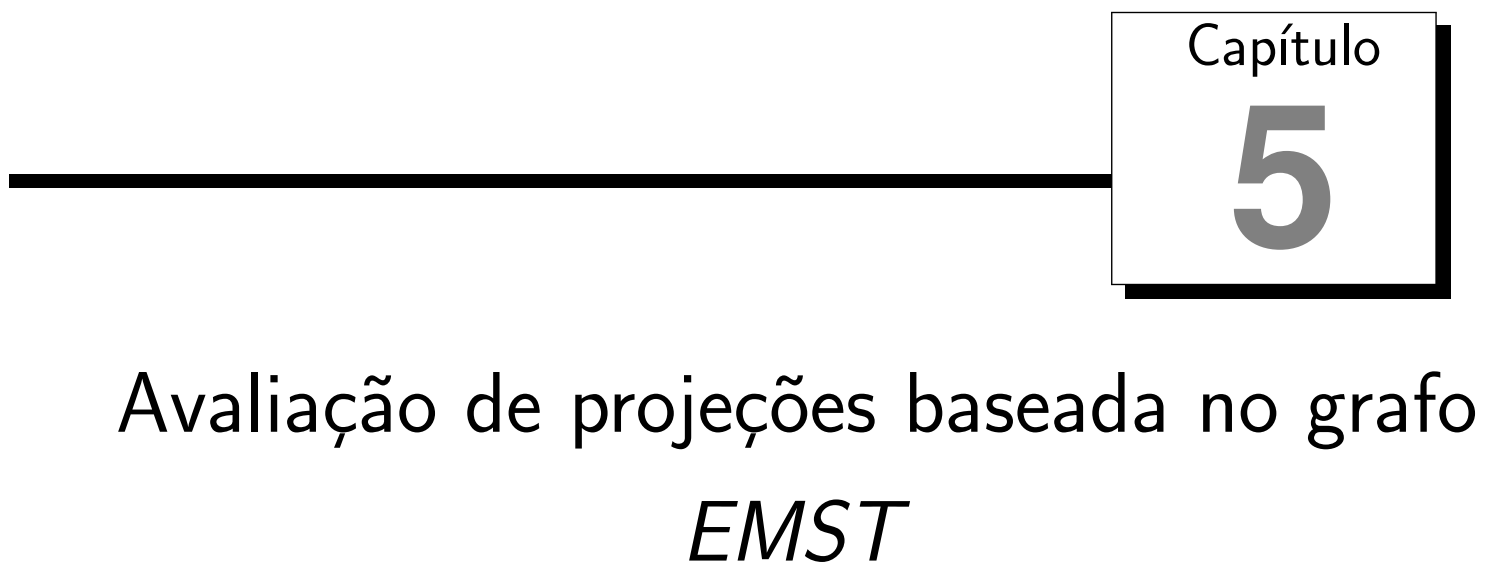

No Capítulo 2 foram apresentadas técnicas de projeção multidimensional e medidas para avaliação das projeções. As limitações das medidas existentes na literatura se dividem entre deficiências para lidar com variações nas propriedades da distribuição dos dados, como densidade, escala e formatos, e dependência de parâmetros dificilmente mensuráveis. Ainda assim, tais medidas podem ser utilizadas de forma aceitável na avaliação de projeções, porém, com um esforço considerável para analisar múltiplas propriedades, o que requer o uso combinado de diversas medidas.

Sendo assim, este projeto teve como foco principal propor um arcabouço robusto para avaliação de projeções que permita avaliar propriedades similares as que são avaliadas por técnicas existentes na literatura, bem como outras propriedades não consideradas pelas técnicas existentes.

Nos Capítulos 3 e 4 construímos um modelo apropriado a ser utilizado na avaliação de projeções. Primeiro, realizamos um estudo focado na percepção dos participantes em relação a vizinhanças e a agrupamentos. Em seguida, estudamos diferentes representações dos dados visando identificar uma representação adequada para ser utilizada em avaliação de projeções. Propusemos um modelo relacional, representado por um grafo de similaridade chamado EMST, que considera características individuais dos pontos de acordo com a região do espaço em que cada ponto se encontra para determinar a sua conectividade. Este grafo EMST apresenta alta precisão tanto na identificação das vizinhanças como na identificação de agrupamentos de pontos, como discutido nas Seções 4.2 e 4.3, respectivamente. 
Agora, neste Capítulo exploramos o grafo EMST como modelo de representação dos dados na proposta de medidas de avaliação de projeção. As medidas introduzidas se dividem em medidas de caracterização da projeção, que avaliam características independentemente do espaço original, e em medidas de preservação, que comparam propriedades das projeções com propriedades do espaço original.

\subsection{Medidas de avaliação de projeção}

As medidas se baseiam no modelo de grafo EMST e são organizadas nos dois grupos, as medidas de caracterização de projeções e as medidas de preservação de propriedades. Duas medidas são propostas para caracterização de projeção, as quais são dependentes de dados com classes (rotulados). Três medidas são propostas para avaliar a preservação de propriedades, avaliando a consistência da projeção com os dados originais. As cinco medidas são sumarizadas na Tabela 5.1 e descritas em detalhe na sequência. A Tabela 5.2 retoma algumas das notações já utilizadas e introduz outras utilizadas nas medidas propostas.

Tabela 5.1: Sumário das medidas propostas.

\begin{tabular}{lrr}
\hline Medida & requer classes & compara com o espaço original \\
\hline Class Separation & $\operatorname{sim}$ & não \\
Class Aggregation & $\operatorname{sim}$ & não \\
Class Separation Validation & $\operatorname{sim}$ & sim \\
Neighborhood Validation & não & sim \\
Group Validation & não & sim \\
\hline
\end{tabular}

As medidas são computadas ponto a ponto para considerar o comportamento local das técnicas de projeção, sendo a média de todos os pontos (ou de um subconjunto) um indicativo de qualidade global da projeção (ou de qualquer seleção arbitrária de pontos). Todas as medidas resultam em um valor entre [0-1], com altos valores indicando melhores cenários. As medidas são inicialmente ilustradas sobre os conjuntos de dados Swiss Roll e Iris, os quais são amplamente conhecidos em visualização e mineração de dados.

O Swiss Roll ${ }^{1}$ é formado por pontos gerados de uma distribuição $2 \mathrm{D}$ com quatro Gaussianas amostradas com diferentes centros, representando quatro classes. Uma distribuição 3D é obtida com o mapeamento $(x, y) \rightarrow(x \cos x, y, x \sin x)$. As Figuras 5.3 (a) e (b) ilustram ambas as distribuições com 1.600 pontos coloridos pelas classes (400 pontos por classe). O Iris $^{2}$, já introduzido, contém 150 instâncias de 3 classes, descritas por

\footnotetext{
${ }^{1}$ http://people.cs.uchicago.edu/ $\operatorname{dinoj} /$ manifold/swissroll.html

${ }^{2}$ http://archive.ics.uci.edu/ml/datasets/Iris
} 
Tabela 5.2: Notação

\begin{tabular}{lr}
\hline$p_{i}$ & $i$-ésima instância ou ponto $\left(x_{i}\right.$ em $R^{m}$ ou $y_{i}$ em $\left.R^{2}\right)$ \\
\hline$L$ & número de classes \\
\hline$l$ & uma classe particular \\
\hline$l\left(p_{i}\right)$ & classe de $p_{i}$ \\
\hline$|S|$ & número de elementos de um conjunto $S$ \\
\hline$v_{i}$ & vértice representando $p_{i}$ no grafo \\
\hline$\left(v_{i}, v_{j}, w_{i j}\right)$ & aresta com peso conectando os vértices $v_{i}$ e $v_{j}$ \\
\hline$N_{i}^{G}=\left\{v_{j} \mid\left(v_{i}, v_{j}\right) \in A\right\}$ & conjunto de vizinhos de $p_{i}$ no grafo $E M S T(V, A)$ \\
\hline$N_{i, l}^{G}$ & conjunto de vizinhos de $p_{i}$ (no grafo $\left.G\right)$ com classe $l$ \\
\hline$E M S T^{R^{2}}$ & grafo EMST construído dos dados projetados em $R^{2}$ \\
\hline$E M S T^{R^{m}}$ & grafo EMST construído dos dados em $R^{m}$ \\
\hline$\left\langle w^{A}\right\rangle$ & peso médio das arestas do grafo $\mathrm{G}(\mathrm{V}, \mathrm{A})$ \\
\hline$w_{i j}^{G}$ & peso da aresta conectando $v_{i}$ e $v_{j}$ no grafo $\mathrm{G}$ \\
\hline$C_{i}^{R^{2}}$ & agrupamento bidimensional no qual $p_{i} \in C_{i}^{R^{2}}$ \\
\hline$C_{i}^{R^{m}}$ & agrupamento $m$-dimensional no qual $p_{i} \in C_{i}^{R^{m}}$ \\
\hline
\end{tabular}

4 atributos. Os atributossepal length e sepal width são utilizados no mapeamento 2D mostrado.

\subsubsection{Medidas de caracterização de projeções}

Medidas de caracterização de projeções focam principalmente na análise de desordem visual, para apresentar ao usuário uma distribuição menos sobrecarregada, e na análise de separação visual das classes, para facilitar a exploração de dados com um mesmo rótulo. Neste trabalho, propomos duas medidas com foco na separação visual das classes, definidas como Class Separation e Class Aggregation.

As medidas propostas permitem comparar vários mapeamentos em relação à sua capacidade de transmitir uma dada distribuição de classes. Ambas buscam quantificar a eficácia de uma projeção em transmitir a distribuição de classes em termos de pureza e da segregação, com base na vizinhança de cada ponto $p_{i}$ com classe $l$ no grafo EMST construído com base nos dados projetados.

A medida Class Separation quantifica a pureza da vizinhança local de um dado ponto, e a medida Class Aggregation quantifica a agregação visual de pontos de uma mesma classe. Dessa forma, a principal diferença entre estas medidas é o fato da primeira fazer uma verificação local, e a segunda avaliar de forma mais global a agregação de pontos de uma mesma classe, penalizando os pontos pertencentes às classes que foram separadas em diferentes regiões na projeção.

Para calcular as medidas, primeiramente são definidas duas funções $\sigma$ e $\gamma$, como segue: dado $v_{j} \in N_{i}^{E M S T}$, então $\sigma\left(v_{i}, v_{j}\right)=1$ se ambos $p_{i}$ e $p_{j}$ são da mesma classe, caso contrário $\sigma\left(v_{i}, v_{j}\right)=0 ; \gamma\left(v_{i}, v_{j}\right)=1$ se há um caminho para $v_{j}$ de $v_{i}$ passando somente por arestas 
$\left(v_{a}, v_{b}\right)$ em que $\sigma\left(v_{a}, v_{b}\right)=1$, e caso contrário $\gamma\left(v_{i}, v_{j}\right)=0$.

A Class Separation de um ponto $p_{i}$ é definida pela Equação 5.1, como a porcentagem de seus vizinhos (adjacentes na $E M S T$ ) que também são da classe $l$. Altos valores indicam que $p_{i}$ está cercado majoritariamente por pontos da mesma classe, baixos valores indicam uma vizinhança com mistura de classes.

$$
\operatorname{class\_ separation}\left(p_{i}\right)=\frac{1}{\left|N_{i}^{E M S T}\right|} \sum_{j}^{N_{i}^{E M S T}} \sigma\left(v_{i}, v_{j}\right)
$$

A Class Aggregation, computada pela Equação 5.2, mede a agregação visual de pontos de uma classe particular. Os valores mais altos indicam que a classe está mais agrupada, enquanto os valores mais baixos indicam um maior espalhamento da classe pela projeção.

$$
\operatorname{class\_ aggregation}\left(p_{i}\right)=\frac{\sum_{j}^{N} \sigma\left(v_{i}, v_{j}\right) \cdot \gamma\left(v_{i}, v_{j}\right)}{\sum_{j}^{N} \sigma\left(v_{i}, v_{j}\right)}
$$

A Figura 5.1 mostra em (a) as classes do Swiss Roll em 2D, com as medidas Class Separation e Class Aggregation correspondentes a cada ponto mapeadas na projeção em (b) e (c), respectivamente. Nesta e nas figuras seguintes adotou-se a escala de cores $\mathrm{He}$ ated Objects (Levkowitz, 1997), na qual cores escuras indicam altos valores. Os números mostrados nas imagens refletem o valor global da medida correspondente (referente à projeção). Como a separação de classes é boa, ambas as medidas mostram um comportamento similar, com menores valores em geral próximos a fronteiras das classes. Ainda assim, alguns pontos nas bordas tem alto valor de Class Separation e baixo valor de Class Aggregation, fato que ocorre quando um ponto tem a maioria dos vizinhos de sua própria classe, mas não foi bem agrupado com os demais pontos da sua classe.

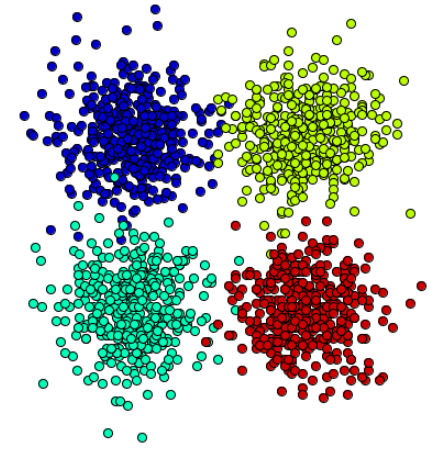

(a)

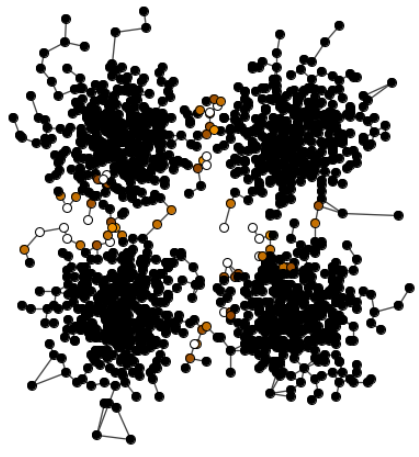

(b) 0.98

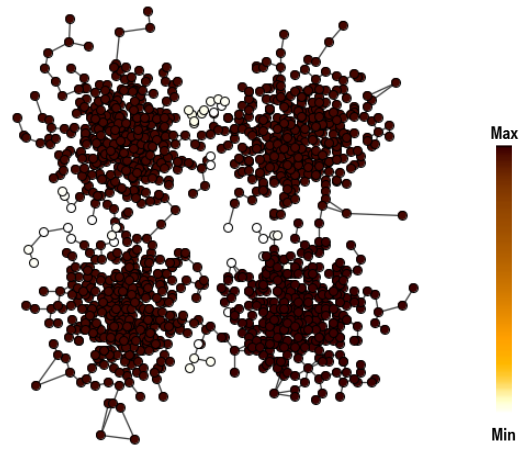

(c) 0.92

Figura 5.1: Representação 2D do Swiss Roll: (a) quatro classes dos dados; (b) Class Separation; e (c) Class Aggregation mapeados com a escala de cores Heated Objects (cores escuras indicam valores maiores). 
O mapeamento das medidas Class Separation e Class Aggregation para o Iris é mostrado na Figura 5.2. Observe que em ambos os casos os pontos da classe mais separada (cor rosa) têm altos valores. A visualização $2 \mathrm{D}$ realmente segrega esta classe das outras duas. Valores da medida Class Aggregation são visivelmente menores para as classes cinza e verde, as quais não estão bem agrupadas.

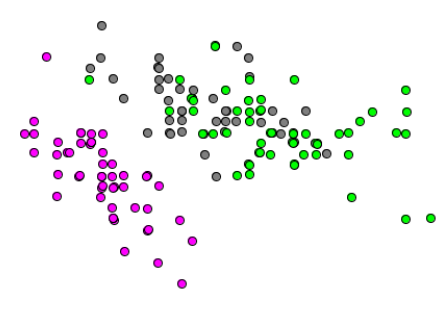

(a)

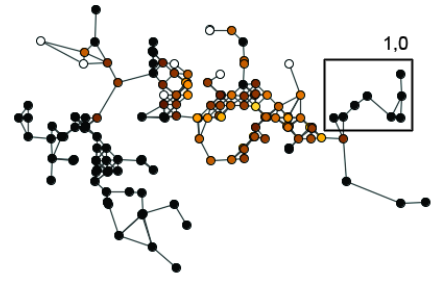

(b) 0.73

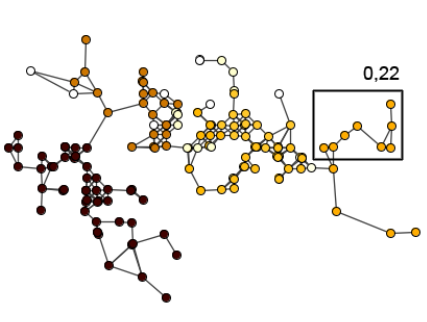

(c) 0.46

Figura 5.2: Representação 2D do Iris (a) três classes dos dados; (b) Class Separation e (c) Class Aggregation mapeados com a escala de cores Heated Objects (cores escuras indicam valores maiores).

Ainda na Figura 5.2 observa-se a diferença entre as medidas Class Separation e Class Aggregation nos aspectos local e global. Para os pontos mais a direita vemos alta pureza local, resultando em um valor de Class Separation igual a 1, mas de modo geral a classe verde não foi visualmente separada da classe cinza, resultando em um valor baixo de Class Aggregation, igual a 0,22 .

\subsubsection{Medidas de preservação de propriedades dos dados}

Medidas de preservação avaliam o quanto uma projeção preserva uma determinada propriedade de interesse, ou seja, o quanto ela transmite uma imagem fiel dos dados em $R^{m}$ relativamente a uma determinada propriedade. Pelo fato dos usuários efetuarem uma exploração visual baseada principalmente em proximidade entre pontos e agrupamentos, as medidas propostas neste contexto em geral visam avaliar a preservação destas duas propriedades.

Propomos medidas para avaliar a preservação de propriedades de vizinhança, classe e estrutura de agrupamentos, todas com base também na rede EMST, mas desta vez computada no espaço da projeção $\left(E M S T^{R^{2}}\right)$ e no espaço original $\left(E M S T^{R^{m}}\right)$. Os grafos gerados para os dois espaços dos dados são comparados para capturar se (i) uma propriedade observada na projeção está consistente com o espaço original, a qual é chamada de precisão (precision), e se (ii) propriedades observadas em $R^{m}$ foram mapeadas na projeção, chamada de cobertura (recall). O uso deste termos está consistente com os empregados por Venna et al. (2010), que utilizaram o mesmo conceito na avaliação de preservação de vizinhanças. 
Precisão e cobertura são definidos, respectivamente, como $\frac{T P}{T P+F P}$ e $\frac{T P}{T P+F N}$, sendo $T P$ o número de verdadeiros positivos (true positives), FP o número de falsos positivos (false positives) e $F N$ o número de falsos negativos (false negatives). Os significados específicos de TP, FP e FN para cada medida dependem da propriedade a ser avaliada, e serão descritos em detalhes a seguir. A precisão e a cobertura podem ser consideradas diretamente como medidas de qualidade ou combinadas em uma única medida F-measure (Rijsbergen, 1979), como na Equação 5.3. Embora elas sejam ponderadas igualmente na Equação 5.3, outras ponderações podem ser consideradas.

$$
F-\text { measure }=\frac{2 \cdot \text { precisão } \cdot \text { cobertura }}{\text { precisão }+ \text { cobertura }}
$$

O cálculo da precisão e da cobertura é definido para cada medida a fim de obter os valores de cada ponto para as três medidas de preservação, nomeadas Class Separation Validation, Neighborhood Validation e Group Validation. A primeira medida é aplicável a dados rotulados, enquantos as demais não utilizam informação de classe. As medidas são novamente ilustradas com base no Swiss Roll, considerando o mapeamento 2D como uma "projeção" do mapeamento 3D.

A medida Class Separation Validation quantifica a "pureza da vizinhança" segundo as classes, ou seja, a composição das classes nas vizinhanças dos pontos. O objetivo é verificar se a "pureza" de um ponto na vizinhança observada na projeção é consistente com a do espaço original, com precisão e cobertura sendo computados segundo a Equação 5.4.

Para computar a precisão, o denominador $T P+F P$ indica todos os "positivos" na projeção, que neste caso é a fração de pontos na vizinhança de $p_{i}$ na projeção que tem a mesma classe de $p_{i}$, a qual chamaremos de fração $f_{2}$. De forma análoga, tendo $f_{m}$ como a fração de instâncias na vizinhança de $p_{i}$ no espaço original que tem a mesma classe de $p_{i}$, obtém-se o valor dos verdadeiros positivos $T P$ como o mínimo entre $f_{2}$ e $f_{m}$. Isso porque, se $f_{2}<f_{m}$ então toda fração de pontos da mesma classe na vizinhança na projeção está contida na fração do espaço original, e portanto $T P=f_{2}$ e $F N=f_{m}-f_{2}$, e, caso contrário, toda fração de instâncias da mesma classe no espaço original está contida na fração da projeção, e portanto $T P=f_{m}$ e $F P=f_{2}-f_{m}$. De forma similar é possível computar a cobertura, na qual o denominador $T P+F N$ indica todos os "positivos" no espaço original, sendo os capturados pela projeção $(T P)$ e os não capturados $(F N)$. 


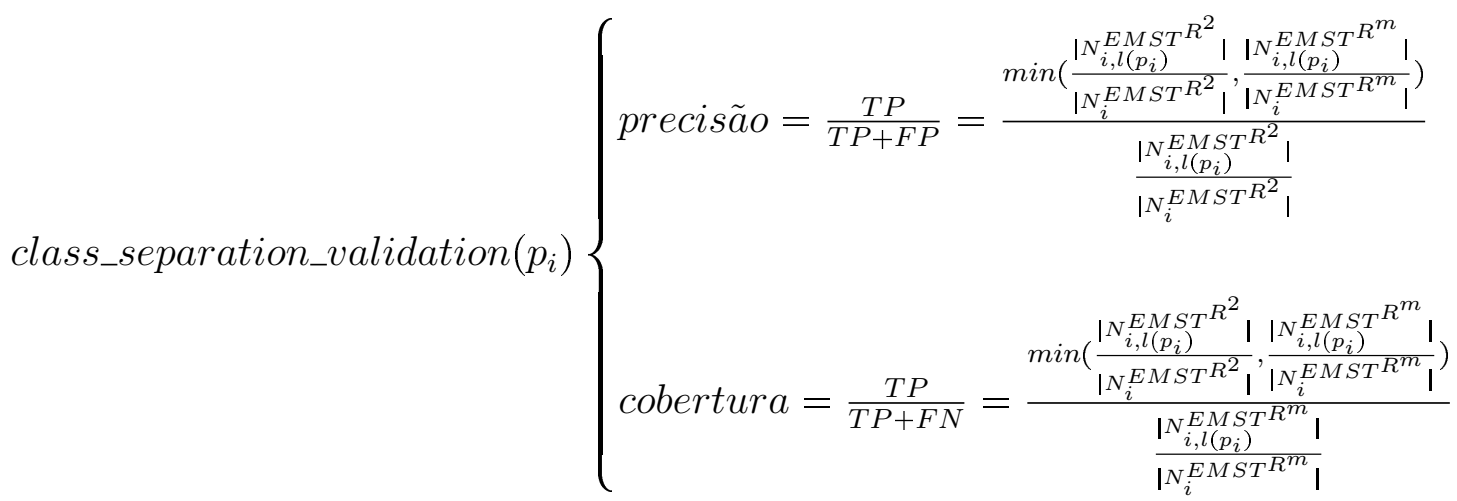

A Figura 5.3 ilustra o mapeamento da medida Class Separation Validation para cada ponto nas distribuições 2D e 3D do Swiss Roll. O mapeamento na distribuição 2D indica que vizinhos da mesma classe são, em sua maioria, muito bem preservados. A preservação é ruim em alguns pontos localizados nas fronteiras de classes, mas é esperado já que em (b) podemos ver que os pontos de fronteira realmente têm vizinhança de classes misturadas em 3D.

Seguindo o mesmo raciocínio, a medida Neighborhood Validation avalia o quanto a projeção preserva a vizinhança original de um ponto $p_{i}$, independente da classe. Precisão e cobertura são computadas pela Equação 5.5 e combinadas em uma F-Measure de Neighborhood Validation. Um ponto tem alto valor de precisão quando a maioria de seus vizinhos na projeção coincide com seus vizinhos no espaço original. A cobertura é alta se a maioria dos vizinhos do espaço original está na vizinhança da projeção.

Portanto, o valor de TP para a medida Neighborhood Validation representa quantos pontos coincidem na vizinhança de $p_{i}$ na projeção e no espaço original, calculado pela intersecção entre os conjuntos formados pelos vizinhos de $p_{i}$ em cada espaço. O valor de $T P+F P$ refere-se a todos os "positivos" de $p_{i}$ na projeção, ou seja, é o tamanho da vizinhança de $p_{i}$ na projeção. E o valor de $T P+F N$ refere-se ao número de "positivos" de $p_{i}$ no espaço original, ou seja, o tamanho da vizinhança de $p_{i}$ no espaço original.

$$
\text { neighborhood_validation }\left(p_{i}\right)\left\{\begin{array}{l}
\text { precisã } O=\frac{T P}{T P+F P}=\frac{\left|N_{i}^{E M S T^{R^{2}}} \cap N_{i}^{E M S T^{R^{m}}}\right|}{\left|N_{i}^{E M S T} R^{2}\right|} \\
\text { cobertura }=\frac{T P}{T P+F N}=\frac{\left|N_{i}^{E M S T^{R^{2}}} \cap N_{i}^{E M S T^{R^{m}}}\right|}{\left|N_{i}^{E M S T^{m}}\right|}
\end{array}\right.
$$

Os valores da medida Neighborhood Validation para o Swiss Roll são mostrados na Figura 5.4, com (a) e (b) mostrando o mapeamento de cores nas distribuições 2D e 3D, respectivamente. Observe que baixos valores ocorrem nas fronteiras de classes e nas extremidades das distribuições Gaussianas. Figura (c) mostra, à esquerda, a distribuição 2D 


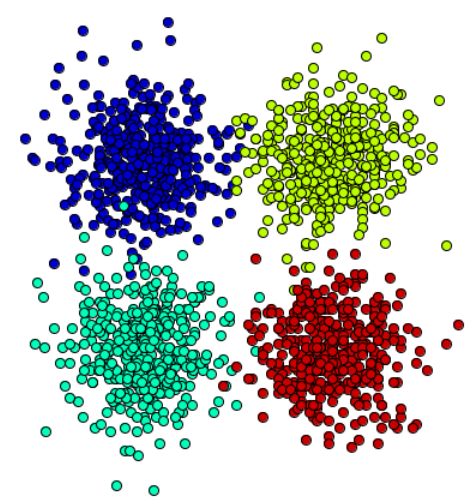

(a)

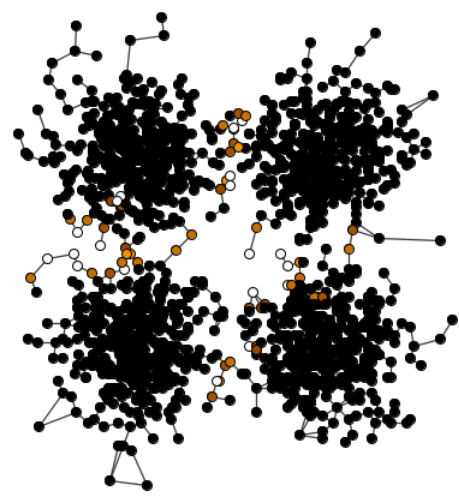

(c) 0.98

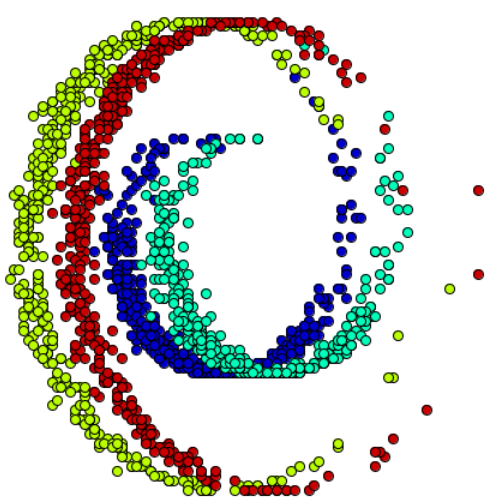

(b)

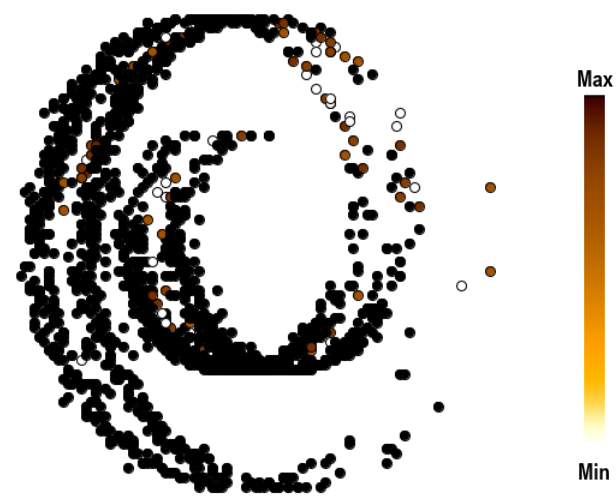

(d)

Figura 5.3: Swiss Roll: distribuições (a) 2D e (b) 3D com as cores mapeando as 4 classes. A medida Class Separation Validation é mapeada em cores para as distribuições (c) 2D e (d) 3D (na escala Heated Objects, com cores escuras indicam valores maiores).

com dois pontos destacados (círculos vermelhos), os quais têm Neighborhood Validation iguais a 0 (ponto branco) e 1 (ponto preto). Os mesmos pontos e seus respectivos adjacentes no grafo $E M S T$ são destacados na distribuição 3D, à direita, com seus correspondentes vizinhos mostrados em marrom.

É possível observar que os dois vizinhos do ponto preto são realmente vizinhos na distribuição 3D, os pontos estão próximos na distribuição 3D e se mantém próximos na distribuição 2D. Com comportamento oposto, o ponto branco, ilustrado mais abaixo na distribuição 3D, teve pontos distantes dele mapeados próximos em 2D, resultando em um baixo valor de Neighborhood Validation.

A terceira medida proposta de preservação de propriedades é relativa à preservação de agrupamentos, chamada de Group Validation. Uma medida de validação de agrupamentos percebidos é potencialmente valiosa, considerando que a detecção e exploração de grupos de pontos similares é uma tarefa usual na análise de dados baseada em projeções. Para evitarmos comportamentos tendenciosos de algoritmos de identificação de agrupamentos, 


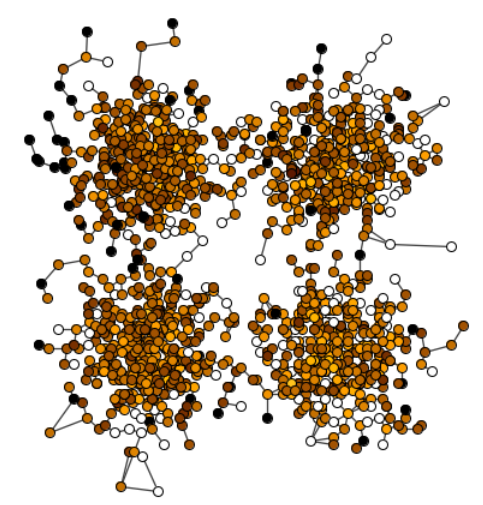

(a)

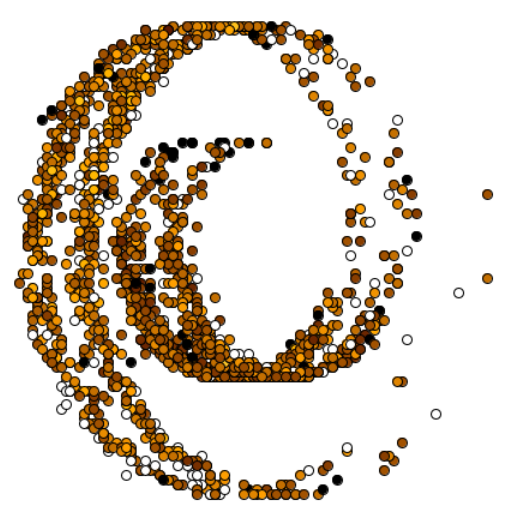

(b) 0.51

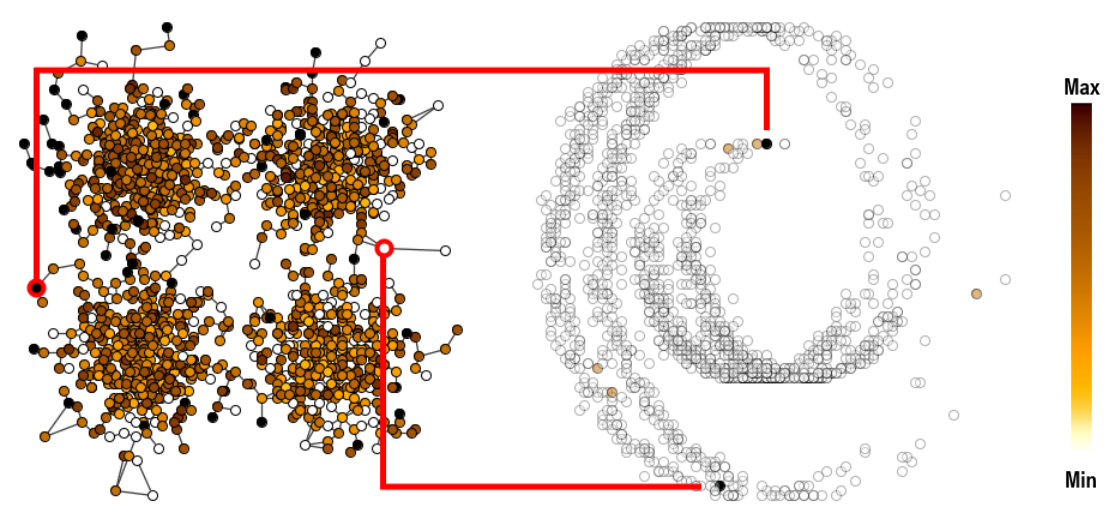

(c)

Figura 5.4: Swiss Roll: distribuições (a) 2D e (b) 3D com as cores mapeando a medida Neighborhood Validation. (c) mostra (esquerda) dois pontos destacados na distribuição 2D, um com máxima (preto) e outro com mínimo (branco) preservação, e (direita) ambos os pontos na distribuição 3D com seus correspondentes vizinhos (escala de cores Heated Objects, na qual cores escuras indicam valores maiores).

ao invés de tomar como referência um modelo de agrupamento extraído por um algoritmo, utilizamos os grupos identificados nos espaços original e projetado como referências relativas para verificar a capacidade da projeção de reter e transmitir grupos de instâncias semelhantes em $R^{m}$.

Os agrupamentos são extraídos dos grafos EMST computados na projeção $\left(E M S T^{R^{2}}\right)$ e no espaço original ( $E M S T^{R^{m}}$ ) com o algoritmo relacional Adaptive Clustering $(A C)$ (Ye et al., 2008). Para determinar o número "ideal" de agrupamentos a extrair o algoritmo busca uma solução que maximize as arestas internas nos agrupamentos e minimize as arestas entre vértices em diferentes grupos. Algoritmos relacionais de identificação de agrupamentos não são afetados pelo formato ou densidade dos dados, e dependem apenas do modelo de grafo. Na Seção 4.3 observamos que o algoritmo $A C$ mostrou-se uma escolha robusta, após comparar técnicas relacionais e não relacionais de identificação de agrupamentos, sendo que as técnicas relacionais desempenharam melhor. Em particular 
o algoritmo $A C$ aplicado ao grafo EMST apresentou ótimos resultados, com a vantagem da rede EMST ser um modelo não paramétrico.

Para computar a medida Group Validation é verificado (i) se a distância média, computada em $R^{m}$, entre os pontos de um grupo $C_{i}^{R^{2}}$ é realmente menor do que a distância média entre os pontos externos ao agrupamento (precisão); e (ii) se a distância média, computada em $R^{2}$, entre os pontos de um grupo $C_{i}^{R^{m}}$ é realmente menor do que a distância média entre os pontos externos ao agrupamento (cobertura).

A precisão de um ponto $p_{i} \in C_{i}^{R^{2}}$ é computada como descrito na Equação 5.6. O valor da precisão é alto quando os agrupamentos $C_{i}^{R^{2}}$ são realmente formados por pontos que estão próximos em $R^{m}$, ou seja, que são mais similares entre si, comparados aos demais. A cobertura é computada analogamente. Altos valores de cobertura indicam boa preservação da estrutura de agrupamentos do espaço original, ou seja, os pontos de um grupo $C_{i}^{R^{m}}$ foram projetados mais próximos entre si, comparativamente aos pontos externos ao agrupamento.

$$
\text { group_validation }\left(p_{i}\right)\left\{\begin{array}{l}
\text { precisão }=\frac{T P}{T P+F P}=\frac{\frac{1}{\left|R_{i}^{R^{2}}\right|} \sum_{p_{j}}^{C^{R^{2}}} \delta\left(p_{i}, p_{j}\right)}{\frac{1}{N} \sum_{p_{k}}^{N} \delta\left(p_{j}, p_{k}\right)}=\frac{N \sum_{p_{j}}^{C^{R^{2}}} \delta\left(p_{i}, p_{j}\right)}{\left|C_{i}^{R^{2}}\right| \sum_{p_{k}}^{N} \delta\left(p_{j}, p_{k}\right)} \\
\text { cobertura }=\frac{T P}{T P+F N}=\frac{\frac{1}{\left|C_{i}^{R^{m}}\right|} \sum_{p_{j}}^{C_{i}^{R^{m}}} d\left(p_{i}, p_{j}\right)}{\frac{1}{N} \sum_{p_{k}}^{N} d\left(p_{j}, p_{k}\right)}=\frac{N \sum_{p_{j}}^{C_{i}^{R^{m}}} d\left(p_{i}, p_{j}\right)}{\left|C_{i}^{R^{m}}\right| \sum_{p_{k}}^{N} d\left(p_{j}, p_{k}\right)}
\end{array}\right.
$$

Os valores da medida Group Validation para o Swiss Roll são mostrados na Figura 5.5 (a) e (b). A Figura (c) apresenta (a) com dois agrupamentos destacados, e (d) apresenta estes agrupamentos na distribuição 3D.

Os valores são maiores no grupo superior na Figura (c), mostrados em preto na Figura (d). O grupo mais abaixo tem pontos com valores menores e é mostrado em marrom na Figura (d). Observe que o primeiro, que apresenta boa preservação, é realmente muito coeso em 3D, enquanto o segundo, com baixa preservação, não é realmente um agrupamento quando observado em 3D.

A seguir, as duas medidas propostas de caracterização de projeções e as três de preservação de propriedades são aplicadas em projeções de conjuntos de dados reais, e são discutidas detalhadamente. Por fim, apresentamos uma comparação entre a medida proposta de preservação de vizinhança, a Neighborhood Validation, e medidas da literatura para o mesmo fim. 


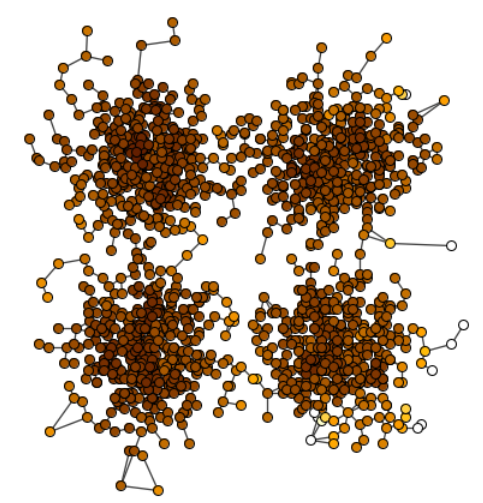

(a)

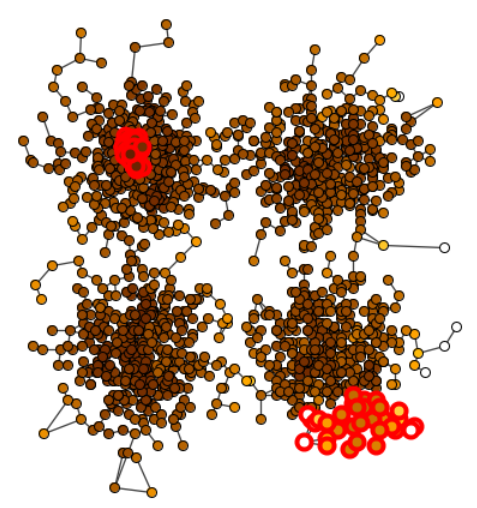

(c)

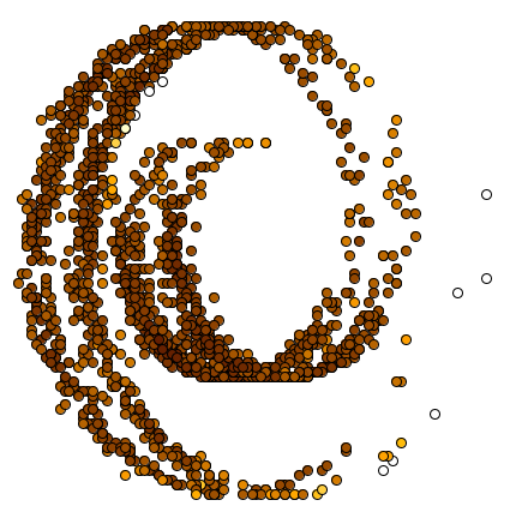

(b) 0.73

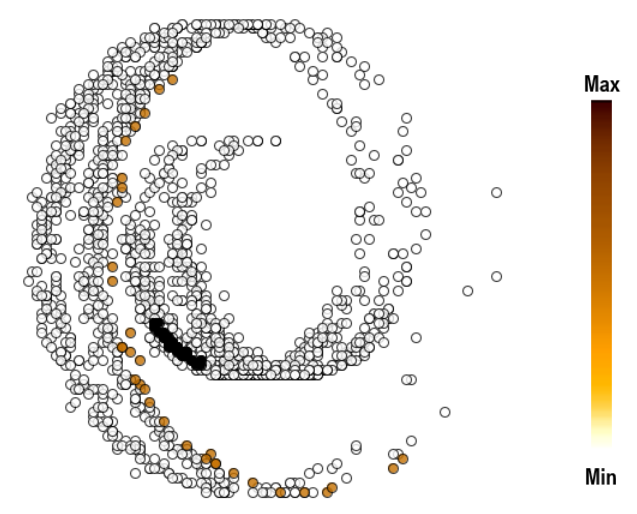

(d)

Figura 5.5: Swiss Roll: distribuição (a) 2D e (b) 3D com mapeamento em cores da medida Group Validation; em (c) dois grupos são destacados, com alta e baixa preservação; em (d) ambos os agrupamentos são mostrados em 3D (pontos pretos são do grupo superior e pontos marrons do grupo inferior).

\subsection{Avaliação das medidas propostas}

Nesta Seção, a aplicabilidade de cada medida proposta é discutida analisando quatro projeções de dois conjuntos de dados sumarizados na Tabela 5.3.

Os conjuntos de dados são nomeados Optical Recognition of Handwritten Digits (Optdigits) do repositório $\mathrm{UCI}^{3}$, o qual contém ocorrências de dígitos de 0 a 9 manuscritos, e News2011, uma coleção de $R S S$ feeds coletados de diversos provedores de notícias (AP, $C N N$, Reuters e $B B C$ ) durante 4 semanas em junho e julho de 2011 e rotulados manualmente de acordo com o assunto (Roman et al., 2013).

O News2011 é descrito por um vetor de 834 termos e é altamente desbalanceado, como detalhado na Tabela 5.3. Um classificador $K N N(\operatorname{com} k=3)$ com validação cruzada 10fold gerou uma classificação com alta precisão (91,8\%), o que sugere que as classes estão

${ }^{3}$ UCI KDD Archive, http://archive.ics.uci.edu/ml/datasets/Optical+Recognition+of +Handwritten+Digits 
Tabela 5.3: Conjuntos de dados.

\begin{tabular}{rrrrrr}
\hline \hline Nome & Conteúdo & Classes & \#Instâncias & \#Atributos & Dissimilaridade \\
\hline Optdigits & dígitos manuscritos (conjunto de teste) & 10 & 1.797 & 64 & Euclidiana \\
News2011 & RSS news feeds & 23 & 1.771 & 834 & Cosseno \\
\hline \hline & \multicolumn{4}{c}{ Optdigits: 10 classes balanceadas } \\
& & menor contendo 9,7\% e maior com 10,2\% das instâncias. \\
\hline & & News2011 23 classes desbalanceadas \\
& & menor contendo 0,7\% e maior com 19,0\% das instâncias. \\
\hline \hline
\end{tabular}

bem formadas, uma propriedade que deve ser refletida em uma boa projeção. No Optidigits as instâncias são dígitos de 0 a 9 descritos por bitmaps 8x8, nas quais os dígitos diferem as classes, que são balanceadas, como mostrado na Tabela 5.3. A Tabela 5.4 mostra a matriz de confusão resultante após executar o classificador $K N N \operatorname{com} k=3$, o qual atingiu uma precisão de 86,7\%: observe que os dígitos 8 e 2 foram frequentemente classificados erradamente como 1, assim como 8 e 9 são também frequentemente classificados como 3. Uma matriz de distâncias entre as instâncias em $R^{m}$ é mostrada a esquerda da Tabela 5.4. Para todos os conjuntos de dados assumimos que as medidas de dissimilaridade usadas refletem bem as relações de distância entre os pares de instâncias no espaço original, mas é possível que outras medidas produzam melhores resultados.

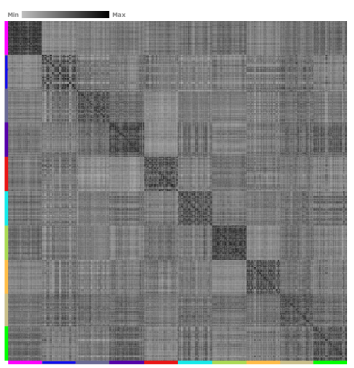

\begin{tabular}{ccccccccccc}
\hline 0 & 1 & 2 & 3 & 4 & 5 & 6 & 7 & 8 & 9 & $\leftarrow$ classificados como \\
\hline 173 & 1 & 0 & 0 & 1 & 1 & 2 & 0 & 0 & 0 & classe 0 \\
0 & 182 & 0 & 0 & 0 & 0 & 0 & 0 & 0 & 0 & classe 1 \\
0 & 22 & 152 & 1 & 0 & 0 & 0 & 1 & 1 & 0 & classe 2 \\
0 & 10 & 3 & 159 & 0 & 4 & 0 & 3 & 0 & 4 & classe 3 \\
0 & 11 & 0 & 0 & 168 & 0 & 0 & 2 & 0 & 0 & classe 4 \\
2 & 7 & 0 & 5 & 2 & 162 & 1 & 1 & 0 & 2 & classe 5 \\
1 & 4 & 0 & 0 & 1 & 0 & 175 & 0 & 0 & 0 & classe 6 \\
0 & 5 & 1 & 0 & 1 & 0 & 0 & 172 & 0 & 0 & classe 7 \\
0 & 66 & 2 & 20 & 1 & 5 & 3 & 3 & 71 & 3 & classe 8 \\
1 & 9 & 0 & 18 & 0 & 4 & 0 & 2 & 2 & 144 & classe 9 \\
\hline
\end{tabular}

Tabela 5.4: Matriz de distâncias organizadas por classes e matriz de confusão para o conjunto de dados Optdigits.

Geramos projeções com quatro técnicas de projeção, duas clássicas e duas recentes. O critério de seleção visou técnicas caracterizadas por adotarem abordagens distintas no mapeamento dos pontos e suficientes para nosso objetivo de ilustrar o potencial das medidas de avaliação propostas. As técnicas selecionadas são Principal Component Analysis (PCA) (Jolliffe, 2002), Sammon's Mapping (Sammon, 1969), Least Square Projection (LSP) (Paulovich et al., 2008) e t-Distributed Stochastic Neighbor Embedding ( $t$ SNE) (van der Maaten e Hinton, 2008).

Foram utilizadas implementações próprias dos métodos PCA, LSP e Sammon's Mapping, e a implementação da $t$-SNE fornecida pelos autores ${ }^{4}$. Na $P C A$ foram considerados os dois primeiros componentes principais como as dimensões da projeção. O Sammon's Mapping foi executado com a configuração padrão de 1.797 iterações e fator mágico 0,3. A

\footnotetext{
${ }^{4}$ http://homepage.tudelft.nl/19j49/t-SNE.html
} 
t-SNE também foi executada com as configurações padrão, definidas com valor perplexity igual a 30 e considerando os primeiros 30 componentes principais da $P C A$ para a redução de dimensionalidade inicial. A $L S P$ também foi executada com os valores de parâmetros sugeridos como padrão, com número de pontos de controle igual a $10 \%$ dos pontos (179 para Optdigits e 177 para News2011) e tamanho da vizinhança igual a 15 (Paulovich et al., 2008).

As Tabelas 5.5 e 5.6 apresentam as projeções e as três medidas dependentes da classe, Class Separation, Class Aggregation e Class Separation Validation. Na primeira linha os pontos são coloridos de acordo com a classe, e nas demais linhas as cores mapeiam as três medidas propostas. Nas Tabelas 5.7 e 5.8 são apresentadas as projeções com as cores mapeando as medidas de preservação de vizinhança e de agrupamentos, a Neighborhood Validation e a Group Validation. Cada célula também mostra o valor da medida relativa à projeção, com os valores de precisão e cobertura entre parênteses. Em seguida analisamos os resultados, replicando algumas figuras por clareza e conveniência.

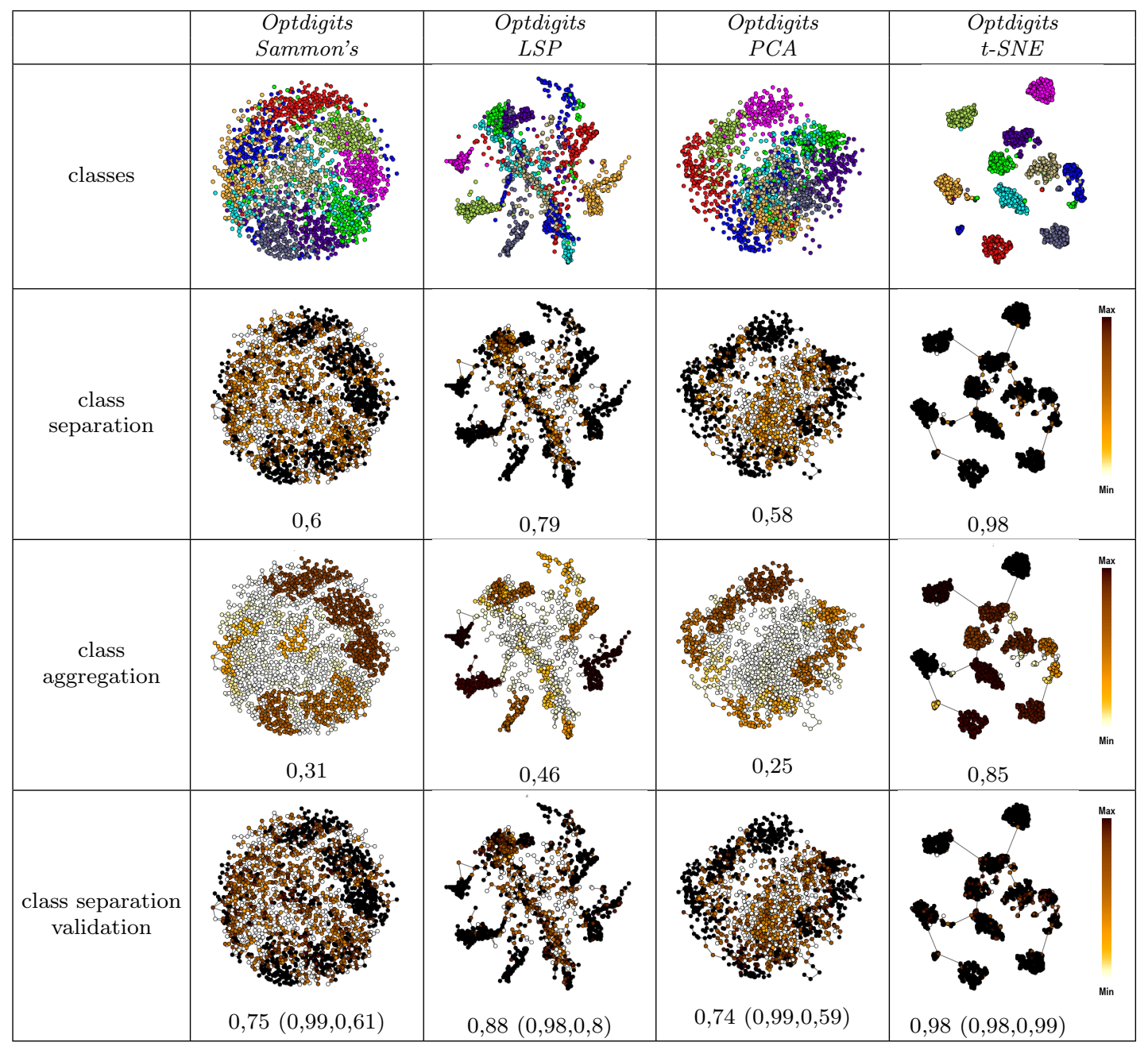

Tabela 5.5: Projeções do Optdigits. Na linha 1, com os pontos coloridos por classe, e nas linhas 2, 3 e 4 coloridos de acordo com a medida proposta. O mapeamento de cores para as medidas segue a escala de cores Heated Objects (quanto mais escuro, melhor). Cada célula mostra também o valor médio referente à medida em questão. 


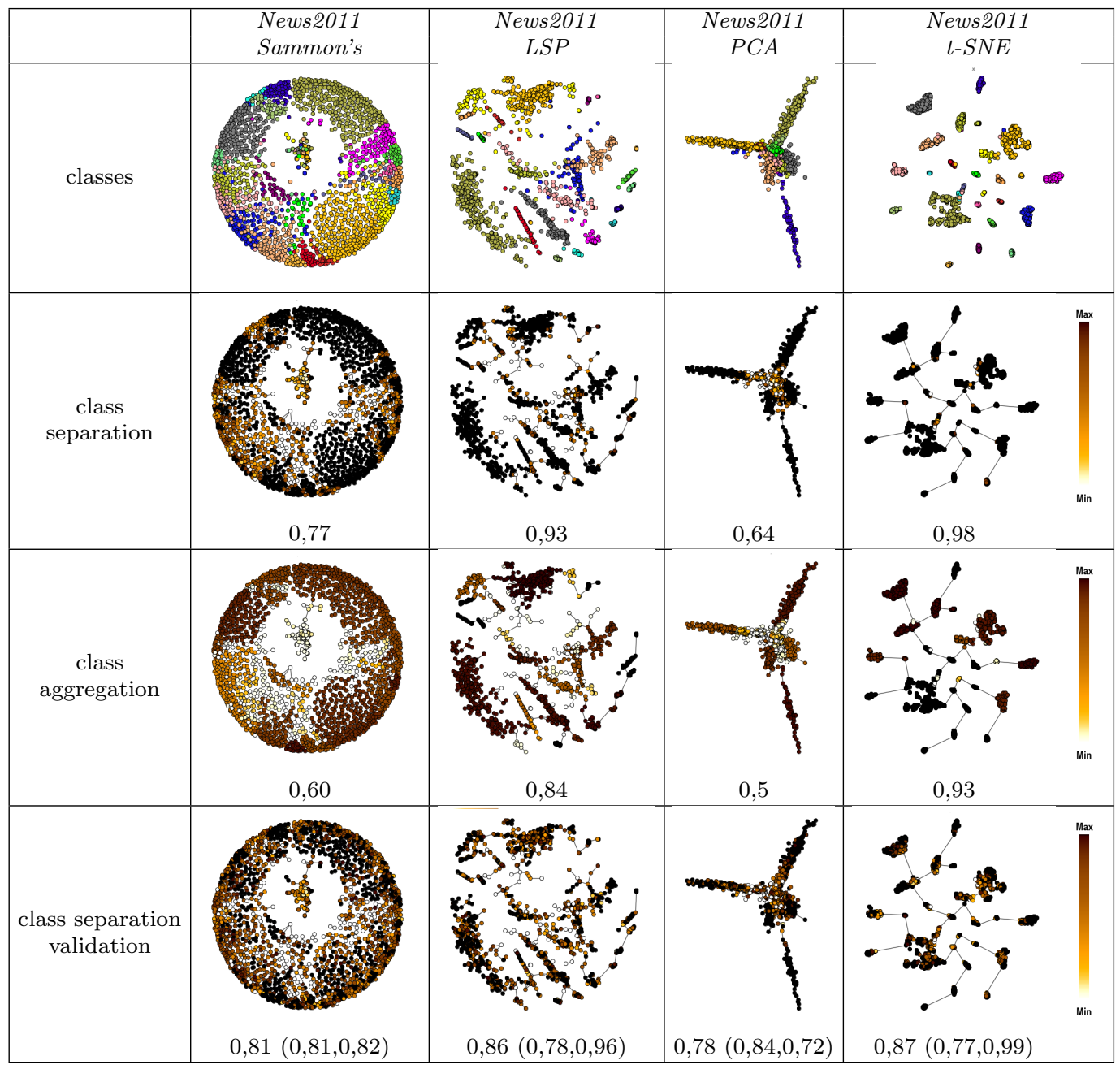

Tabela 5.6: Projeções do News2011. Na linha 1, com os pontos coloridos por classe, e nas linhas 2, 3 e 4 coloridos de acordo com a medida proposta. Cada célula mostra também o valor médio referente à medida em questão.

Iniciando pelo comportamento das medidas Class Separation e Class Aggregation no conjunto de dados News2011, destacamos os mapeamentos gerados pelas técnicas LSP e PCA na Tabela 5.6 (replicados na Figura 5.6). No mapeamento obtido pela LSP a maioria dos pontos possuem alto valor de Class Separation, as exceções sendo os pontos localizados entre grupos de diferentes classes. O mapeamento obtido pela $P C A$, por outro lado, mistura as classes na região central, apesar do alto valor de Class Separation em algumas regiões. A técnica $P C A$ é uma abordagem de redução de dimensionalidade, e não de projeção, e seu desempenho pior é consequência direta da impossibilidade de capturar a variabilidade das 23 classes, utilizando apenas dois componentes principais.

Pontos pertencentes às classes que não foram espalhadas em diversas regiões terão alto valor de Class Aggregation. A técnica $L S P$ novamente exibe valores mais altos comparados à $P C A$, mas ainda assim poucas classes estão concentradas em um único aglomerado de pontos, o que é refletido pelo baixo valor geral de Class Aggregation, se comparado à medida Class Separation. Os valores menores de Class Aggregation podem ser observados 


\begin{tabular}{|c|c|c|c|c|c|}
\hline & $\begin{array}{c}\text { Optdigits } \\
\text { Sammon's }\end{array}$ & $\begin{array}{l}\text { Optdigits } \\
\text { LSP }\end{array}$ & $\begin{array}{c}\text { Optdigits } \\
P C A\end{array}$ & $\begin{array}{l}\text { Optdigits } \\
t \text {-SNE }\end{array}$ & \\
\hline $\begin{array}{l}\text { neighborhood } \\
\text { validation }\end{array}$ & 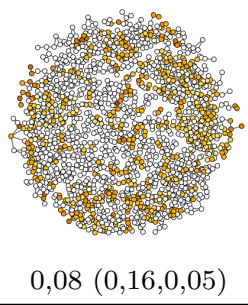 & 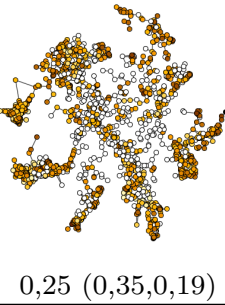 & 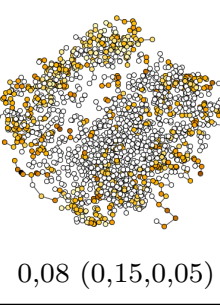 & $0,42(0,82,0,28)$ & Min \\
\hline $\begin{array}{c}\text { group } \\
\text { validation }\end{array}$ & 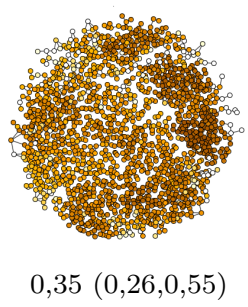 & 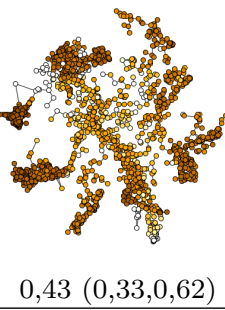 & 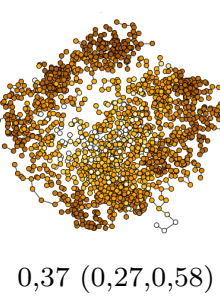 & $0,57(0,43,0,84)$ & Min \\
\hline
\end{tabular}

Tabela 5.7: Projeções do Optdigits. Cada linha contém os pontos coloridos de acordo com a medida proposta. Cada célula mostra também o valor médio referente à medida em questão e entre parênteses os valores de precisão e cobertura.

\begin{tabular}{|c|c|c|c|c|c|}
\hline & $\begin{array}{l}\text { News2011 } \\
\text { Sammon's }\end{array}$ & $\begin{array}{c}\text { News2011 } \\
\text { LSP }\end{array}$ & $\begin{array}{c}\text { News2011 } \\
\text { PCA }\end{array}$ & $\begin{array}{c}\text { News2011 } \\
t-S N E\end{array}$ & \\
\hline $\begin{array}{c}\text { neighborhood } \\
\text { validation }\end{array}$ & $0,07(0,19,0,04)$ & 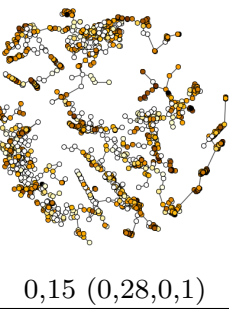 & 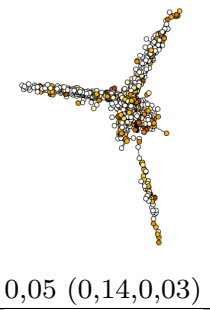 & $0,12(0,39,0,07)$ & $\begin{array}{l}\text { Min } \\
\text { M }\end{array}$ \\
\hline $\begin{array}{c}\text { group } \\
\text { validation }\end{array}$ & $0,15(0,09,0,46)$ & 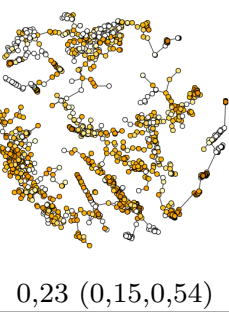 & 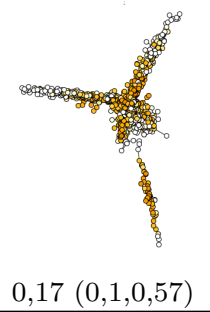 & $0,27(0,18,0,58)$ & Min \\
\hline
\end{tabular}

Tabela 5.8: Projeções do News2011. Cada linha contém os pontos coloridos de acordo com a medida proposta. Cada célula mostra também o valor médio referente à medida em questão e entre parênteses os valores de precisão e cobertura.

na classe amarela, que foi separada em duas regiões por pontos da classe laranja, nas classes azul, salmão e rosa claro, que estão próximas da região central, e também em um grupo de pontos da classe vermelha que está em formato alongado mais abaixo. A maioria dos pontos com valores baixos estão próximos de fronteiras de classes ou entre classes. Algumas classes possuem a maioria de seus pontos próximos no mapeamento obtido pela $P C A$, por exemplo o azul e o verde oliva, e seus pontos tem altos valores. Valores intermediários de Class Aggregation ocorrem nas classes amarela, salmão, rosa claro e verde. Além disso, outras classes com seus pontos separados e sobrepostos na região central resultaram em baixos valores na $P C A$. 
Observando novamente as Tabelas 5.5 e 5.6 nota-se que o mapeamento da $t$-SNE é melhor que os demais em ambos os conjuntos de dados, com excelente valor global de Class Separation e de Class Aggregation. No Optdigits a maioria dos pontos tem valor muito alto de Class Aggregation, com exceção da classe azul (dígito 1), o qual foi dividido em três grupos.

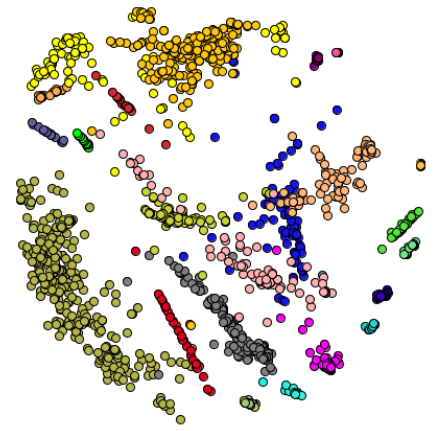

(a) $L S P$ classes

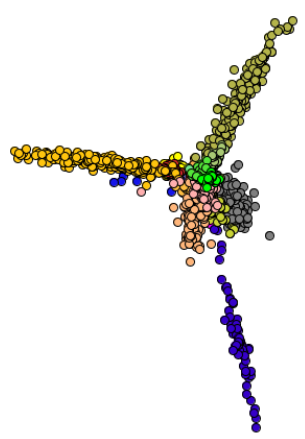

(d) $P C A$ : classes

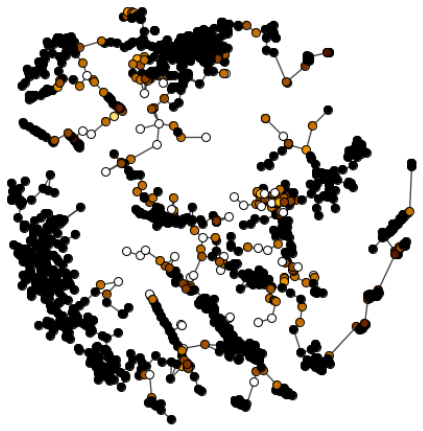

(b) Class Separation: 0,93

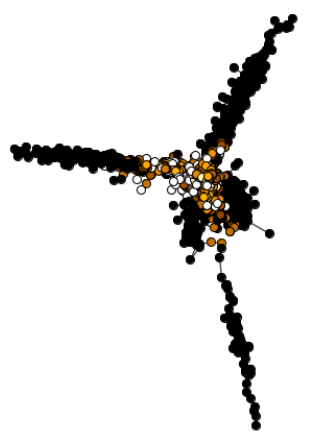

(e) Class Separation: 0,64

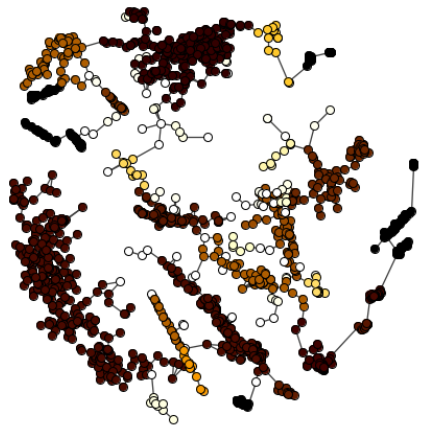

(c) Class Aggregation: 0,84

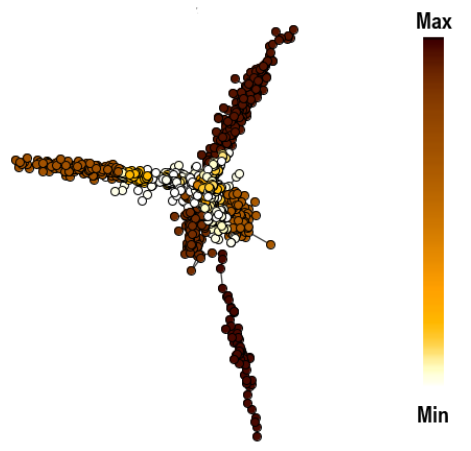

(f) Class Aggregation: 0,5

Figura 5.6: Projeções LSP e PCA para o News2011, e os correspondentes valores de Class Separation e Class Aggregation mapeados em cores (cores escuras são melhores). Números se referem ao valor médio da medida para a projeção.

A medida Class Separation Validation ajuda a identificar se regiões com alta "pureza de classes" observadas na projeção existem de fato no espaço original. Observando as projeções $L S P$ e $t$-SNE replicadas na Figura 5.7, é notável que altos valores (marrom escuro e preto) são, em sua maioria, associados a pontos em regiões bem segregadas, como os dígitos $0,6,2,7$ e 3 na $L S P$ e todas as classes na $t-S N E$. Na $L S P$, pontos da classe 8 são espalhados e tem vizinhos de diversas outras classes, como por exemplo, 5, 3, 2, 1. Como mencionado, o classificador $K N N$ classificou erradamente muitas instâncias da classe 8, portanto não surpreende que ocorra mistura dos pontos desta classe. Novamente, na projeção $t$-SNE todas as classes estão bem separadas.

Os bons valores globais de Class Separation Validation ocorreram mais devido à precisão do que à cobertura. Valores de precisão foram muito altos (média acima de 0,75 ) em todas as projeções consideradas (veja Tabelas 5.5 e 5.6) enquanto valores de cobertura 
foram, em geral, menores (abaixo de 0,59). Todas as técnicas desempenharam bem em ambos os conjuntos de dados, mas novamente a projeção $t$-SNE apresentou os melhores resultados.

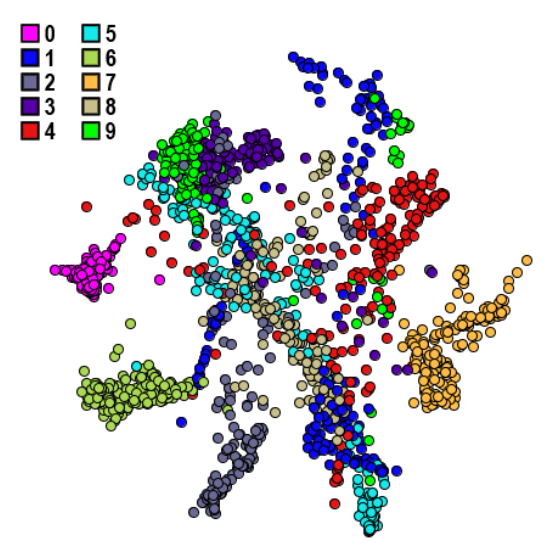

(a) $L S P$

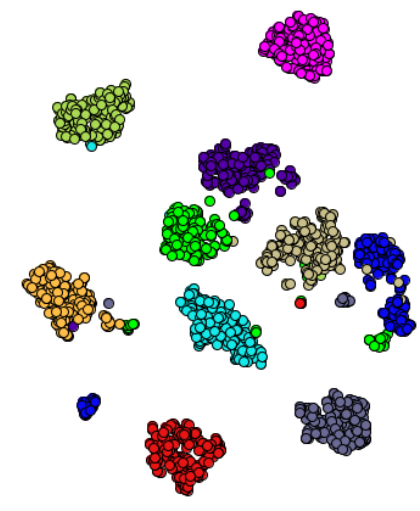

(c) $t-S N E$

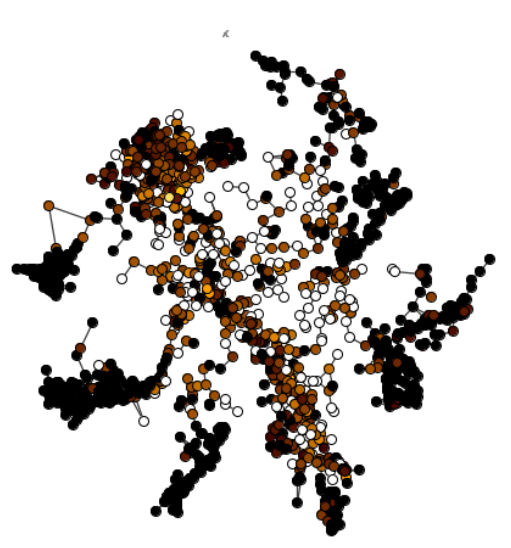

(b) $\operatorname{LSP}(0,88)$

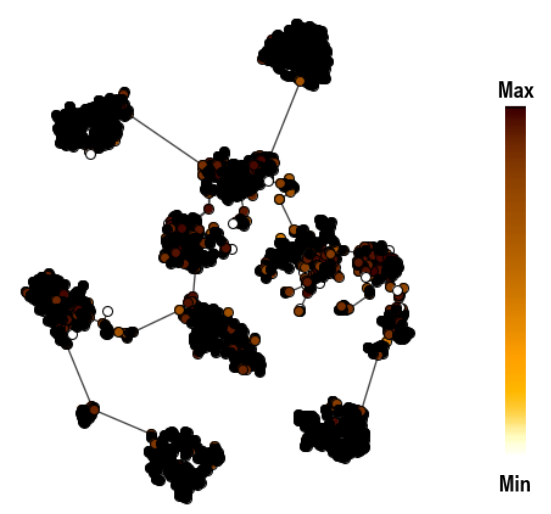

(d) $t$-SNE $(0,98)$

Figura 5.7: Projeções $L S P$ e $t$-SNE para o Optdigits: (a) $L S P$ com classes; (b) $L S P$ com cores mapeando a Class Separation Validation; (c) t-SNE com classes; (d) $t$-SNE com cores mapeando Class Separation Validation. Um valor global da medida é mostrado entre parênteses.

A Figura 5.8 mostra a medida Neighborhood Validation das projeções do conjunto de dados Optdigits. Valores são maiores nos pontos em aglomerados visuais. Entretanto, grupos são observáveis somente na $L S P$ e $t$-SNE. O que não ocorre para o mapeamento gerado pela Sammon's, que otimiza uma função de erro global das distâncias no espaço original em relação às distâncias na projeção, ou para a $P C A$, que não considera distâncias ou vizinhanças. Já a $L S P$ foi proposta para preservar vizinhanças locais, e a $t$-SNE é conhecida por preservar as similaridades entre pontos de alta dimensionalidade. Os melhores resultados de preservação de vizinhança são então esperados para as projeções $L S P$ e $t$-SNE, com os melhores desempenhos globais sendo novamente para a $t-S N E$.

Nas Tabelas 5.7 e 5.8 as linhas referentes à medida Neighborhood Validation indicam 
que a maioria dos pontos tem baixo valor de preservação de vizinhança em todos mapeamentos, com exceção da t-SNE no Optdigits, confirmando a dificuldade de preservação de vizinhanças. Outro indicativo dessa dificuldade são os baixos valores de cobertura, confirmando que é difícil preservar as vizinhanças no espaço bidimensional. A precisão tem desempenho um pouco melhor, mas ainda assim evidenciando perda da vizinhança original. Os mapeamentos gerados pela $t$-SNE e $L S P$ apresentam os melhores valores globais, tanto em termos de cobertura como de precisão.

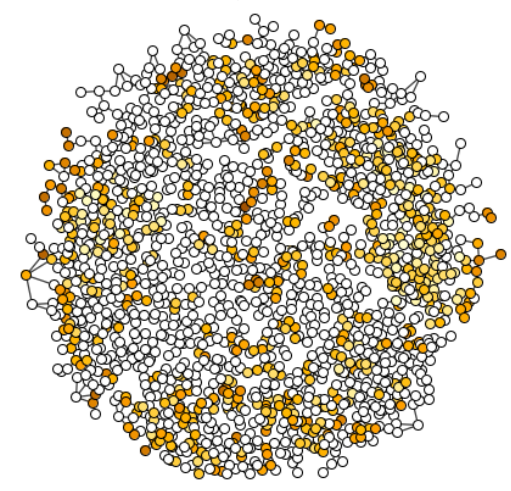

(a) Sammon's $(0,08)$

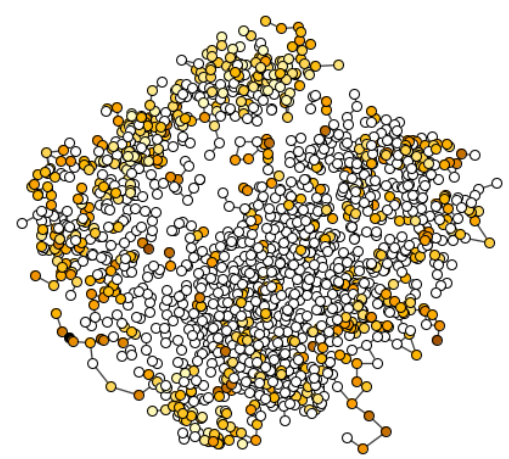

(c) $P C A(0,08)$

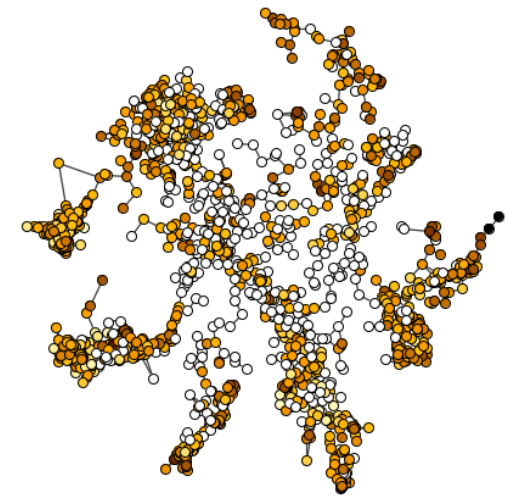

(b) $\operatorname{LSP}(0,25)$

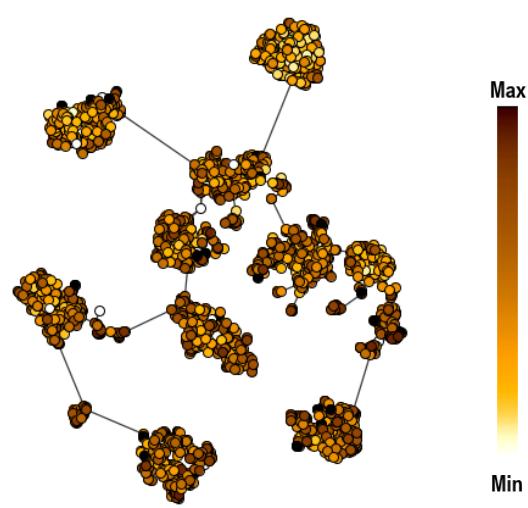

(d) $t$-SNE $(0,42)$

Figura 5.8: Projeções Sammon's, LSP, PCA e t-SNE do Optdigits, com a Neighborhood Validation mapeada em cores.

Em dados com classes bem definidas espera-se uma alta correlação entre as classes e os agrupamentos extraídos no espaço original por um bom algoritmo de identificação de agrupamentos. Sabemos que as classes no Optdigits são bem definidas, exceto por alguns dígitos com maior variabilidade na escrita, e portanto alguma mistura de classes é esperada. O algoritmo de identificação de agrupamentos $A C$ identificou 15 grupos no grafo EMST construído com base no espaço original, e 41 e 35 grupos, respectivamente, nos grafos EMST das projeções $L S P$ e $t-S N E$.

A Tabela 5.9 mostra a relação entre as classes e os agrupamentos obtidos no espaço 
original. Como previsto, 10 dos 15 grupos incluem, em sua maioria, pontos de uma única classe, com pureza superior a 98\%. A pureza é inferior a 90\% apenas nos grupos 11 e 12. Classes 1, 3, 7 e 9 foram separadas em dois ou três subgrupos, indicando maior variabilidade na escrita desses dígitos.

\begin{tabular}{ccccccccccccc}
\cline { 3 - 12 } & \multicolumn{11}{c}{} & \multicolumn{11}{c}{ classe } & pureza & 0 & 1 & 2 & 3 & 4 & 5 & 6 & 7 & 8 & 9 \\
\hline grupo 0 & 0 & $100 \%$ & 178 & 0 & 0 & 0 & 0 & 0 & 0 & 0 & 0 & 0 \\
grupo 1 & 1 & $98 \%$ & 0 & 99 & 0 & 0 & 0 & 0 & 0 & 0 & 2 & 0 \\
grupo 2 & 1 & $96,6 \%$ & 0 & 56 & 0 & 0 & 0 & 0 & 0 & 0 & 1 & 1 \\
grupo 3 & 1 & $100 \%$ & 0 & 27 & 0 & 0 & 0 & 0 & 0 & 0 & 0 & 0 \\
grupo 4 & 2 & $100 \%$ & 0 & 0 & 176 & 0 & 0 & 0 & 0 & 0 & 0 & 0 \\
grupo 5 & 3 & $92,3 \%$ & 0 & 0 & 0 & 12 & 0 & 0 & 0 & 0 & 0 & 1 \\
grupo 6 & 3 & $98,2 \%$ & 0 & 0 & 1 & 164 & 0 & 0 & 0 & 0 & 1 & 1 \\
grupo 7 & 4 & $100 \%$ & 0 & 0 & 0 & 0 & 175 & 0 & 0 & 0 & 0 & 0 \\
grupo 8 & 5 & $98,9 \%$ & 0 & 0 & 0 & 0 & 0 & 173 & 0 & 0 & 0 & 2 \\
grupo 9 & 6 & $98,9 \%$ & 0 & 0 & 0 & 0 & 0 & 1 & 180 & 0 & 1 & 0 \\
grupo 10 & 7 & $97,1 \%$ & 0 & 0 & 0 & 2 & 3 & 0 & 0 & 166 & 0 & 0 \\
grupo 11 & 7 & $56,5 \%$ & 0 & 0 & 0 & 0 & 0 & 0 & 0 & 13 & 0 & 10 \\
grupo 12 & 8 & $89,9 \%$ & 0 & 0 & 0 & 5 & 3 & 7 & 1 & 0 & 169 & 3 \\
grupo 13 & 9 & $100 \%$ & 0 & 0 & 0 & 0 & 0 & 0 & 0 & 0 & 0 & 19 \\
grupo 14 & 9 & $99,3 \%$ & 0 & 0 & 0 & 0 & 0 & 1 & 0 & 0 & 0 & 143 \\
\hline
\end{tabular}

Tabela 5.9: Composição de classes nos 15 agrupamentos extraídos pelo algoritmo $A C$ do espaço original do conjunto de dados Optidigits.

Como somente os mapeamentos gerados pela $L S P$ e $t$-SNE favoreceram a percepção de estruturas de agrupamentos, analisamos apenas estas projeções do conjunto Optidigits em relação à medida Group Validation (F-measure, precisão e cobertura) (replicadas na Figura 5.9). Observa-se que a sua cobertura tem valores maiores, particularmente em regiões que agrupam pontos de uma mesma classe, com altos valores indicando que a distribuição dos pontos na projeção reflete agrupamentos do espaço original. Também observa-se na projeção $L S P$ que os altos valores ocorrem, em sua maioria, nos agrupamentos com alta pureza e baixa variabilidade, tal como os associados as classes 0 e 6 . O mapeamento $t$-SNE apresentou valores maiores do que o mapeamento $L S P$ em relação a medida Group Validation, tanto em precisão como em cobertura.

Ambos os mapeamentos têm baixos valores de precisão, indicando que agrupamentos identificados pelo algoritmo $A C$ na projeção não necessariamente correspondem a agrupamentos no espaço original. Este é um efeito esperado da redução de dimensionalidade. Também é importante lembrar que o algoritmo $A C$ identificou 41 e 35 agrupamentos nos mapeamentos $L S P$ e $t$-SNE, respectivamente, contra apenas 15 no espaço original, o que é mais um indicativo de que a estrutura de agrupamentos é bastante alterada nas projeções.

As Tabelas 5.7 e 5.8 mostram que, de forma similar à medida Neighborhood Validation, valores da medida Group Validation são tipicamente baixos. Porém, ao contrário da 
medida de vizinhança, valores de cobertura são frequentemente maiores que os de precisão. Os valores maiores de cobertura indicam que uma projeção está aproximando bem pontos agrupados em $R^{m}$; menores valores de precisão indicam que os agrupamentos identificados no mapeamento não necessariamente refletem grupos em $R^{m}$.

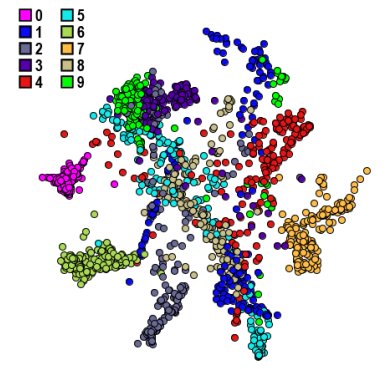

(a) LSP classes

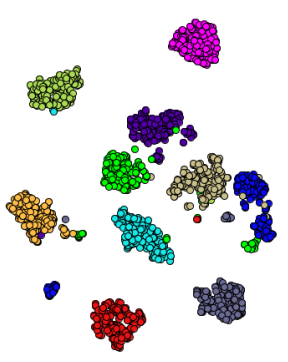

(e) $t$-SNE classes

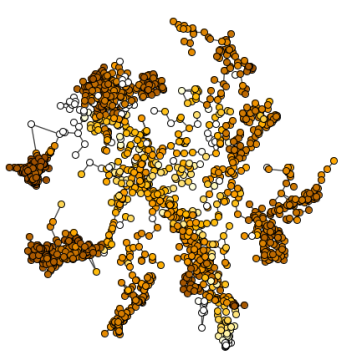

(b) Group Validation $(0,43)$

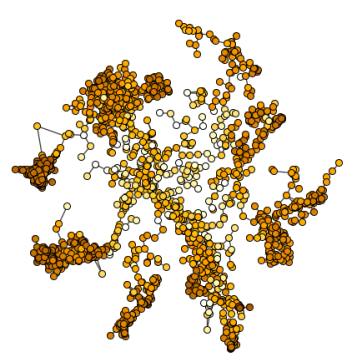

(c) Group Validation (precision: 0,33 )

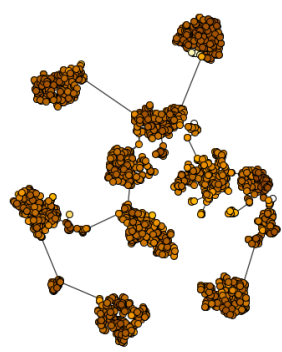

(f) Group Validation $(0,57)$

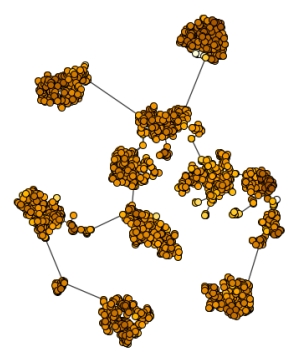

(g) Group Validation (precision: 0,43)

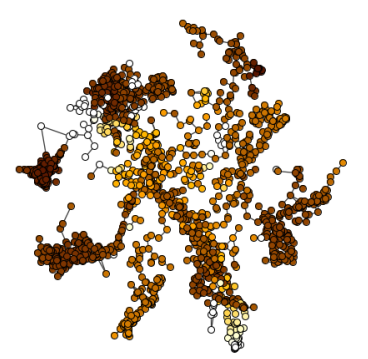

(d) Group Validation (recall: $0,62)$

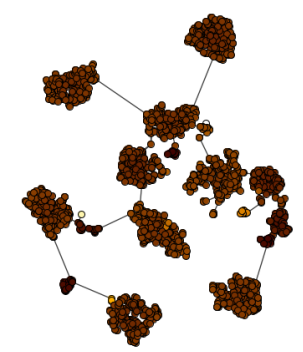

(h) Group Validation (recall: 0,84)

Figura 5.9: Projeções $L S P$ e $t$-SNE do conjunto de dados Optdigits, com as cores mapeando a medida Group Validation em (b) e (f), a medida Group Validation precisão em (c) e (g); e a medida Group Validation cobertura em (d) e (h).

Após uma análise mais cuidadosa das cinco medidas propostas, percebe-se que as medidas de caracterização das projeções atingem, em geral, valores altos e facilitam a identificação da melhor projeção dependendo da tarefa a ser desempenhada. As medidas de preservação de propriedades devem ser mais cuidadosamente utilizadas, pois é natural que o mapeamento bidimensional de um conjunto de dados de alta dimensionalidade resulte em uma grande perda de informação.

Entretanto, as medidas apresentam uma informação de potencial utilidade na exploração visual dos dados, reforçando as constatações observadas nos conjuntos de dados Swiss Roll e Iris, na Seção anterior.

\subsection{Comparação com outras medidas de preservação de vizinhança}

Nesta Seção apresentamos um estudo comparativo da medida Neighborhood Validation. Medidas de preservação de vizinhança são muito exploradas em avaliação de projeções. 
Um arcabouço recente e bastante estudado é a matriz de co-ranking, proposta por Lee e Verleysen (2009). Este arcabouço (detalhado no Capítulo 2) mapeia os dados em uma matriz que contém informações da preservação no espaço projetado do ranking das distâncias entre os pontos no espaço original. Para o estudo comparativo consideramos duas medidas baseadas neste arcabouço, a proposta por Lee e Verleysen (2010), chamada $Q_{N X}$ e a proposta por Mokbel et al. (2013), a qual é uma evolução da anterior, chamada $Q_{N D}$.

Neste estudo comparativo utilizamos a técnica de projeção $t$-SNE, com valor de perplexity configurado igual a 15, e um novo conjunto de dados chamado Coil-20 $0^{5}$, configuração exatamente igual à utilizada por Mokbel et al. (2013). O conjunto de dados Coil-20 consiste de 1.440 imagens de 128x128 bitmaps de 20 objetos. Cada objeto é caracterizado como uma classe e foi fotografado em uma sequência de 72 rotações, cada qual variando 5 graus em relação à anterior.

Espera-se que imagens referentes a rotações seguidas sejam mais similares entre si do que pares de imagens com grande variação na rotação. Ademais, imagens referentes a rotações de objetos simétricos serão mais similares entre si (Figuras 5.10 (e)-(h)) do que as imagens dos objetos não simétricos (Figura 5.10 (a)-(d)).

A Figura 5.11 (a) mostra as classes dos dados, as Figuras 5.11 (b)-(d) mostram, respectivamente, o mapeamento da medida Neighborhood Validation e a correspondente precisão e cobertura; (e)-(g) mostram as medidas baseadas na matriz de co-ranking: (e) refere-se à medida proposta por Lee e Verleysen (2010), com $K_{\max }=4$ (o valor ótimo obtido com a estratégia proposta pelos autores); (f) mostra a medida proposta por Mokbel et al. (2013) com $K_{t}=K_{s}=K_{\max }=4$, e por fim o mapeamento em (g) mostra a mesma medida de (f), mas considerando $K_{s}=4, K_{t}=10$ (uma escolha arbitrária para $K_{t}$ ).

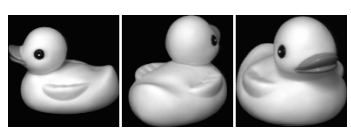

(a) classe 1

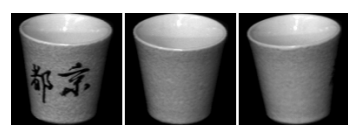

(e) classe 12

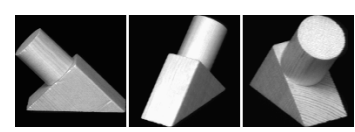

(b) classe 2

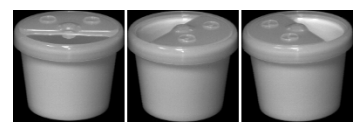

(f) classe 15

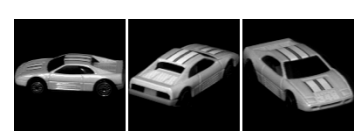

(c) classe 3

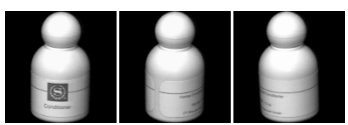

(g) classe 16

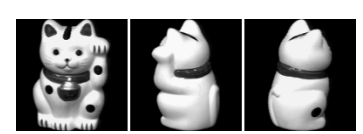

(d) classe 4

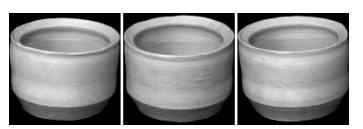

(h) classe 17

Figura 5.10: Amostra de oito objetos do conjunto de dados Coil-20 visualizados em três rotações distintas. (a)-(d) ilustram classes com altos valores de Neighborhood Validation, (e)-(h) ilustram as classes com piores valores deNeighborhood Validation na Figura 5.11.

Em geral, os mapeamentos são consistentes e indicam que a preservação de vizinhança é majoritariamente muito alta, segundo todas as medidas. Todas mostram alguns pontos de algumas poucas classes com baixos valores, por exemplo, as classes 6, 12, 14, 15, 16, 17 e 19, o que sinaliza alguma discrepância nas vizinhanças original e projetada.

\footnotetext{
${ }^{5}$ http://www.cs.columbia.edu/CAVE/software/softlib/coil-20.php
} 

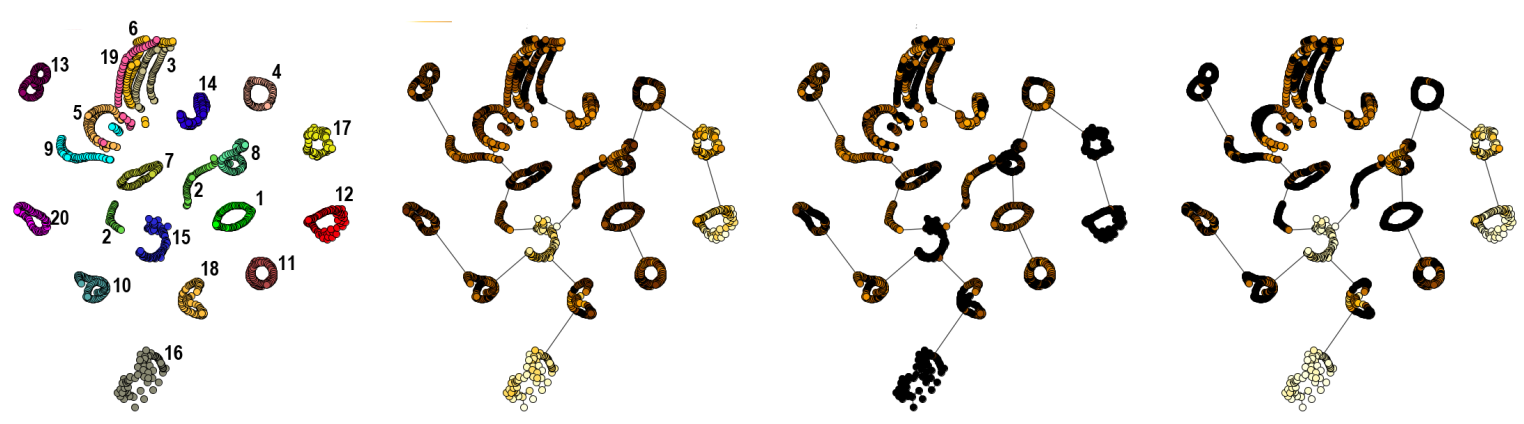

(a) $t$-SNE classes

(b) Neighborhood

Valida-

(c) Neighborhood Validation (d) Neighborhood Validation $(0,309)$

- precisão $(0,749)$

tion - cobertura $(0,195)$
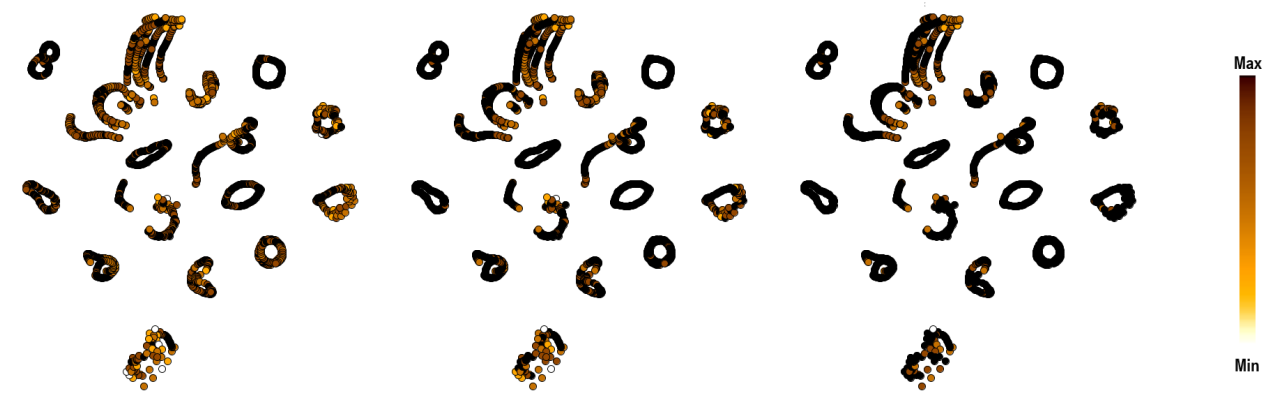

(e) $Q_{N X}$ (Lee e Verleysen, (f) $Q_{N D}$ (Mokbel et al., (g) $Q_{N D}$ (Mokbel et al., 2010) $\left.K_{\max }=4(0,721) \quad 2013\right) \quad K_{s}=K_{t}=K_{\max }=4$ 2013) $K_{s}=4 K_{t}=10(0,949)$ $(0,902)$

Figura 5.11: Projeções $t$-SNE do conjunto de dados Coil-20. (a) apresenta as classes, e (b)-(g) mostram diferentes medidas de preservação de vizinhança mapeadas em cores.

Observa-se, entretanto, que a preservação medida pela Neighborhood Validation é pior nas classes 12 15, 16 e 17, comparada às demais medidas. As Figuras 5.10 (e)-(h) mostram os objetos descritos por estas classes (nas rotações 0, 120 e 240 graus). Ao contrário de todos demais objetos, estes quatro são simétricos quando rotacionados, e todas as imagens apresentam alta similaridade no espaço de alta dimensionalidade, correspondendo a pontos muito próximos no espaço original.

Idealmente, uma projeção deveria agrupar estes pontos muito fortemente, de forma quase sobreposta. Enquanto as medidas baseadas na matriz co-ranking indicam altos valores de preservação de vizinhança para pontos destas classes, a medida Neighborhood Validation está indicando que o mapeamento não reflete isto. Ela indica que a precisão é boa, ou seja, a vizinhança que está na projeção também está de fato no espaço original, mas os valores de cobertura são os menores entre as classes 12, 15, 16 e 17 (veja Tabela 5.10). Mesmo que a precisão seja alta, o baixo valor de cobertura indica que nem toda vizinhança existente no espaço original está sendo preservada na projeção.

As medidas baseadas na matriz de co-ranking não identificaram esta perda de informação na projeção, isso por que elas não consideram características individuais na identificação da vizinhança de cada ponto, trabalhando com uma quantidade fixa de vizi- 
Tabela 5.10: Neighborhood Validation (precisão e cobertura) para as classes do conjunto de dados Coil-20.

\begin{tabular}{|c|c|c|c|c|c|}
\hline classe & $\begin{array}{c}\text { precisão } \\
\text { média }\end{array}$ & $\begin{array}{l}\text { cobertura } \\
\text { média }\end{array}$ & classe & $\begin{array}{c}\text { precisão } \\
\text { média }\end{array}$ & $\begin{array}{c}\text { cobertura } \\
\text { média }\end{array}$ \\
\hline 1 & 0,660 & 0,995 & 11 & 0,733 & 0,808 \\
\hline 2 & 0,592 & 0,968 & 12 & 0,997 & 0,073 \\
\hline 3 & 0,824 & 0,922 & 13 & 0,607 & 0,984 \\
\hline 4 & 0,675 & 0,990 & 14 & 0,531 & 0,666 \\
\hline 5 & 0,680 & 0,817 & 15 & 0,984 & 0,060 \\
\hline 6 & 0,713 & 0,793 & 16 & 0,997 & 0,049 \\
\hline 7 & 0,852 & 0,938 & 17 & 0,994 & 0,119 \\
\hline 8 & 0,941 & 0,622 & 18 & 0,841 & 0.714 \\
\hline 9 & 0,561 & 0,883 & 19 & 0,739 & 0,612 \\
\hline 10 & 0,609 & 0,904 & 20 & 0,859 & 0,796 \\
\hline
\end{tabular}

nhos para todos os pontos. Já a medida Neighborhood Validation, por ser baseada no grafo EMST, considerou vizinhança diferente para cada ponto, e também vizinhanças diferentes do, ponto na projeção e no espaço original. Todos os pontos das quatro classes destacadas (classes 12, 15, 16 e 17) se conectaram a todos os demais de sua classe no grafo EMST gerado para o espaço original.

Portanto, em geral as medidas utilizadas neste estudo comparativo apresentam resultados semelhantes na avaliação de preservação de vizinhança. Porém, a Neighborhood Validation tem a vantagem de ser não paramétrica e capaz de capturar informações baseadas em características locais dos pontos.

\subsection{Comparação de diferentes parametrizações da técnica de pro- jeção $t-S N E$}

Para avaliar as medidas propostas no contexto de diferentes parametrizações de uma mesma técnica de projeção, efetuamos uma avaliação comparativa da técnica $t$-SNE. O conjunto de dados Optdigits foi novamente utilizado, desta vez com valores de perplexity configurados iguais a 5, 30 e 100, resultando em três diferentes projeções. O parâmetro perplexity, dado como entrada para a técnica $t-S N E$, indica a variância da Gaussiana que é considerada em cada instância, e pode ser interpretada como uma medida de suavização do tamanho das vizinhanças, com altos valores resultando em mais vizinhos a serem considerados para o mapeamento de cada instância.

A Figura 5.12 apresenta as três projeções resultantes, com as cores indicando as classes, e a Tabela 5.11 sumariza os valores de cada medida. A primeira projeção (P1), referente ao parâmetro perplexity $=5$, apresenta maior diferença visual, enquanto as outras duas (P2 
e P3) são visualmente mais similares entre si. Nesta projeção, devido à maior restrição sobre as vizinhanças, há uma quantidade maior de agrupamentos contendo poucos pontos, ainda que visualmente as classes estejam bem separadas, assim como as demais.

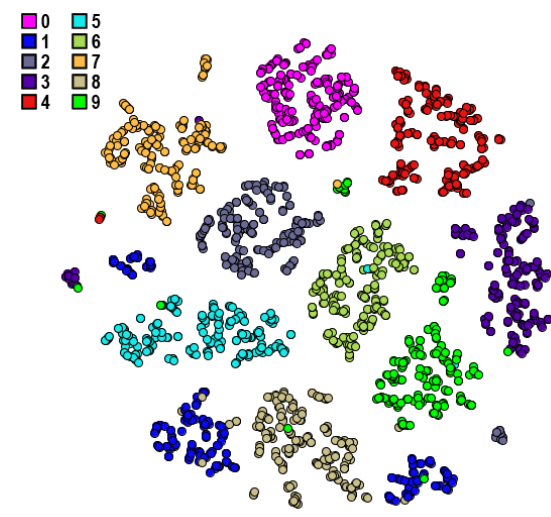

(a) P1 (perplexity=5)

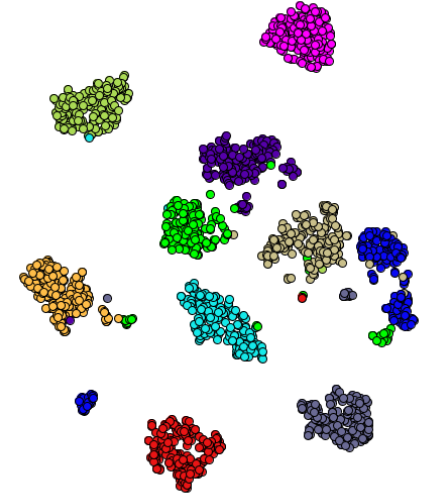

(b) P2 (perplexity=30)

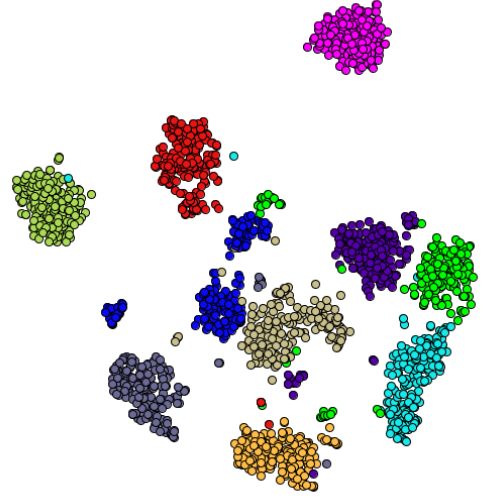

(c) P3 (perplexity=100)

Figura 5.12: Projeções do conjunto de dados Optdigits, geradas com a técnica $t$-SNE e com valores de perplexity iguais a (a) 5, (b) 30 e (c) 100.

Tabela 5.11: Valores das medidas propostas para as projeções do conjunto de dados Optdigits, resultantes de diferentes parametrizações da técnica $t$-SNE.

\begin{tabular}{|l|c|c|c|}
\hline Medida & P1 & P2 & P3 \\
\hline Class Separation & 0,98 & 0,98 & 0,98 \\
Class Aggregation & 0,80 & 0,85 & 0,86 \\
Class Separation Validation & 0,98 & 0,99 & 0,98 \\
Neighborhood Validation & 0,39 & 0,41 & 0,38 \\
Group Validation & 0,5 & 0,56 & 0,55 \\
\hline
\end{tabular}

Devido ao conjunto Optdigits ter boa separação das classes e as projeções P1, P2 e P3 terem mantido esta separação, as três projeções apresentaram altos valores para as medidas Class Separation (Figura 5.13) e Class Separation Validation (Figura 5.14), com valores equivalentes em termos de separação e preservação de classes.

As medidas Class Aggregation e Group Validation são as que apresentaram valor médio mais diferenciado entre as três projeções, mostrada nas Figuras 5.15 e 5.16, respectivamente. A projeção P1 tem os menores valores de ambas, enquanto as outras duas projeções têm valores similares de cada medida. Esta diferença, ainda que pequena, ocorre em consequência do maior espalhamento dos pontos na P1, devido às menores vizinhanças.

Em relação à preservação das vizinhanças, avaliada pela medida Neighborhood Validation e apresentada na Figura 5.17, houve uma diferença menor entre os valores médios obtidos, com a projeção P2 (b) tendo o valor mais alto e a projeção P3 (c) o menor valor. O resultado pior para a projeção P3 (c) era esperado, pois considera vizinhanças mais 


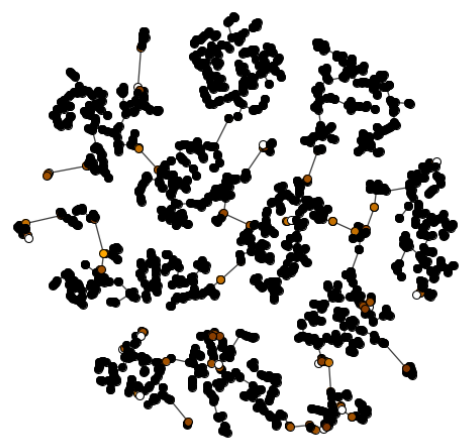

(a) Class Separation $(0,98)$

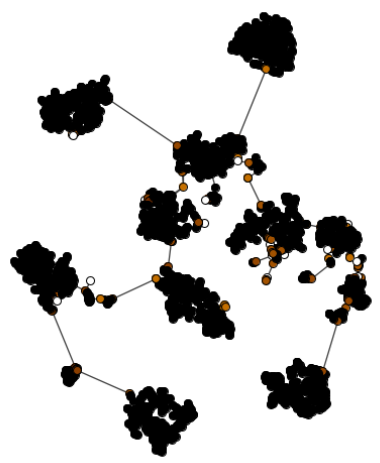

(b) Class Separation $(0,98)$

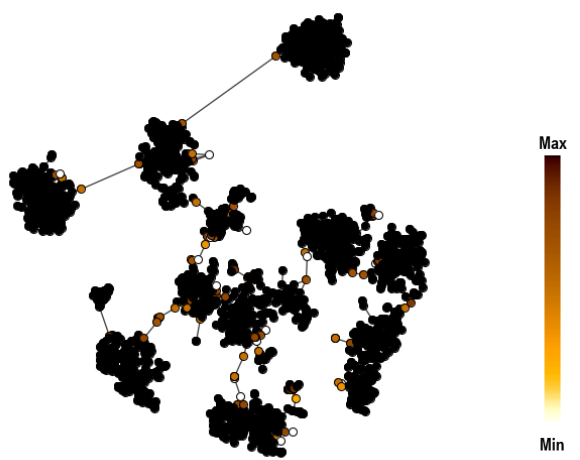

(c) Class Separation $(0,98)$

Figura 5.13: Projeções t-SNE do Optdigits com as cores mapeando a medida de Class Separation.

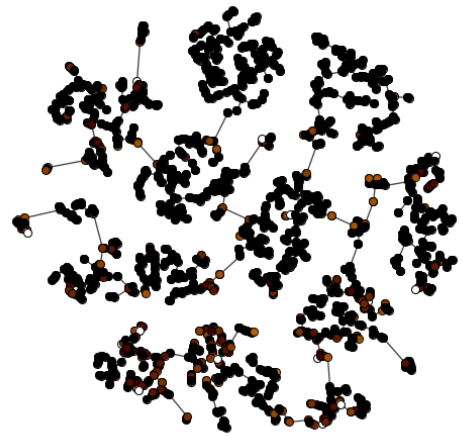

(a) Class Separation Validation $(0,98)$

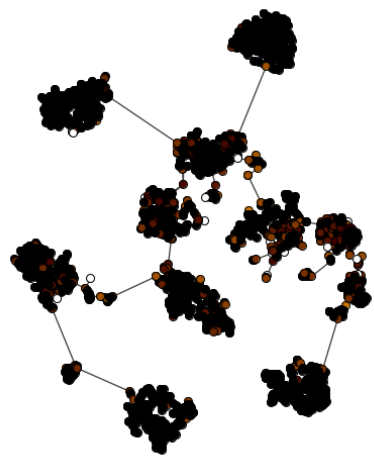

$(0,99)$
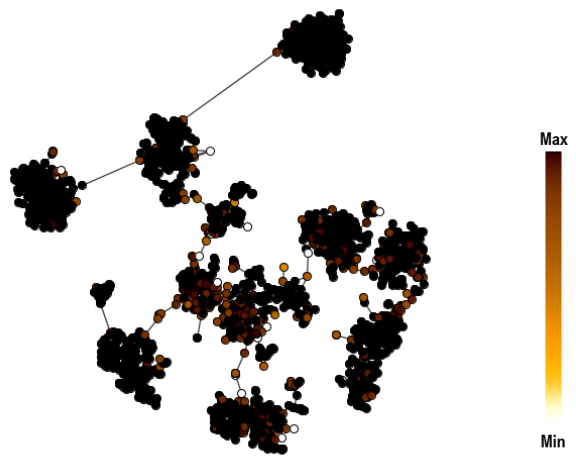

(c) Class Separation Validation $(0,98)$

Figura 5.14: Projeções t-SNE do Optdigits com as cores mapeando a medida de Class Separation Validation.

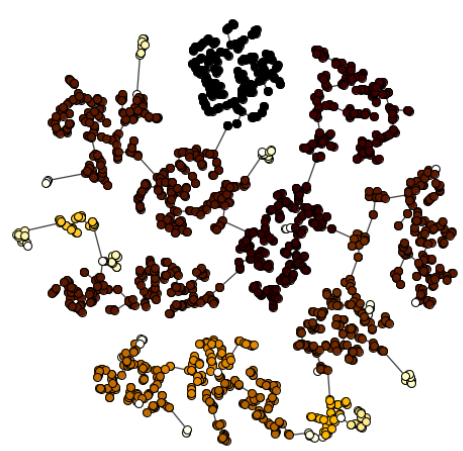

(a) Class Aggregation $(0,8)$

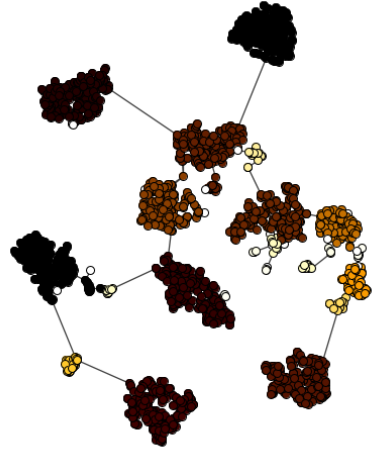

(b) Class Aggregation $(0,85)$

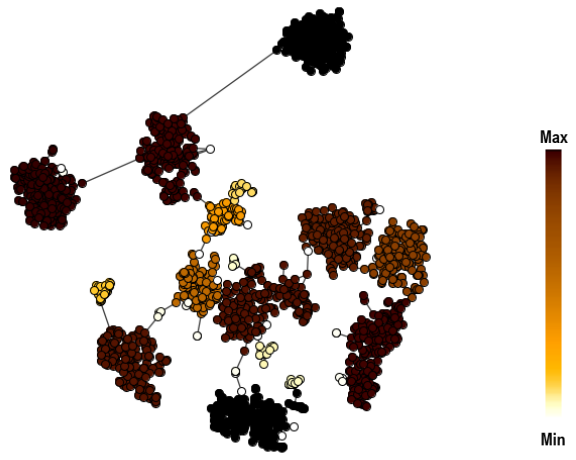

(c) Class Aggregation $(0,86)$

Figura 5.15: Projeções t-SNE do Optdigits com as cores mapeando a medida de Class Aggregation. 


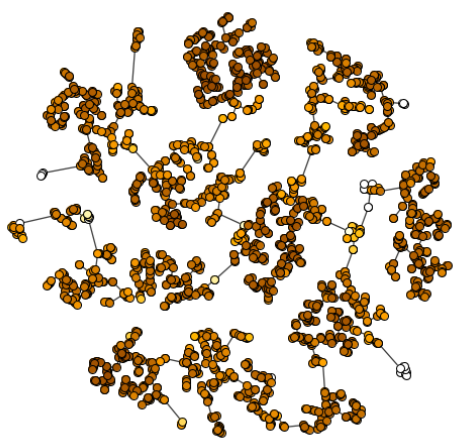

(a) Group Validation $(0,5)$

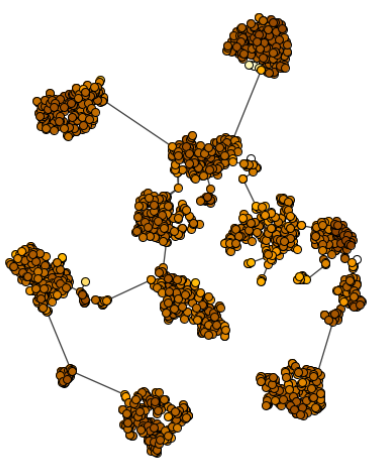

(b) Group Validation $(0,56)$

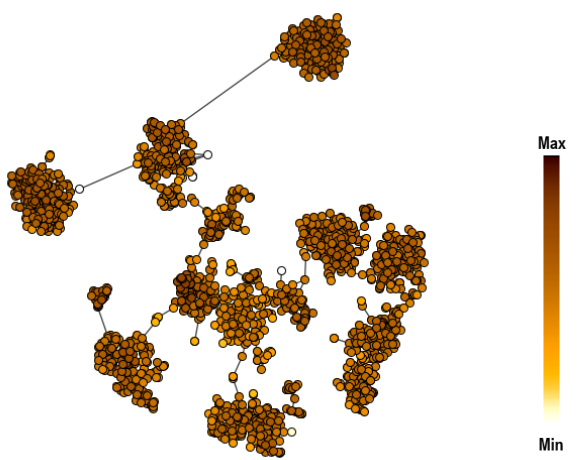

(c) Group Validation $(0,55)$

Figura 5.16: Projeções t-SNE do Optdigits com as cores mapeando a medida de Group Validation.

amplas. Porém, o valor médio maior para a projeção P2 (b) em relação à projeção P1 (a) indica que a técnica é capaz de preservar as vizinhanças mesmo que não seja definido um valor tão restritivo para o parâmetro perplexity, e assim permitindo que outras características, como as avaliadas pelas medidas Class Aggregation e Group Validation, sejam também bem preservadas.

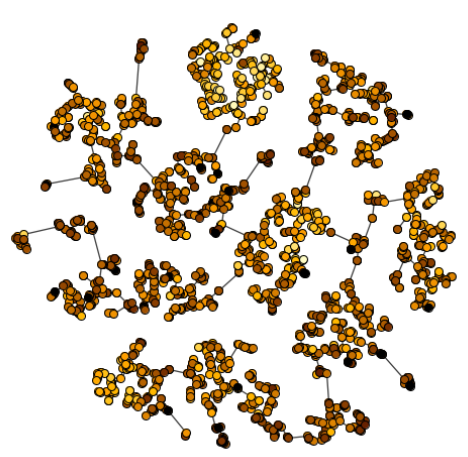

(a) Neighborhood Validation $(0,39)$

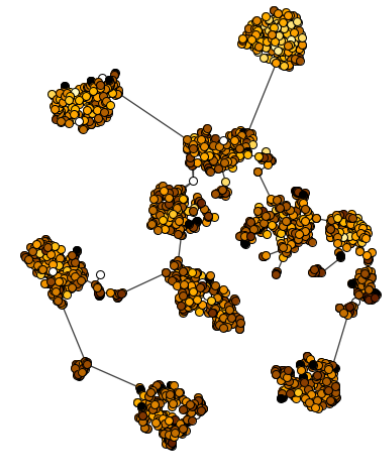

(b) Neighborhood Validation $(0,41)$

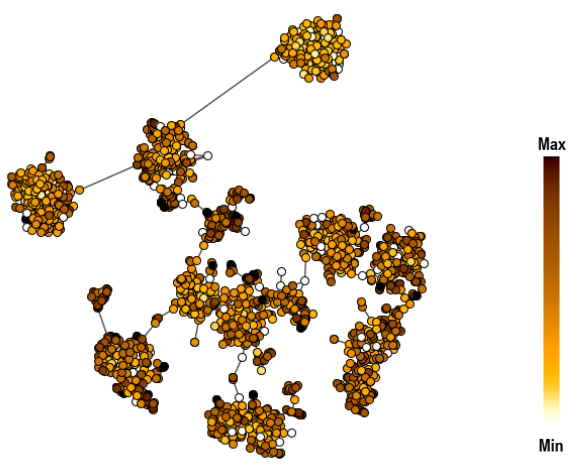

(c) Neighborhood Validation $(0,38)$

Figura 5.17: Projeções $t$-SNE do Optdigits com as cores mapeando a medida de Neighborhood Validation.

Entretanto, as análises foram realizadas considerando o valor médio para cada medida, o que pode estar mascarando informações relevantes. Pontos específicos, grupos de pontos ou classes podem estar bem representados em uma determinada projeção mesmo que o valor global seja baixo. Portanto, aqui apresentamos a capacidade de utilizar as medidas propostas de avaliação de projeção para avaliar diferentes parametrizações, mas melhores resultados podem ser obtidos com uma análise por ponto mais aprofundada (ou por região de pontos).

Cada técnica de projeção possui uma parametrização específica e a utiliza para influ- 
enciar a construção da solução. No caso da técnica t-SNE a parametrização influencia na vizinhança considerada para cada ponto e as projeções resultantes não apresentaram diferenças muito representativas para o conjunto Optdigits. Ainda assim, pudemos observar que três medidas, a Class Aggregation, a Group Validation e a Neighborhood Validation, apresentaram uma pequena discrepância nos valores e indicaram que a projeção com o parâmetro perplexity $=30$, em geral, preservou melhor as propriedades dos dados originais, no caso do Optdigits.

Na Tabela 5.12 apresentamos uma comparação das medidas propostas com medidas existentes na literatura, em relação a diferentes propriedades que cada medida contempla. As medidas foram agrupadas em três categorias, a primeira contém as medidas que avaliam estritamente a distribuição das classes na projeção, a segunda categoria contém as medidas que avaliam características de vizinhança, e a terceira categoria as medidas que avaliam a qualidade dos grupos formados.

Tabela 5.12: Comparação das medidas propostas com medidas da literatura.

\begin{tabular}{|c|c|c|c|c|c|c|c|c|c|}
\hline A. Caracterização da projeção & [A1] & [A2] & [A3] & [A4] & [A5] & [A6] & [A7] & [A8] & [A9] \\
\hline Distance Consistency (Sips et al., 2009) & $\mathrm{X}$ & $\mathrm{X}$ & $\mathrm{X}$ & $\mathrm{X}$ & & & $\mathrm{X}$ & & \\
\hline Distribution Consistency (Sips et al., 2009) & $\mathrm{X}$ & $\mathrm{X}$ & & $\mathrm{X}$ & & & $\mathrm{X}$ & & $\mathrm{X}$ \\
\hline Class Density Measure (Tatu et al., 2009) & $\mathrm{X}$ & $\mathrm{X}$ & & & $\mathrm{X}$ & & $\mathrm{X}$ & & \\
\hline Class Separation & $\mathrm{X}$ & $\mathrm{X}$ & $\mathrm{X}$ & & & $\mathrm{X}$ & $\mathrm{X}$ & & $\mathrm{X}$ \\
\hline Class Aggregation & $\mathrm{X}$ & $\mathrm{X}$ & $\mathrm{X}$ & & & $\mathrm{X}$ & & $\mathrm{X}$ & $\mathrm{X}$ \\
\hline B. Preservação baseada em vizinhança & [B1] & [B2] & [B3] & [B4] & [B5] & [B6] & [B7] & [B8] & [B9] \\
\hline Neighborhood Preservation (Paulovich e Minghim, 2006) & $\mathrm{X}$ & $\mathrm{X}$ & & $\mathrm{X}$ & & $\mathrm{X}$ & & & \\
\hline Trustworthiness (Venna e Kaski, 2001) & $\mathrm{X}$ & $\mathrm{X}$ & & $\mathrm{X}$ & & $\mathrm{X}$ & $\mathrm{X}$ & & $\mathrm{X}$ \\
\hline Lee e Verleysen (2009) & $\mathrm{X}$ & & & $\mathrm{X}$ & & $\mathrm{X}$ & & & $\mathrm{X}$ \\
\hline Mokbel et al. (2013) & $\mathrm{X}$ & $\mathrm{X}$ & & $\mathrm{X}$ & & $\mathrm{X}$ & & & $\mathrm{X}$ \\
\hline Class Separation Validation & $\mathrm{X}$ & $\mathrm{X}$ & $\mathrm{X}$ & & $\mathrm{X}$ & $\mathrm{X}$ & $\mathrm{X}$ & $\mathrm{X}$ & \\
\hline Neighborhood Validation & $\mathrm{X}$ & $\mathrm{X}$ & $\mathrm{X}$ & & $\mathrm{X}$ & $\mathrm{X}$ & $\mathrm{X}$ & & \\
\hline C. Preservação baseada em agrupamentos & [C1] & [C2] & [C3] & [C4] & [C5] & [C6] & [C7] & & \\
\hline Marghescu (2006) & $\mathrm{X}$ & & $\mathrm{X}$ & $\mathrm{X}$ & & & $\mathrm{X}$ & & \\
\hline Group Validation & $\mathrm{X}$ & $\mathrm{X}$ & $\mathrm{X}$ & $\mathrm{X}$ & $\mathrm{X}$ & $\mathrm{X}$ & & & \\
\hline
\end{tabular}

Características

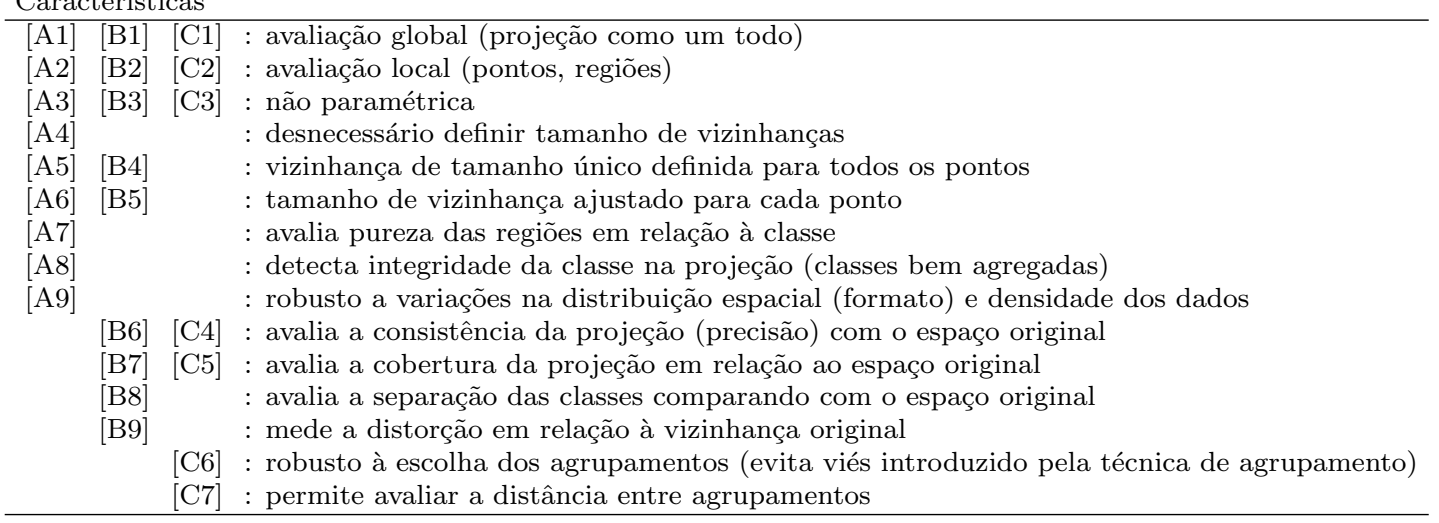





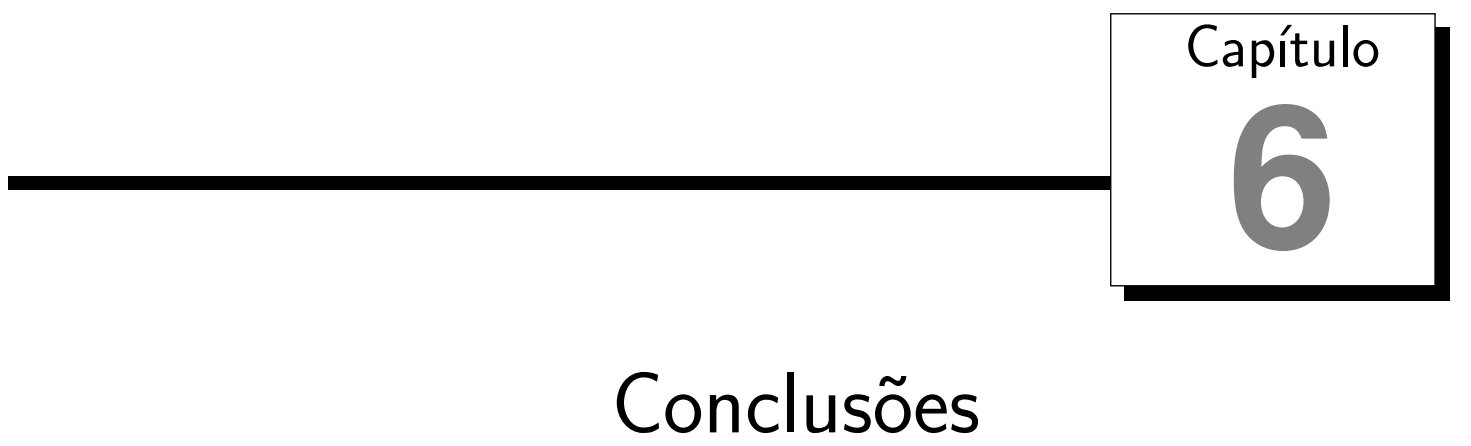

Projeções Multidimensionais têm sido amplamente utilizadas nos últimos anos para apoiar tarefas de Mineração de Dados. As projeções agregam uma representação visual às tarefas de extração de padrões, auxiliando neste processo de maneira menos sistemática e mais exploratória. Neste cenário, medidas de avaliação de projeções são fundamentais para efetuar análises visuais, comparar projeções e apoiar a sua interpretação.

Medidas de avaliação de projeções multidimensionais, em geral, avaliam a separação visual das classes, a preservação de vizinhança e a preservação de agrupamentos, principalmente devido a estas serem características comumente utilizadas pelos usuários na análise exploratória. Porém, as medidas existentes avaliam características isoladas e precisam ser combinadas para se ter uma avaliação mais completa de uma projeção, ou seja, não existe um arcabouço que permita avaliar múltiplas propriedades de uma projeção.

Sendo assim, este trabalho teve como principal objetivo propor um arcabouço robusto que possa ser utilizado para avaliar múltiplas propriedades. Para isso, inicialmente foi conduzido um estudo para avaliar como potenciais usuários observam as projeções, buscando identificar padrões na forma como percebem vizinhanças e agrupamentos. Em seguida, foi proposta uma representação dos dados eficaz na identificação de vizinhanças e de agrupamentos. Por fim, com base no conhecimento adquirido foram investigadas medidas para serem aplicadas a tarefas de avaliação de projeções multidimensionais.

Para atingir estes objetivos, este trabalho considerou três hipóteses principais:

1. Um estudo com usuários poderia esclarecer como os participantes observam as projeções: esta hipótese foi confirmada no estudo de percepção apresentado no Capítulo 3. O estudo avaliou a identificação de agrupamentos e a capacidade dos participantes 
identificarem os vizinhos mais próximos a um dado ponto nas projeções. Na identificação dos agrupamentos observou-se alta discrepância na quantidade de grupos visualmente identificados pelos participantes, o que sugere que os agrupamentos não são tão claros nas projeções. Na identificação dos vizinhos mais próximos observouse um padrão mais claro, sendo que em geral uma grande porcentagem dos participantes percebeu as vizinhanças de forma parecida. Além disso, para diferentes pontos de referência avaliados os participantes identificaram diferentes tamanhos de vizinhança com alta precisão, confirmando que pontos devem ser tratados de acordo com suas características.

2. É possível gerar uma representação dos dados eficaz para identificar vizinhanças e agrupamentos: foi confirmada com o grafo EMST e o estudo descrito no Capítulo 4. Representações relacionais foram exploradas a fim de identificar uma forma de associar uma vizinhança a cada ponto. Um modelo de grafo não paramétrico denominado Extended Minimum Spanning Tree (EMST) foi proposto que representa bem as vizinhanças e também é eficaz para a identificação de agrupamentos. O grafo EMST e outros modelos relacionais e não relacionais foram aplicados às projeções utilizadas no estudo de percepção e os resultados foram comparados aos padrões observados no mesmo estudo. O modelo de grafo EMST apresentou alta precisão na identificação das vizinhanças, comparadas às vizinhanças observadas pelos participantes, e alta precisão na identificação de agrupamentos.

3. É possível propor um arcabouço de medidas para avaliar múltiplas propriedades de projeções multidimensionais: esta é a hipótese que contempla todas as ações deste projeto, a qual foi validada com o uso do modelo de grafo EMST na proposta das medidas e na avaliação conduzida no Capítulo 5. Nesse Capítulo inicialmente foi apresentado um estudo demonstrativo das medidas propostas, sobre conjuntos de dados artificiais e reais. Em seguida, as medidas são aplicadas a outros conjuntos reais. Por fim, um estudo comparativo com medidas da literatura foi realizado, no qual são apresentados exemplos nos quais as medidas têm comportamento semelhante e outros em que as medidas propostas foram mais informativas do que as existentes com as quais foram comparadas.

No processo de validação das hipóteses, algumas contribuições foram alcançadas e são apresentadas a seguir, assim como as limitações e sugestões de trabalhos futuros.

\subsection{Contribuições}

O principal tema abordado neste trabalho foi a avaliação de projeções multidimensionais. Portanto, como primeira contribuição há o amplo levantamento bibliográfico realizado sobre o tema, abordando tanto medidas qualitativas para interpretação dos dados 
e das projeções quanto medidas quantitativas de avaliação. As abordagens de avaliação quantitativa foram categorizadas em avaliação de preservação de distâncias, com base nas funções de stress, avaliação de propriedades visuais das projeções, as quais avaliam características das projeções independentemente dos dados originais, e as avaliações de preservação de vizinhanças e de agrupamentos, as quais de fato comparam características das projeções com as do espaço original dos dados.

O levantamento bibliográfico de técnicas de avaliação de projeções multidimensionais permitiu identificar deficiências nas medidas existentes, guiando as atividades realizadas ao longo do projeto.

Uma segunda contribuição relevante foi o estudo de percepção realizado para entender melhor a forma como as pessoas observam as projeções. Este estudo foi conduzido com 8 diferentes tarefas relacionadas a percepção das projeções, das quais duas foram utilizadas neste trabalho: identificação de agrupamentos e de vizinhanças (as demais foram exploradas em outros trabalhos de colaboradores). Com isso, foi possível avaliar diferentes representações dos dados confrontando-as com as respostas apresentadas pelos participantes do estudo. A representação mais adequada foi o modelo proposto de grafo Extended Minimum Spanning Tree (EMST), o qual é uma das principais contribuições deste trabalho. O grafo EMST apresentou ótimos resultados na identificação de vizinhanças, quando comparado com as percepções dos participantes do estudo, e na identificação de agrupamentos.

Essa representação relacional de dados multidimensionais capaz de capturar vizinhanças e agrupamentos relevantes representa outra contribuição deste trabalho, com potencial de aplicação em outros problemas em mineração e mineração visual de dados. No estudo de identificação de agrupamentos, efetuamos uma comparação de técnicas tradicionais não relacionais de identificação de agrupamentos com técnicas relacionais baseadas em identificação de comunidades em grafos. As técnicas relacionais resultaram em agrupamentos mais "puros" em relação à classe, provavelmente devido a serem baseadas nas conexões e, portanto, mais resilientes a variações de densidade e formato nos agrupamentos.

Após o estudo de identificação de vizinhanças e de agrupamentos, o modelo de grafo EMST foi utilizado como base para propor medidas para avaliação de projeções multidimensionais. Foram propostas cinco medidas, duas delas avaliando propriedades visuais das projeções e três avaliando a preservação de propriedades baseadas em vizinhança e agrupamentos. Das cinco medidas três são dependentes de dados supervisionados, as quais são relacionadas a separação das classes na projeção, e duas não dependem de classes e avaliam a preservação de vizinhanças e de agrupamentos.

Uma contribuição prática deste trabalho é uma ferramenta disponibilizada ${ }^{1}$ para avaliação de projeções. A ferramenta permite que o usuário forneça os dados originais e a projeção, e viabilize uma exploração da projeção segundo cada uma das medidas pro-

\footnotetext{
${ }^{1} \mathrm{http}$ ///vicg.icmc.usp.br/infovis2/EMSTProjectionEvaluation
} 
postas, além de outras medidas de preservação de vizinhança existentes na literatura, as quais utilizamos na comparação final. A ferramenta apresenta também o valor global de cada medida, e permite iteragir com a projeção, movendo pontos, ampliando a visualização, identificando as vizinhanças de um dado ponto e também seus agrupamentos. Além disso, seria interessante comparar as medidas propostas com outras medidas clássicas de avaliação de projeções relatadas na literatura, porém computadas sobre a representação dada pelo grafo EMST.

Por fim, como contribuições para as áreas de mineração de dados e visualização de informação, além da contribuição técnica e desta tese, tem-se três publicações com resultados diretos deste trabalho:

- Etemadpour, R., Motta, R., Paiva, J. G., Minghim, R., de Oliveira, M. C. F., and Linsen, L. Perception-based Evaluation of Projection Methods for Multidimensional Data Visualization. IEEE Transactions on Visualization and Computer Graphics. 2014 (aceito para publicação).

- Etemadpour, R., Motta R., Paiva, J. G., de Oliveira, M. C. F., Minghim, R., and Linsen, L. Role of human perception in cluster-based visual analysis of multidimensional data projections. Em: International Conference on Information Visualization Theory and Applications (IVAPP 2014), p. 276-283, 2014.

- Motta, R., Nogueira, B. M., Jorge, A. M., de Lopes, A. A., Rezende, S. O., e de Oliveira, M. C. F. Comparing relational and non-relational algorithms for clustering propositional data. Em: ACM Symposium on Applied Computing - Data Mining track, v. 1, p. 150-155, 2013.

Além destes, outro artigo foi submetido a um periódico e está em processo de revisão:

- Motta, R., Minghim, R., Lopes, A. A., and Oliveira, M. C. F. Graph-based measures to assist user assessment of multidimensional projections. Submetido para: Neurocomputing Journal.

E outras cinco publicações em temas relacionados, indiretamente a este trabalho, em colaboração com outros pesquisadores:

- Bertini, J. R., Zhao, L., Motta, R., Lopes, A. A. A Nonparametric Classification Method based on K-Associated Graphs. Information Sciences. v. 181, p. 5435-5456, 2011.

- Junio, B., Lopes, A. A., Motta, R. Detecção de Autores Duplicados Utilizando Estrutura de Comunidades em Redes de Cooperação Científica. Em: VIII Encontro Nacional de Inteligência Artificial - ENIA, p. 335-345, 2011. 
- Bertini, J., Lopes, A. A., Motta, R., Zhao, L. Online Classifier Based on the Optimal K-associated Network. Em: 3rd International Workshop on Web and Text Intelligence, p. 1-10, 2010.

- Motta, R., Lopes, A. A., de Oliveira, M. C. F. Centrality Measures from Complex Networks in Active Learning. Em: The Twelfth International Conference on Discovery Science (DS09), v. 5808, p. 184-196, 2009.

- Lopes, A. A., Bertini, J., Motta, R., Zhao, L. Classification Based on the Optimal K-Associated Network. Em: Jie Zhou. (Org.). Complex Sciences. : Springer. 2009.v. 4, p. 1167-1177.

\subsection{Limitações}

Nossa contribuição apresenta algumas limitações, que podem ser abordadas em trabalhos futuros. A primeira diz respeito à tarefa de identificação de agrupamentos no estudo de percepção realizado. Não utilizamos uma ferramenta que permitisse que os participantes respondessem quais foram os agrupamentos percebidos, como consequência, a análise dos resultados ficou restrita à quantidade de agrupamentos e não ao agrupamento a que cada ponto pertence, inviabilizando cruzar os agrupamentos identificados automaticamente com os percebidos pelos participantes do estudo.

Uma segunda limitação é a complexidade computacional da solução proposta. Abordagens relacionais se mostraram mais precisas na identificação de vizinhanças e agrupamentos, porém sua complexidade dificulta o uso em grandes conjuntos de dados, com milhões de instâncias, por exemplo. A construção do grafo EMST tem complexidade $O\left(N^{2}\right)$, e ainda assim é a menor complexidade dentre os modelos relacionais.

Outra limitação do grafo EMST é que a sua construção depende sempre de todos os dados, ou seja, sua construção não permite seu uso incremental. O grande volume de dados gerado a cada dia faz com que muitas vezes esta seja uma característica fundamental para algumas atividades de análise de dados. Porém, é possível transformar o algoritmo de construção do grafo EMST em incremental ao se construir uma estrutura de dados adequada e algumas adaptações no algoritmo.

Por fim, outra limitação é a análise de vizinhança restritiva que utilizamos. Nas medidas propostas consideramos a vizinhança no grafo em uma única profundidade, porém, é possível adaptar as medidas permitindo uma profundidade variável na vizinhança considerada, inclusive com diferentes pesos. Esta adaptação permitiria ampliar avaliações locais, resultando em avaliações por níveis. 


\subsection{Trabalhos futuros}

Das limitações levantadas, algumas são diretamente relacionadas com trabalhos futuros. A construção de um modelo de grafo incremental com base na EMST seria útil em atividades de análise de dados contínuos, o qual vem recebendo grande atenção. Tornar o grafo EMST de menor complexidade, e portanto escalável, é uma tarefa mais complexa, porém ainda possível principalmente se permitirmos um modelo aproximado e não determinístico.

O grafo EMST também poderia ser utilizado em outras tarefas de mineração de dados, como classificação. O grafo se mostrou eficiente na identificação de agrupamentos, possivelmente por representar bem instâncias em regiões com diferentes densidades e formatos na distribuição dos dados. Portanto, o uso de uma representação relacional como a EMST poderia trazer grandes benefícios em outras tarefas de mineração.

A hipótese de usar diferentes níveis de profundidade nas vizinhanças para ampliar as avaliações locais também poderia ser considerada. A ferramenta resultante deste trabalho poderia ser adaptada para permitir tais níveis.

Outra extensão do grafo EMST na avaliação de projeções poderia ser a inclusão de medidas para avaliar outras propriedades. A análise de vizinhança foi bem explorada analisando-se separação visual das classes, preservação da "pureza" e preservação dos vizinhos. Porém, a análise de agrupamentos ainda se restringiu à verificação de grupos de pontos próximos, sendo ainda possível explorar a densidade destes grupos, a proximidade entre os grupos, e outras características de agrupamentos.

Por fim, a ferramenta provida para análise e avaliação de projeções multidimensionais pode ser evoluída com funcionalidades que auxiliem na exploração e também com a implementação de outras medidas de avaliação, por exemplo, avaliando a desordem na distribuição dos pontos, elementos centrais na projeção e no espaço original, outliers, entre outras propriedades. 


\section{Referências Bibliográficas}

Aoyama, K., Saito, K., Sawada, H., e Ueda, N. (2011). Fast approximate similarity search based on degree-reduced neighborhood graphs. Em Proceedings of the 17th ACM SIGKDD international conference on Knowledge discovery and data mining, KDD '11, páginas 1055-1063, New York, NY, USA. ACM. Citado na página 43.

Bagrow, J. e Bollt, E. (2005). A local method for detection communities. Physical Review E, 72:046108. Citado na página 52.

Bayá, A. E. e Granitto, P. M. (2011). Clustering gene expression data with a penalized graph-based metric. BMC Bioinformatics, 12:2. Citado na página 44.

Bellman, R. (1961). Adaptive Control Processes. Princeton University Press. Citado na página 21.

Bertini Jr., J. R., Zhao, L., Motta, R., e de Andrade Lopes, A. (2011). A nonparametric classification method based on k-associated graphs. Information Sciences, 181(24):5435 - 5456. Citado na página 42.

Börner, K., Chen, C., e Boyack, K. W. (2003). Visualizing Knowledge Domains. Annual Review of Information Science \& Technology, 37. Citado na página 1.

Card, S. K., Mackinlay, J. D., e Shneiderman, B., editores (1999). Readings in Information Visualization: Using Vision to Think. Morgan Kaufmann Publishers Inc., San Francisco, CA, USA. Citado na página 1.

Clauset, A. (2005). Finding local community structure in networks. Physical Review E, 72:026132. Citado na página 52.

Clauset, A., Newman, M., e Moore, C. (2004). Finding community structure in very large networks. Physical Review E, 70(1):066111. Citado na página 52. 
Costa, L., Rodrigues, F. A., Travieso, G., e Boas, P. V. (2007). Characterization of complex network: A survey of measurements. Advances of Physics, 56(1):167-242. Citado na página 42.

Cox, T. F. e Cox, M. A. A. (2000). Multidimensional Scaling. Chapman \& Hall/CRC, second edição. Citado na página 2 e 9.

Cuadros, A. M., Paulovich, F. V., Minghim, R., e Telles, G. P. (2007). Point placement by phylogenetic trees and its application to visual analysis of document collections. Em Proceedings of IEEE Symposium on Visual Analytics Science and Technology, páginas 99-106, Sacramento - CA, USA. IEEE CS Press. Citado na página 2.

Danon, L., Guilera, A. D., Duch, J., e Arenas, A. (2005). Comparing community structure identification. Journal of Statistical Mechanics: Theory and Experiment, 2005(9):P09008-09008. Citado na página 52.

Ding, C. H. Q., He, X., Zha, H., e Simon, H. D. (2002). Adaptive dimension reduction for clustering high dimensional data. Em IEEE International Conference on Data Mining, páginas 147-154. IEEE Computer Society. Citado na página 5.

Duch, J. e Arenas, A. (2005). Community detection in complex networks using extremal optimization. Physical Review E, 72:027104. Citado na página 52.

Etemadpour, R., Motta, R., de Souza Paiva, J., Minghim, R., Oliveira, M. F., e Linsen, L. (2014). Perception-based evaluation of projection methods for multidimensional data visualization. IEEE Transactions on Visualization and Computer Graphics, 99(PrePrints):1. Citado na página 30.

Faloutsos, C. e Lin, K.-I. (1995). Fastmap: a fast algorithm for indexing, data-mining and visualization of traditional and multimedia datasets. Em Carey, M. e Schneider, D., editores, Proceedings of the 1995 ACM SIGMOD International Conference on Management of Data, páginas 163-174. ACM Press. Citado na página 9.

Fayyad, U. M., Piatetsky-Shapiro, G., e Smyth, P. (1996). Knowledge discovery and data mining: Towards a unifying framework. Em Proceedings of Knowledge Discovery and Data Mining Conference, páginas 82-88, EUA. AAAI Press. Citado na página 1.

Fodor, I. K. (2002). A survey of dimension reduction techniques. Center for Applied Scientific Computing Lawrence Livermore National Laboratory, 9(1):1-18. Citado na página 5 e 9.

Gashi, I., Stankovic, V., Leita, C., e Thonnard, O. (2009). An experimental study of diversity with off-the-shelf antivirus engines. Em Proceedings of the IEEE International 
Symposium on Network Computing and Applications, páginas 4-11. IEEE Computer Society. Citado na página 2 e 7.

Girvan, M. e Newman, M. (2002). Community structure in social and biological networks. Proceedings of the National Academy of Sciences of the United States of America, 49(2):247-252. Citado na página 52.

Hamel, P. e Eck, D. (2010). Learning features from music audio with deep belief networks. Em Downie, J. S. e Veltkamp, R. C., editores, International Society for Music Information Retrieval Conference, páginas 339-344. International Society for Music Information Retrieval. Citado na página 2 e 7.

Hubert, L. e Arabie, P. (1985). Comparing partitions. Journal of Classification, 2:193-218. 10.1007/BF01908075. Citado na página 53.

Hurter, C., Ersoy, O., e Telea, A. (2012). Graph bundling by kernel density estimation. Computer Graphics Forum, 31(3pt1):865-874. Citado na página 22.

Ingram, S., Munzner, T., e Olano, M. (2009). Glimmer: multilevel MDS on the GPU. IEEE Transactions on Visualization and Computer Graphics, 15(2):249-261. Citado na página 9 e 26.

Jain, A. K. e Dubes, R. C. (1988). Algorithms for clustering data. Prentice-Hall, Inc., Upper Saddle River, NJ, USA. Citado na página 50 e 51.

Jamieson, A. R., Giger, M. L., Drukker, K., Li, H., Yuan, Y., e Bhooshan, N. (2010). Exploring nonlinear feature space dimension reduction and data representation in breast cadx with laplacian eigenmaps and t-sne. Medical Physics, 37(1):339-51. Citado na página 2 e 7.

Ji, S. e Ye, J. (2009). Linear dimensionality reduction for multi-label classification. Em Proceedings of the 21st International Jont Conference on Artifical Intelligence, IJCAI'09, páginas 1077-1082, San Francisco, CA, USA. Morgan Kaufmann Publishers Inc. Citado na página 6.

Jiang, D., Tang, C., e Zhang, A. (2004). Cluster analysis for gene expression data: a survey. IEEE Transactions on Knowledge and Data Engineering, 16(11):1370 - 1386. Citado na página 52.

Jolliffe, I. T. (2002). Principal Component Analysis. Springer, second edição. Citado na página 9,26 , e 68 .

Kaski, S. (1998). Dimensionality reduction by random mapping: Fast similarity computation for clustering. Em Proceedings of International Joint Conference on Neural Networks, volume 1, páginas 413-418. Piscataway, NJ: IEEE. Citado na página 5. 
Keim, D. A. (2002). Information visualization and visual data mining. IEEE Transactions on Visualization and Computer Graphics, 8(1):1-8. Citado na página 5.

Klein, D., Kamvar, S. D., e Manning, C. D. (2002). From instance-level constraints to space-level constraints: Making the most of prior knowledge in data clustering. Em Proceedings of the 19th International Conference on Machine Learning, ICML'02, páginas 307-314, San Francisco, CA, USA. Morgan Kaufmann Publishers Inc. Citado na página 54.

Kruskal, J. (1964). Multidimensional scaling by optimizing goodness of fit to a nonmetric hypothesis. Psychometrika, 29(1):1-27-27. Citado na página 12.

Lancichinetti, A. e Fortunato, S. (2009). Community Detection Algorithms: A Comparative Analysis. Physical Review E, 80(5):056117+. Citado na página 53.

Larsen, B. e Aone, C. (1999). Fast and effective text mining using linear-time document clustering. Em Proceedings of the 5th ACM SIGKDD International Conference on Knowledge Discovery and Data Mining, KDD '99, páginas 16-22, New York, NY, USA. ACM. Citado na página 53.

Lee, J. A. e Verleysen, M. (2009). Quality assessment of dimensionality reduction: Rankbased criteria. Neurocomputing, 72(7-9):1431-1443. Citado na página xiv, 16, 17, 19, 77 , e 83 .

Lee, J. A. e Verleysen, M. (2010). Scale-independent quality criteria for dimensionality reduction. Pattern Recognition Letters, 31(14):2248-2257. Citado na página 16, 77, e 78 .

Lespinats, S. e Aupetit, M. (2011). Checkviz: Sanity check and topological clues for linear and non-linear mappings. Computer Graphics Forum, 30(1):113-125. Citado na página xiv, 21, e 22.

Levkowitz, H. (1997). Color Theory and Modeling for Computer Graphics, Visualization, and Multimedia Applications. Kluwer Academic Publishers. Citado na página 60.

Li, J. e Wang, J. Z. (2003). Automatic linguistic indexing of pictures by a statistical modeling approach. IEEE Transactions on Pattern Analysis and Machine Intelligence, 25(9):1075-1088. Citado na página 26.

Lilian Berton, A. d. A. L. (2014). Graph construction based on labeled instances for semisupervised learning. Em Proc. 22nd International Conference on Pattern Recognition (in press). ACM. Citado na página 42. 
MacQueen, J. B. (1967). Some methods for classification and analysis of multivariate observations. Em Cam, L. M. L. e Neyman, J., editores, Proceedings of the 5th Berkeley Symposium on Mathematical Statistics and Probability, volume 1, páginas 281-297. University of California Press. Citado na página 19 e 50.

Marghescu, D. (2006). Evaluating the effectiveness of projection techniques in visual data mining. Em Villanueva, J. J., editor, Proceddings of the 6th International Conference on Visualization, Imaging, and Image Processing, páginas 94-103, Palma de Mallorca, Spain. ACTA Press. Citado na página 2, 9, 19, 20, e 83.

Marghescu, D. (2007). Evaluation of projection techniques using hubert's gamma statistics. Em Proceedings of IADIS European Conference on Data Mining, páginas 192-197. IADIS Press. Citado na página 19 e 20.

Martins, R. M., Andery, G. F., Heberle, H., Paulovich, F. V., Lopes, A. A., Pedrini, H., e Minghim, R. (2012). Multidimensional projections for visual analysis of social networks. Journal of Computer Science and Technology, 27(4):791-810. Citado na página xiii, 2, 6 , e 7 .

Martins, R. M., Coimbra, D. B., Minghim, R., e Telea, A. C. (2014). Visual analysis of dimensionality reduction quality for parameterized projections. Computers $\&$ Graphics, 41:26-42. Citado na página xiv, 21, 22, e 23.

Mokbel, B., Lueks, W., Gisbrecht, A., e Hammer, B. (2013). Visualizing the quality of dimensionality reduction. Neurocomputing, 112:109-123. Citado na página xiii, xiv, $17,77,78$, e 83 .

Moraes, M. L., Petri, L., Oliveira, V., Olivati, C. A., Oliveira, M. C. F., Paulovich, F. V., Oliveira, O. N., e Ferreira, M. (2012). Detection of glucose and triglycerides using information visualization methods to process impedance spectroscopy data. Sensors and Actuators B: Chemical, 166-167:231 - 238. Citado na página 2 e 7.

Morrison, A. e Chalmers, M. (2004). A pivot-based routine for improved parent-finding in hybrid mds. Information Visualization, 3(2):109-122. Citado na página 12.

Motta, R., Lopes, A. A., e Oliveira, M. C. F. (2009). Centrality measures from complex networks in active learning. Em Proceedings of the 12th International Conference on Discovery Science, páginas 184-196, Berlin, Heidelberg. Springer-Verlag. Citado na página 44.

Motta, R., Nogueira, B. M., Jorge, A. M., Lopes, A. A., Rezende, S. O., e Oliveira, M. C. F. (2013). Comparing relational and non-relational algorithms for clustering propositional data. Em Proceedings of the 28th Annual ACM Symposium on Applied 
Computing, SAC '13, páginas 150-155, New York, NY, USA. ACM. Citado na página 53.

Newman, M. (2003). The structure and function of complex networks. Society for Industrial and Applied Mathematics Review, 45(2):167-256. Citado na página 52.

Newman, M. (2004). Detecting community structure in networks. European Physical Journal B, 38(2):321-330. Citado na página 52 e 53.

Newman, M. (2006). Finding community structure in networks using the eigenvectors of matrices. Physical Review E, 74(1):036104. Citado na página 52.

Oliveira, M. C. F. e Levkowitz, H. (2003). From visual data exploration to visual data mining: A survey. IEEE Transactions on Visualization and Computer Graphics, 9(3):378394. Citado na página 1.

Paiva, J. G. S., C., L. F., Pedrini, H., Telles, G. P., e Minghim, R. (2011). Improved similarity trees and their application to visual data classification. IEEE Transactions on Visualization and Computer Graphics, 17(12):2459-2468. Citado na página 26.

Paulovich, F. V. (2008). Mapeamento de dados multi-dimensionais - integrando minera $\tilde{A} \S \tilde{A} £$ o e visualiza $\tilde{A} \S \tilde{A} £ o$. Tese de Doutorado, USP, SÃ £o Carlos, SP. ICMC-USP. Citado na página 8 e 12.

Paulovich, F. V. e Minghim, R. (2006). Text map explorer: a tool to create and explore document maps. Em Proocedings of the 10th International Conference on Information Visualisation, páginas 245-251, London - UK. IEEE CS Press. Citado na página 2, 9, 14 , e 83.

Paulovich, F. V., Moraes, M. L., Maki, R. M., Ferreira, M., Oliveira Jr., O. N., e Oliveira, M. C. F. (2011). Information visualization techniques for sensing and biosensing. The Analyst, 136:1344. Citado na página 2.

Paulovich, F. V., Nonato, L. G., e Minghim, R. (2006). Visual mapping of text collections through a fast high precision projection technique. Em 10th International Conference on Information Visualisation, páginas 282-290. IEEE Computer Society. Citado na página 2.

Paulovich, F. V., Nonato, L. G., Minghim, R., e Levkowitz, H. (2008). Least square projection: a fast high precision multidimensional projection technique and its application to document mapping. IEEE Transactions on Visualization and Computer Graphics, 14(3):564-575. Citado na página 2, 6, 9, 13, 26, 68, e 69.

Pearson, K. (1901). On lines and planes of closest fit to systems of points in space. Philosophical Magazine, 2(6):559-572. Citado na página 9. 
Peng, W., Ward, M. O., e Rundensteiner, E. A. (2004). Clutter reduction in multidimensional data visualization using dimension reordering. Em Proceedings of the IEEE Symposium on Information Visualization, páginas 89-96. IEEE Computer Society. Citado na página 12.

Perinoto, A. C., Maki, R. M., Colhone, M. C., Santos, F. R., Migliaccio, V., Daghastanli, K. R., Stabeli, R. G., Ciancaglini, P., Paulovich, F. V., Oliveira, M. C. F., e Zucolotto, V. (2010). Biosensors for efficient diagnosis of leishmaniasis: Innovations in bioanalytics for a neglected disease. Analytical Chemistry, 82:9763 - 9768. C Citado na página 2.

Pons, P. e Latapy, M. (2004). Computing communities in large networks using random walks. Journal of Graph Algorithms and Applications, 10:284-293. Citado na página 52.

Radicchi, F., Castellano, C., Cecconi, F., Loreto, V., e Parisi, D. (2004). Defining and identifying communities in networks. Proceedings of the National Academy of Sciences of the United States of America, 101(9):2658-2663. Citado na página 52.

Raghavan, U. N., Albert, R., e Kumara, S. (2007). Near linear time algorithm to detect community structures in large-scale networks. Physical Review E, 76(3):036106+. Citado na página 52.

Rand, W. M. (1971). Objective Criteria for the Evaluation of Clustering Methods. Journal of the American Statistical Association, 66(336):846-850. Citado na página 53.

Reichardt, J. e Bornholdt, S. (2006). Statistical mechanics of community detection. Physical Review E, 74:016110. Citado na página 52.

Rijsbergen, C. J. V. (1979). Information Retrieval. Butterworth-Heinemann, Newton, MA, USA, 2nd edição. Citado na página 53 e 62.

Rodrigues, F. A. (2007). Caracteriza $\tilde{A} \S \tilde{A} £ o$, classifica $\tilde{A} \S \tilde{A} £ o$ e an $\tilde{A}$ jlise de redes complexas. Tese de Doutorado, USP, SÃ £o Carlos, SP. IFSC-USP. Citado na página 52.

Roman, F. S., de Pinho, R. D., Minghim, R., e Oliveira, M. C. F. (2013). A study on the role of similarity measures in visual text analytics. Em Proceedings of the 6th International Conference on Information Visualization Theory and Applications, páginas 429-438. Citado na página 67.

Rosvall, M. e Bergstrom, C. T. (2008). Maps of random walks on complex networks reveal community structure. Proceedings of the National Academy of Sciences of the United States of America, 105(4):1118-1123. Citado na página 53.

Roweis, S. T. e Saul, L. K. (2000). Nonlinear dimensionality reduction by locally linear embedding. Science, 290:2323-2326. Citado na página 6. 
Sammon, J. W. (1969). A nonlinear mapping for data structure analysis. IEEE Transactions on Computers, 18(5):401-409. Citado na página 2, 9, 12, e 68.

Savaresi, S. M. e Boley, D. L. (2004). A comparative analysis on the bisecting k-means and the pddp clustering algorithms. Intelligent Data Analysis, 8(4):345-362. Citado na página 51.

Sedlmair, M., Tatu, A., Munzner, T., e Tory, M. (2012). A Taxonomy of Visual Cluster Separation Factors. Computer Graphics Forum, 31(3):1335-1344. Citado na página 21, 23,25 , e 54 .

Shindler, M., Wong, A., e Meyerson, A. (2011). Fast and accurate k-means for large datasets. Em Shawe-Taylor, J., Zemel, R. S., Bartlett, P. L., Pereira, F. C. N., e Weinberger, K. Q., editores, Neural Information Processing Systems, páginas 23752383. Citado na página 19.

Sips, M., Neubert, B., Lewis, J. P., e Hanrahan, P. (2009). Selecting good views of highdimensional data using class consistency. Computer Graphics Forum, 28(3):831-838. Citado na página 13, 21, 25, e 83.

Sorzano, C. O. S., Vargas, J., e Montano, A. P. (2014). A survey of dimensionality reduction techniques. ArXiv e-prints. Citado na página 5.

Tatu, A., Albuquerque, G., Eisemann, M., Schneidewind, J., Theisel, H., Magnor, M., e Keim, D. A. (2009). Combining automated analysis and visualization techniques for effective exploration of high-dimensional data. Em Proceedings of the IEEE Symposium on Visual Analytics Science and Technology, páginas 59-66. Citado na página 14, 21, 25 , e 83 .

Tejada, E., Minghim, R., e Nonato, L. G. (2003). On improved projection techniques to support visual exploration of multidimensional data sets. Information Visualization, 2(4):218-231. Citado na página 9.

Tenembaum, J. B., de Silva, V., e Langford, J. C. (2000). A global geometric faramework for nonlinear dimensionality reduction. Science, 290:2319-2323. Citado na página 26.

Tenenbaum, J. B. (1998). Mapping a manifold of perceptual observations. Em Advances in Neural Information Processing Systems 10, páginas 682-688. MIT Press. Citado na página 9.

Theodoridis, S. e Koutroumbas, K. (2006). Pattern Recognition, Third Edition. Academic Press. Citado na página 19.

Thomas, J. e Cook, K., editores (2005). Illuminating the Path: The Research and Development Agenda for Visual Analytics. IEEE CS Press. Citado na página 8. 
van der Maaten, L. e Hinton, G. (2008). Visualizing data using t-SNE. Journal of Machine Learning Research, 9:2579-2605. Citado na página 6, 9, e 68.

Vendramin, L., Campello, R. J. G. B., e Hruschka, E. R. (2010). Relative clustering validity criteria: A comparative overview. Statistical Analysis and Data Mining, 3(4):209235. Citado na página 51.

Venna, J. e Kaski, S. (2001). Neighborhood preservation in nonlinear projection methods: An experimental study. Em Proceedings of the International Conference on Artificial Neural Networks, páginas 485-491, London, UK. Springer-Verlag. Citado na página 2, 14 , e 83.

Venna, J., Peltonen, J., Nybo, K., Aidos, H., e Kaski, S. (2010). Information retrieval perspective to nonlinear dimensionality reduction for data visualization. Journal of Machine Learning Research, 11:451-490. Citado na página 18, 35, e 61.

Wagstaff, K. e Cardie, C. (2000). Clustering with instance-level constraints. Em Proceedings of the 17th International Conference on Machine Learning, páginas 1103-1110. Citado na página 54.

Wilkinson, L., Anand, A., e Grossman, R. (2005). Graph-theoretic scagnostics. Em Proceedings of the 2005 IEEE Symposium on Information Visualization, INFOVIS '05, páginas 21-, Washington, DC, USA. IEEE Computer Society. Citado na página 12.

Ye, Z., Hu, S., e Yu, J. (2008). Adaptive clustering algorithm for community detection in complex networks. Physical Review E, 78(4):046115. Citado na página 53 e 65.

Young, G. e Householder, A. (1938). Discussion of a set of points in terms of their mutual distances. Psychometrika, 3(1):19-22. Citado na página 9.

Zhao, Y. e Karypis, G. (2004). Empirical and theoretical comparisons of selected criterion functions for document clustering. Machine Learning, 55(3):311-331. Citado na página 52 .

Zhu, X. (2005). Semi-Supervised Learning Literature Survey. Relatório técnico, Computer Sciences, University of Wisconsin-Madison. Citado na página 43. 